\title{
Athens Journal of Business \& Economics
}

Quarterly Academic Periodical, Volume 8, Issue 2, April 2022

URL: https://www.athensjournals.gr/ajbe Email: journals@atiner.gr e-ISSN: 2241-794X DOI: 10.30958/ajbe

Front Pages

STAVROULA MALLA, K. K. KLEIN \& TARYN PRESSEAU

Has the Demand for Fats and Meats in the United States Been Affected by the Health Claim on Risk of Coronary Heart Disease Issued by the Food and Drug Administration?

ABIDEMI ABIOLA \& RASAK A. ADEFABI

Rural Structural Transformation and Agricultural Productivity in Nigeria

BRETEL B. DOLIPAS, JULIE A. BUASEN, MARIA AZUCENA B. LUBRICA, PHIL S. OCAMPO, KENNETH B. PAKIPAC, MARYCEL T. SAJISE E PRECIOUS M. VALENTIN

Assessment of the University Vision, Goals, Mission and Program Objectives: A Management Protocol for Quality Assurance

LITON CHANDRO SARKAR

Empirical Assessment on the Impact of Leverage and Capital Adequacy on Performance of Non-Bank Financial Institutions in Bangladesh

GREGORY T. PAPANIKOS

Greece in the Eurozone: An Evaluation of the First Two Decades 


\section{Athens Journal of Business \& Economics}

Published by the Athens Institute for Education and Research (ATINER)

\section{Editors}

- Dr. Gregory T. Papanikos, President of ATINER and Honorary Professor of Economics, University of Stirling, U.K.

- Dr. Nicholas Marudas, Head, Accounting Unit, ATINER \& Associate Professor, Mercer University, USA.

- Dr. Stavroula Malla, Academic Member, ATINER \& Associate Professor, University of Lethbridge Canada.

- Dr. Peter Yannopoulos, Vice President of Global Communications, ATINER \& Professor, Brock University, Canada.

Editorial \& Reviewers' Board https://www.athensjournals.gr/ajbe/eb

Administration of the Journal

1.Vice President of Publications: Dr Zoe Boutsioli

2.General Managing Editor of all ATINER's Publications: Ms. Afrodete Papanikou

3.ICT Managing Editor of all ATINER's Publications: Mr. Kostas Spyropoulos

4.Managing Editor of this Journal: Ms. Victoria McKinley Bigelow

ATINER is an Athens-based World Association of Academics and Researchers based in Athens. ATINER is an independent and non-profit Association with a Mission to become a forum where Academics and Researchers from all over the world can meet in Athens, exchange ideas on their research and discuss future developments in their disciplines, as well as engage with professionals from other fields. Athens was chosen because of its long history of academic gatherings, which go back thousands of years to Plato's Academy and Aristotle's Lyceum. Both these historic places are within walking distance from ATINER's downtown offices. Since antiquity, Athens was an open city. In the words of Pericles, Athens"...is open to the world, we never expel a foreigner from learning or seeing". ("Pericles' Funeral Oration", in Thucydides, The History of the Peloponnesian War). It is ATINER's mission to revive the glory of Ancient Athens by inviting the World Academic Community to the city, to learn from each other in an environment of freedom and respect for other people's opinions and beliefs. After all, the free expression of one's opinion formed the basis for the development of democracy, and Athens was its cradle. As it turned out, the Golden Age of Athens was in fact, the Golden Age of the Western Civilization. Education and (Re)searching for the 'truth' are the pillars of any free (democratic) society. This is the reason why Education and Research are the two core words in ATINER's name.

The Athens Journal of Business \& Economics (AJBE) is an Open Access quarterly doubleblind peer reviewed journal and considers papers from all areas of business and economics, including papers on accounting, finance, management, marketing, organization etc. The AJBE welcomes theoretical (including methodological), empirical (including case-studies) and policy (i.e., descriptive and non-analytical) papers. Given the mission of ATINER, the AJBE will also consider papers which emphasize country-related studies both at the business and the national economy level as well as economic history, history of economic thought and philosophy of economics papers. All papers are subject to ATINER's Publication Ethical Policy and Statement. 
The Athens Journal of Business \& Economics ISSN NUMBER: 2241-794X- DOI: 10.30958/ajbe Volume8, Issue 2, April 2022

Download the entire issue ( $\underline{\mathrm{PDF}})$

Front Pages

Has the Demand for Fats and Meats in the United States been Affected by the Health Claim on Risk of Coronary Heart Disease Issued by the Food and Drug Administration?

Stavroula Malla, K. K. Klein E Taryn Presseau

Rural Structural Transformation and Agricultural

Productivity in Nigeria

Abidemi Abiola \& Rasak A. Adefabi

Assessment of the University Vision, Goals, Mission and Program Objectives: A Management Protocol for Quality Assurance

Bretel B. Dolipas, Julie A. Buasen, Maria Azucena B. Lubrica, Phil S. Ocampo, Kenneth B. Pakipac, Marycel T. Sajise E Precious M. Valentin

Empirical Assessment on the Impact of Leverage and

Capital Adequacy on Performance of Non-Bank

Financial Institutions in Bangladesh

Liton Chandro Sarkar

Greece in the Eurozone: An Evaluation of the First Two

Decades

Gregory T. Papanikos 


\title{
Athens Journal of Business \& Economics Editorial and Reviewers' Board
}

\author{
Editor \\ - Dr. Gregory T. Papanikos, Honorary Professor, University of Stirling, UK \& President of ATINER.

\section{Co-Editors} \\ - Dr. Stavroula Malla, Academic Member, ATINER \& Associate Professor, University of Lethbridge Canada. \\ - Dr. Nicholas Marudas, Head, Accounting Unit, ATINER \& Associate Professor, Mercer University, USA. \\ - Dr. Christos Sakellariou, Vice President of Administration and Finance, ATINER \& Associate Professor of Economics, Nanyang \\ Technological University, Singapore. \\ - Dr. Henry Thompson, Head, Economics Unit, ATINER \& Emeritus Professor, Auburn University, USA. \\ - Dr. Peter Yannopoulos, Professor, Brock University, Canada \& Vice President of Global Communications, ATINER.
}

\section{Editorial Board}

- Dr. Panagiotis Petratos, Vice President of ICT, ATINER \& Professor, Department of Computer Information Systems, California State University (Stanislaus), USA.

- Dr. Michael P. Malloy, Director, Business \& Law Research Division, ATINER \& Distinguished Professor of Law, University of the Pacific, USA.

- Dr. Peter Koveos, Head, Accounting \& Finance Research Unit, ATINER \& Professor of Finance, Syracuse University, USA.

- Dr. Sharon Claire Bolton, Head, Management Research Unit, ATINER \& Professor, The Management School, University of Stirling, Scotland.

- Dr. Cleopatra Veloutsou, Head, Marketing Research Unit, ATINER \& Professor of Brand Management, University of Glasgow.

- Dr. John Thanopoulos, Professor of International Business (IB), and Dean, Business and Economics, IST College \& Emeritus Professor, University of Piraeus, Greece.

- Dr. Elyas Elyasiani, Professor Finance and Economics, Fox School of Business and Management, Temple University, USA.

- Dr. Eduardo Segarra, Academic Member, ATINER \& Professor, Department of Agricultural \& Applied Economics, Texas Tech University, USA.

- Dr. Samuel Seaman, Academic Member, ATINER \& Professor of Decision Sciences, Graziadio School of Business and Management, Pepperdine University, USA.

- Dr. Hercules Haralambides, Academic Member, ATINER \& Professor of Maritime Economics and Logistics, Department of Econometrics, Erasmus University Rotterdam, The Netherlands.

- Dr. Steven Dellaportas, Academic Member, ATINER \& Professor of Accounting, RMIT (Royal Melbourne Institute of Technology) University, Australia.

- Dr. George V. Priovolos, Professor, Iona College, USA.

- Dr. George Saridakis, Director of Doctoral Programmes, Kingston Business School, Kingston University \& Professor of Small Business and Entrepreneurship, Kingston Hill, Kingston Upon Thames, UK.

- Dr. Liliana Costa, Tutor, Department of Communication and Art, University of Aveiro, Portugal.

- Dr. Gilles Chemla, Academic Member, ATINER \& Professor, Imperial College Business School, UK.

- Dr. Nathalie Homlong, Associate Professor, University College Volda, Norway.

- Dr. Tatyana Boikova, Associate Professor, Business Administration Department, Baltic International Academy, Latvia.

- Dr. Zubin Sethna, Associate Professor of Entrepreneurial Marketing, Regent's University London, UK.

- General Managing Editor of all ATINER's Publications: Ms. Afrodete Papanikou

- ICT Managing Editor of all ATINER's Publications: Mr. Kostas Spyropoulos

- Managing Editor of this Journal: Ms. Victoria McKinley Bigelow ( $\underline{\text { bio }})$

\section{Reviewers' Board}

Click Here 


\section{President's Message}

All ATINER's publications including its e-journals are open access without any costs (submission, processing, publishing, open access paid by authors, open access paid by readers etc.) and is independent of presentations at any of the many small events (conferences, symposiums, forums, colloquiums, courses, roundtable discussions) organized by ATINER throughout the year and entail significant costs of participating. The intellectual property rights of the submitting papers remain with the author. Before you submit, please make sure your paper meets the basic academic standards, which includes proper English. Some articles will be selected from the numerous papers that have been presented at the various annual international academic conferences organized by the different divisions and units of the Athens Institute for Education and Research. The plethora of papers presented every year will enable the editorial board of each journal to select the best, and in so doing produce a top-quality academic journal. In addition to papers presented, ATINER will encourage the independent submission of papers to be evaluated for publication.

The current issue is the second of the eighth volume of the Athens Journal of Business \& Economics (AJBE), published by the Business \& Law Division and the Economics Unit of ATINER.

Gregory T. Papanikos

President

ATINER 


\section{Athens Institute for Education and Research}

\section{A World Association of Academics and Researchers}

\section{7th Annual International Symposium on Economic Theory, Policy and Applications 27-30 June 2022, Athens, Greece}

The Economics Unit of ATINER, will hold its $16^{\text {th }}$ Annual International Symposium on Economic Theory, Policy and Applications, 27-30 June 2022, Athens, Greece sponsored by the Athens Journal of Business \& Economics. The aim of the conference is to bring together academics and researchers of all areas of economics and other related disciplines. You may participate as panel organizer, presenter of one paper, chair a session or observer. Please submit a proposal using the form available (https:/ / www.atiner.gr/2022/FORM-ECO.doc).

\section{Academic Members Responsible for the Conference}

- Dr. Gregory T. Papanikos, President, ATINER \& Honorary Professor, University of Stirling, UK.

- Dr. Chris Sakellariou, Head, Economics Unit \& Associate Professor of Economics, Nanyang Technological University, Singapore.

\section{Important Dates}

- Abstract Submission: 7 March 2021

- Acceptance of Abstract: 4 Weeks after Submission

- Submission of Paper: 30 May 2022

\section{Social and Educational Program}

The Social Program Emphasizes the Educational Aspect of the Academic Meetings of Atiner.

- Greek Night Entertainment (This is the official dinner of the conference)

- Athens Sightseeing: Old and New-An Educational Urban Walk

- Social Dinner

- Mycenae Visit

- Exploration of the Aegean Islands

- Delphi Visit

- Ancient Corinth and Cape Sounion

\section{Conference Fees}

Conference fees vary from $400 €$ to $2000 €$ Details can be found at: https://www.atiner.gr/fees 


\section{Athens Institute for Education and Research}

A World Association of Academics and Researchers

\section{$9^{\text {th }}$ Annual International Conference on Business, Law \& Economics 2-5 May 2022, Athens, Greece}

The Business, Economics and Law Division (BLRD) of ATINER is organizing its 8 $^{\text {th }}$ Annual International Conference on Business, Law \& Economics, 2-5 May 2022, Athens, Greece, sponsored by the Athens Journal of Business \& Economics and the Athens Journal of Law. In the past, the six units of BLRD have organized more than 50 annual international conferences on accounting, finance, management, marketing, law and economics. This annual international conference offers an opportunity for cross disciplinary presentations on all aspects of business, law and economics. This annual international conference offers an opportunity for cross disciplinary presentations on all aspects of business, law and economics. Please submit an abstract (email only) to: atiner@atiner.gr, using the abstract submission form (https://www.atiner.gr/2022/FORM-BLE.doc)

\section{Important Dates}

- Abstract Submission: 10 January 2021

- Acceptance of Abstract: 4 Weeks after Submission

- Submission of Paper: 4 April 2022

\section{Academic Member Responsible for the Conference}

- Dr. Gregory T. Papanikos, President, ATINER.

- Dr. Michael P. Malloy, Director, Business, Economics and Law Division, ATINER \& Distinguished Professor \& Scholar, University of the Pacific, USA.

- Dr. David A. Frenkel, LL.D., Head, Law Research Unit, ATINER \& Emeritus Professor, Law Area, Guilford Glazer Faculty of Business and Management, Ben-Gurion University of the Negev, Beer-Sheva, Israel.

\section{Social and Educational Program}

The Social Program Emphasizes the Educational Aspect of the Academic Meetings of Atiner.

- Greek Night Entertainment (This is the official dinner of the conference)

- Athens Sightseeing: Old and New-An Educational Urban Walk

- Social Dinner

- Mycenae Visit

- Exploration of the Aegean Islands

- Delphi Visit

- Ancient Corinth and Cape Sounion

More information can be found here: https://www.atiner.gr/social-program

\section{Conference Fees}

Conference fees vary from $400 €$ to $2000 €$

Details can be found at: https://www.atiner.gr/fees 



Athens Journal of Business \& Economics -

Volume 8, Issue 2, April 2022-Pages 97-118

\title{
Has the Demand for Fats and Meats in the United States been Affected by the Health Claim on Risk of Coronary Heart Disease Issued by the Food and Drug Administration?
}

\author{
By Stavroula Malla* K. K. Klein ${ }^{ \pm} \&$ Taryn Presseau \\ Health authorities are well aware that a healthy diet can be effective in reducing \\ the risk of many chronic illnesses. To encourage greater consumption of healthy \\ foods, some government agencies have begun issuing specific health claims on \\ particular foods and/or ingredients. This study examines the impacts of a \\ specific health claim on the risk of coronary heart disease on the demand for \\ fats and meats in the United States. Results indicate the health claim decreased \\ demand for foods higher in saturated fats and increased demand for foods lower \\ in saturated fats by relatively small but statistically significant amounts.
}

Keywords: health benefits, functional foods, dietary choices, consumer demand

\section{Introduction}

In the United States, chronic illnesses are estimated to account for $75 \%$ of the $\$ 2$ trillion spent on annual healthcare costs and are one of the top causes of death and disability (Raghupathi and Raghupathi 2018). In addition to the direct costs of chronic illness, there are significant indirect costs including reduced labor market productivity, decreased quality of life and loss of opportunity (Public Health Agency of Canada 2014). Research has found that many chronic diseases, such as cardiovascular diseases (CVDs), obesity and diabetes, can be prevented or the risk can be significantly reduced through the adoption of a healthy lifestyle (Dietz et al. 2016). Leading health organizations such as the American Heart Association, World Health Organization (WHO), and Centers for Disease Control and Prevention (CDC) now strongly encourage consuming a healthy diet to help prevent and mitigate the risk of diet-related chronic illness (WHO 2003, American Heart Association 2017a, CDC 2017).

Growing consumer interest in health foods has been driven by greater understanding about the effects of diet on health as well as the motivation to improve well-being and longevity (Milner 1999, Moors 2012, Malla et al. 2013, Hobbs et al. 2014a). Policymakers also have placed greater emphasis on promoting the adoption of healthy diets as a preventative care strategy in an effort to help alleviate the rising economic burdens of chronic illness (Veeman 2002, Aschemann-Witzel 2011).

\footnotetext{
*Associate Professor, Department of Economics, University of Lethbridge, Alberta, Canada. ${ }^{ \pm}$Professor, Department of Economics, University of Lethbridge, Canada.

*Professional Affiliate, Department of Economics, University of Lethbridge, Canada.
} 
In the United States, the Food and Drug Administration (FDA) recognizes that certain foods, known as 'functional foods', provide extra health benefits and regulates the types of health claims that can be made on these foods. Health claims are statements that indicate a relationship between the consumption of a food and a health benefit (CFIA 2016). The main goal of these health claims is to help consumers make better dietary choices, improve population health, and reduce the direct and indirect economic burdens associated with diet-related illnesses that are placed on society each year.

Several "ex-ante" studies have found that health claims can improve consumer acceptance (e.g., Verbeke 2005, Teratanavat and Hooker 2006, Herath et al. 2008, Markosyan et al. 2009) as well as product evaluations and purchase intentions (e.g., van Kleef et al. 2005, van Trijp and van der Lans 2007, Huang and Lu 2016) of functional foods.

Although various studies have shown that public awareness of diet-related health information and other types of labeling policies can affect consumption patterns, empirical analyses of the effectiveness of specific health claims on increasing the demand for healthier foods (or decreasing the demand for unhealthy foods) has not been adequately addressed. Much attention has been paid to the healthiness of including fats and meats in diets, especially in richer countries where the consumption of these products tends to be higher (e.g., Heart Foundation 2021, CDC 2021). The United States Food and Drug Administration (FDA) issued a health claim in 1993 entitled Dietary Saturated Fat and Cholesterol and Risk of Coronary Heart Disease that provided consumers with scientificallyderived information on the healthiness of consuming these products. The objective of this study is to estimate how the demand for various fats and meats in the United States has been affected by this specific health claim.

\section{Functional Foods \& Health Claims}

The United States Food and Drug Administration (FDA) under the Federal Food, Drug and Cosmetic Act (FDA 2016a, Hobbs et al. 2014b) regulate health claims in the United States ${ }^{1}$. There are three methods for approving new disease risk reduction claims (referred to as 'health claims'). The first method is for fully endorsed NLEA (Nutrition Labeling and Education Act) health claims, which requires the highest level of scientific substantiation prior to approval. The second method is for 'FDAMA (FDA Modernization Act) health claims', which do not require an in-depth review by the FDA but must be based on authoritative statements made by the National Academy of Sciences or certain scientific departments of the United States government. The third method involves the use

\footnotetext{
${ }^{1}$ The FDA defines three types of claims that can be made on foods. Those claims are defined as 1) structure/function claims, 2) health claims, and 3) nutrient content claims. First, structure/ function claims are defined as a statement that refers to the effects of a food or dietary supplement on the normal functioning of the body (FDA 2016b). Second, the FDA defines health claims as statements that indicate a relationship between a food, food constituent, or dietary supplement and the risk of a disease (FDA 2016b). Last, the FDA defines nutrient content claims as claims that describe the quantity or presence of nutrients in a food or dietary supplement (FDA 2016b, FDA 2005).
} 
of 'qualified health claims'. Qualified health claims have significantly reduced the time it takes to get new disease risk reduction claims approved as they require far less robust scientific substantiation to support the claim. NLEA, FDAMA, and qualified health claims also are generic; manufacturers do not need premarket authorization to use approved claims. The United States has approved 55 disease risk reduction claims by 2018, largely a result of the use of qualified health claims: 12 approved NLEA health claims (FDA 2018a), 5 approved FDAMA health claims (FDA 2018b), and 28 approved qualified health claims (FDA 2017). An overview of the disease risk reduction claims is provided in Appendix 1.

\section{Dietary Fats}

Dietary fats assist with absorption of certain vitamins and nutrients and provide energy to the body (American Heart Association 2017a). However, not all dietary fats are the same; some can have negative health consequences when consumed in excess. The main types of dietary fats are: saturated fatty acids (SFAs), trans fatty acids (TFAs), monounsaturated fatty acids, and polyunsaturated fatty acids (American Heart Association 2016a). Each type of dietary fat has different properties and impacts on blood cholesterol levels and overall health.

During the 1980s, research identified that high levels of SFAs in the diet are associated with increased levels of low density lipoprotein (LDL) or "bad" cholesterol (Schleifer 2012), a major risk factor for heart disease and stroke (American Heart Association 2017b).Animal products, such as beef, chicken, and pork, are primary sources of SFAs (American Heart Association 2017b). Public awareness of the deleterious consequences of consuming SFAs grew significantly in the 1990s due to extensive publicity both in scientifically-based journal articles and widespread media reports (Wansink and Cheney 2005).

Trans fatty acids (TFAs) are found naturally in small quantities in some animal products (e.g., meat and dairy products) (American Heart Association 2017c). They can also be created when liquid vegetable oils are converted to solid forms using an industrial partial hydrogenation process (American Heart Association 2017c, Ratnayake et al. 2007). During the 1990s, research revealed that the consumption of TFAs posed an even greater danger to health than SFAs due to their effects on total blood cholesterol (Resnik 2010). TFAs increase total blood cholesterol levels through an increase in "bad" (LDL) cholesterol and a reduction in "good" (HDL) cholesterol (Ratnayake et al. 2007).

The American Heart Association (2017c) noted that a lack of understanding about the negative health effects from consumption of TFAs contributed to a significant rise in its inclusion in processed foods during the 1980s and 1990s. Ratnayake et al. (2007) reported that TFAs accounted for 20 to $50 \%$ of total fat contents found in various margarine brands during that time-period. However, recent changes to production of margarine have led it now recognized as containing "heart healthy" fats (American Heart Association 2017a). .

Mono- and polyunsaturated fats are regarded as "heart healthy" fats (American Heart Association 2016b, 2017a) that reduce levels of LDL (bad) cholesterol, which lowers the risk of heart disease and stroke. They also provide 
essential nutrients and antioxidants to the body. Polyunsaturated fats provide omega- 3 and omega- 6 fatty acids; these are fats that cannot be produced by the body but are crucial for maintaining good health (American Heart Association 2016b). Vegetable oils, such as olive oil, canola oil, peanut oil, and safflower oil are high in monounsaturated fats (American Heart Association 2017a). Soybean oil, corn oil, and sunflower oil are high in polyunsaturated fats (American Heart Association 2016b).

In recent years, significant efforts have been made by public health officials to drastically reduce the consumption of both TFAs and SFAs to mitigate the rising economic burden of heart disease and related illnesses such as high cholesterol, high blood pressure, and stroke.

Previous research has found that belief and credibility in the health benefits of functional foods are the most important factors for consumer acceptance (Urala and Lähteenmäki 2004, Verbeke 2005, van Kleef et al. 2005). Further, the use of health claims can significantly improve acceptance rates and understanding of the health benefits (van Kleef et al. 2005, van Trijp and van der Lans 2007, Chrysochou and Grunert 2014, Huang and Lu 2016). However, the format and delivery of health claims (van Kleef et al. 2005, van Trijp and van der Lans 2007) as well as familiarity and personal relevance with the claimed benefit (Peng et al. 2006, Ding et al. 2015) play an important role in shaping consumers' understanding and acceptance.

The demand literature indicates that consumers adjust their dietary patterns in response to awareness of health information obtained from non-advertising sources. A health information index that accounts for the number of related published journal articles over the period is typically used as a proxy for awareness of health information (e.g., Brown and Schrader 1990, Capps and Schmitz 1991, Nichele 2003, Adhikari et al. 2006, Adhikari et al. 2007, Chang and Kinnucan 1991, Boetel and Lui 2003, Tonsor et al. 2010, Xiong et al. 2014). Evidence from a number of studies indicates that an increase in available health information (nonadvertising sources) regarding the negative health impacts of consuming foods that are high in saturated fats (such as butter and beef) decreased the demand for these foods (e.g., Brown and Schrader 1990, Capps and Schmitz 1991, Chang and Kinnucan 1991, Nichele 2003, Boetel and Liu 2003, Adhikari et al. 2006, Tonsor et al. 2010). Also, an increase in this type of health information increased the demand for foods lower in saturated fats (e.g., salad oils and fish) (e.g., Capps and Schmitz 1991, Boetel and Liu 2003, Nichele 2003, Tonsor et al. 2010).

It has been found that certain labelling policies can increase the demand for healthy foods (Mathios 2000, Tiesl et al. 2001, Dedah et al. 2011). Previous research on nutrition and health labelling policies has focused on the use of retail scanner data that records the prices and quantities of goods sold in grocery stores using point-of-sale systems. The literature indicates that the introduction of mandatory NLEA (Nutrition Labelling and Education Act) labelling policies in the United States reduced the market share of previously unlabeled salad dressings between 2.2 and $3.1 \%$ with high fat salad dressings having the largest decrease (Mathios 2000). Further, nutrient content claims provided on shelf tags in grocery stores were found to increase the demand for milk by $13 \%$, cream cheese by $9 \%$, 
and refried beans by $50 \%$ compared to conventional versions that did not have the nutrient content claims on shelf tags (Tiesl et al. 2001).

In general, the literature on acceptance of functional foods and the demand for foods indicated that consumers consider information from various sources when making dietary decisions. However, the current literature has not specifically examined the impacts of information provided in health claims on the demand for foods. Hence, the contribution of this study will be to empirically evaluate the efficacy of a current health claim in the United States at influencing demand of fats and meats.

\section{Empirical Analysis}

The health claim, "Dietary Saturated Fat and Cholesterol and Risk of Coronary Heart Disease (1993)" is analyzed for its impacts on food demand and population health in the United States. Two demand systems are estimated, based on available datasets.

The first system is the demand for fats, which includes three share equations for butter, margarine and lard. A binary variable (HC) has been included which takes the value of 0 before the approval of the health claim related to dietary fats and heart disease in 1993 and 1 thereafter.

It is expected that the "Dietary Saturated Fat and Cholesterol and Risk of Coronary Heart Disease (1993)" claim has negatively affected butter and lard demand due to their high saturated fat contents and positively affected demand for margarine. At the time of approval of this claim, the significant adverse impacts of TFAs were not as well understood as SFAs. It is expected that when this claim was approved in the United States (1993), consumers might have viewed margarine as a better choice than other types of fat due to greater concerns and awareness about saturated fats.

The second system analyzed is the demand for meats, which includes three share equations for poultry, pork and beef. The budget share for poultry is expected to be positively impacted due to low levels of saturated fat while beef and pork share equations are expected to show negative effects due to higher levels of saturated fat content.

\section{Data}

Per capita annual domestic disappearance data on a retail weight basis was used as a proxy for annual per capita consumption of fats and meats in the United States. Domestic disappearance data for fats was obtained from Economic Research Services (ERS), United States Department of Agriculture's Oil Crops Yearbooks for the years 1974 to 2016.

Per capita domestic disappearance data for poultry, pork, and beef in the meat demand system was obtained from the ERS (2017a) for the years 1970 to 2016. The per capita quantity of poultry is calculated as the sum of chicken, broilers, and turkey on an eviscerated weight basis. The per capita quantity of beef is calculated 
as the sum of beef and veal on a retail weight basis. The per capita quantity of pork is obtained on a retail weight basis.

Based on the best available dataset, average retail prices of margarine, lard, and fat in the United States from 1970 to 2016 are used for analysis. The average retail price of margarine was obtained from BLS (2017a). The price of margarine was missing for the years 1997 to 1999. Since observations already were limited and the price did not vary much over those years, the price of 1996 was used for 1997 and the price of 2000 for 1999. For 1998, the average price of 1996 and 2000 was used. Average retail price of lard was obtained from ERS (2017c). Average retail price data for butter was obtained from ERS (2017d).

The United States consumer price indices for poultry, pork and beef are used to proxy for prices from 1970 to 2016. The CPI for poultry is obtained from BLS (2017b), the CPI for pork is obtained from BLS (2017c) and lastly, the CPI for beef is obtained from BLS (2017d). A summary of the descriptions and sources for all data used in this study is provided in Appendix 2.

\section{Empirical Results}

The linear approximate almost ideal demand system (LA/AIDS) is used as the functional form for all the estimated demand systems. Zellner's iterative seemingly unrelated regressions (ITSUR) is used to estimate the demand for the products in each system and the theoretical conditions of homogeneity, symmetry and addingup are imposed in the models ${ }^{2}$.

\section{The Demand for Fats in the United States}

The annual per capita consumption of margarine has steadily declined while that for butter and lard also have declined but remained relatively constant from 1984 to 2010 (Figure 1) (ERS 2017a).

The coefficient estimates for the demand for fats in the United States from 1984 to 2010 are shown in Table 1 . The share equation for butter has an $R^{2}$ of 0.947. The results for the butter share equation show that butter's own-price and the price of margarine are statistically significant at the $1 \%$ level. The health claim variable is significant at the $1 \%$ level and indicates that, on average, the demand for butter was 7.1\% lower after the approval of the "Dietary Saturated Fat and Cholesterol and Risk of Coronary Heart Disease" claim in 1993. In addition, the time trend is significant at the $1 \%$ level and indicates that the demand for butter has increased an average of $1.31 \%$ per year over the sample period.

\footnotetext{
${ }^{2}$ The SUR approach is used to estimate a series of separate equations as a system rather than individually due to the assumption that there is correlation among the random error terms that should be considered during estimation to improve statistical inference. The Breusch-Pagan (BP) test of independence is a test used to evaluate the appropriateness of SUR estimation by testing for correlation among the residuals in the share equations. If the null hypothesis that the correlation among the errors is zero is rejected, then SUR is an appropriate estimation method (Wooldridge 2010). Based on the results of the BP tests, all systems showed correlation among the error terms of each equation and are estimated using seemingly unrelated regressions.
} 
Figure 1. Per Capita Consumption of Fats in the United States (1984-2010)

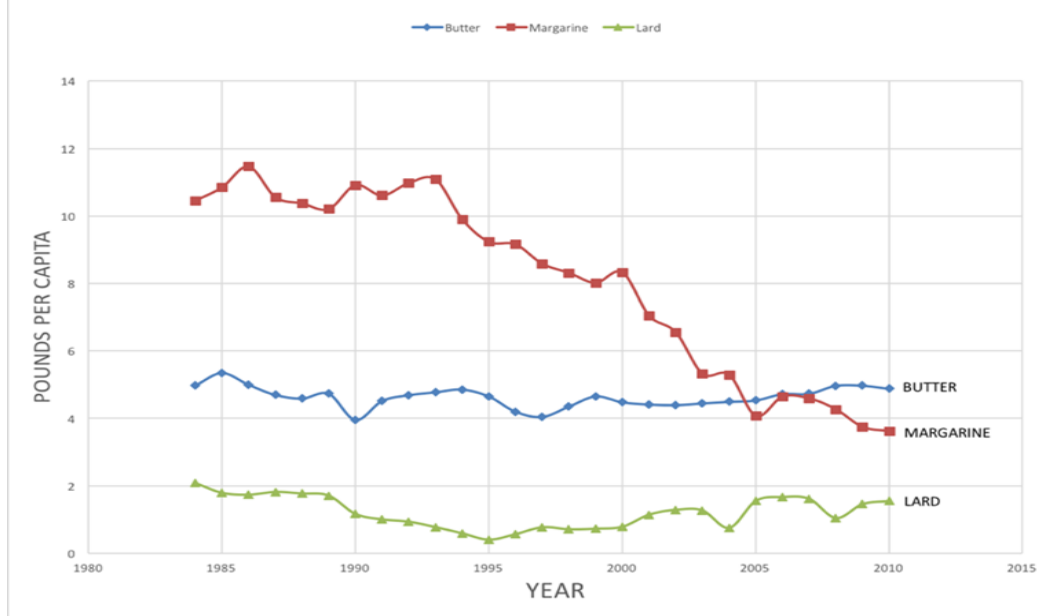

Source: ERS (2017a).

Table 1. Coefficient Estimates - Demand for Fats in the United States

\begin{tabular}{|l|c|c|c|}
\hline & \multicolumn{3}{|c|}{ Share Equation } \\
\hline $\begin{array}{l}\text { Independent } \\
\text { Variables }\end{array}$ & Butter & Margarine & Lard \\
\hline Butter Price & $0.244^{* * *}$ & $-0.243^{* * *}$ & -0.001 \\
\hline & $(0.028)$ & $(0.030)$ & $(0.003)$ \\
\hline Margarine Price & $-0.243^{* * *}$ & $0.253^{* * *}$ & $-0.010^{* *}$ \\
\hline & $(0.030)$ & $(0.033)$ & $(0.004)$ \\
\hline Lard Price & -0.001 & $-0.010^{* *}$ & $0.011^{* * *}$ \\
\hline & $(0.003)$ & $(0.004)$ & $(0.002)$ \\
\hline Expenditure & -0.079 & 0.083 & -0.004 \\
\hline & $(0.152)$ & $(0.167)$ & $(0.019)$ \\
\hline HC1993 & $-0.0710 * * *$ & $0.0850 * * *$ & $(0.003)$ \\
\hline & $(0.026)$ & $(0.029)$ & $0.00073 * * *$ \\
\hline Time & $0.0131 * * *$ & $-0.0138 * * *$ & $(0.0002)$ \\
\hline & $(0.002)$ & $(0.002)$ & 0.047 \\
\hline Constant & 0.566 & 0.387 & $(0.086)$ \\
\hline & $(0.681)$ & $(0.746)$ & 27 \\
\hline Observations & 27 & 27 & 0.656 \\
\hline R-squared & 0.947 & 0.94 & \\
\hline Strat & & \\
\hline
\end{tabular}

Standard errors reported in parentheses.

Significance at $* * * 1 \%, * * 5 \%, * 10 \%$ level.

Source: Authors.

Next, the share equation for margarine has an $\mathrm{R}^{2}$ of 0.94 . The results show that the price of margarine and butter, and lard are significant at the $1 \%$ and $5 \%$ levels. In addition, the health claim variable is significant at the $1 \%$ level and indicates that, on average, the demand for margarine was $8.50 \%$ greater after the approval of the health claim in 1993. The time trend is also significant at the $1 \%$ level and indicates that margarine demand fell by an average of $1.38 \%$ per year over the sample period. 
Last, the share equation for lard has an $\mathrm{R}^{2}$ of 0.656 . The results from the lard equation show that the price of lard, and margarine are significant at the $1 \%$ and $5 \%$ level, respectively. The health claim variable is also significant at the $1 \%$ level and indicates that the demand for lard was, on average, $1.41 \%$ lower after the approval of the health claim in 1993. In addition, the time trend is significant at the $1 \%$ level and indicates that the demand for lard increased by approximately $0.073 \%$ per year over the sample period.

The results of the "Dietary Saturated Fat and Cholesterol and Risk of Coronary Heart Disease (1993)" health claim on the demand for butter, margarine, and lard in the United States were as expected. After the approval in 1993, the demand for butter decreased (7.1\%), the demand for margarine increased $(8.50 \%)$, and the demand for lard decreased (1.41\%). The "Dietary Saturated Fat and Cholesterol and Risk of Coronary Heart Disease" health claim describes the adverse health effects of saturated fats on cholesterol and the risk of heart disease. Therefore, it makes sense that consumers would respond to this type of health information by decreasing the demand for butter and lard, which are high in saturated fats. In addition, during the early 1990s, there was considerable published research and media attention about the link between saturated fats and heart disease that could have contributed to the success of this health claim.

The positive impacts on the demand for margarine after the approval of the "Dietary Saturated Fat and Cholesterol and Risk of Coronary Heart Disease (1993)" also make sense. During the 1980s and 1990s, manufacturers increasingly used trans fats as a replacement for saturated fats in margarine to make them a lower saturated fat alternative. While trans fats are now known to have significant adverse effects on health, the health implications of trans fats were not yet fully understood at the time of approval of the "Dietary Saturated Fat and Cholesterol and Risk of Coronary Heart Disease (1993)" health claim. Therefore, it makes sense that, in 1993, consumers would respond to advice about saturated fats with an increase in the demand of an alternative lower saturated fat option, in this case, margarine.

In addition, the results from the trend variables also make sense. It appears that consumers have adjusted their demand for butter (1.31\% increase per year), margarine (1.38\% decrease per year), and lard ( $0.073 \%$ increase per year) over the whole sample period to reflect the significant changes in the understanding of the role of different dietary fats on health. Specifically, the realization that trans fats have even more severe health consequences than saturated fats is captured by the decrease in margarine demand over time. The increase in butter and lard demand over time might be a result of improved understanding by consumers of the consequences of trans fats, leading to higher consumption of butter.

The elasticity estimates for the demand for fats in the United States are presented in Table 2. The own-price elasticities for butter (-0.487), margarine (-0.489), and lard (-0.104) are all inelastic. In addition, the cross-price elasticities for the price of margarine with respect to butter demand $(-0.373)$ and vice versa $(-0.680)$ indicates a complementary relationship. In the margarine share equation, the cross-price elasticity for the price of lard is -0.025 , also indicating a complementary relationship. In the lard share equation, cross-price elasticities 
indicate butter (0.105) is a substitute for lard and margarine $(-0.676)$ is a complement for lard. Last, the expenditure elasticities indicate that butter (0.860), margarine (1.194), and lard (0.679) are normal goods with margarine slightly income elastic and butter and lard income inelastic.

Table 2. Elasticity Estimates - Fats in the United States

\begin{tabular}{|l|c|c|c|}
\hline & \multicolumn{3}{|c|}{ Share Equation } \\
\hline Butter Price & Butter & Margarine & Lard \\
\hline & $-0.487 * * *$ & $-0.680^{* * *}$ & 0.105 \\
\hline Margarine Price & $(0.129)$ & $(0.265)$ & $(0.947)$ \\
\hline & $-0.373 * * *$ & $-0.489 * *$ & -0.676 \\
\hline Lard Price & $(0.090)$ & $(0.222)$ & $(1.074)$ \\
\hline & 0.0001 & $-0.025 * *$ & -0.104 \\
\hline Expenditure & $(0.007)$ & $(0.011)$ & $(0.181)$ \\
\hline & $0.860 * * *$ & $1.194 * * *$ & 0.679 \\
\hline
\end{tabular}

Standard errors reported in parentheses.

Significance at $* * * 1 \%, * * 5 \%, * 10 \%$ level.

Source: Authors.

The inelastic own-price elasticities and expenditure elasticities were not surprising as they are consistent with previous findings in the literature. Chang and Kinnucan (1991) also found inelastic own-prices for butter (-0.74), margarine (0.09), and shortening (-0.29). Goddard and Amuah (1989) found butter to be income elastic (1.18) and margarine to be income inelastic (0.84). Goddard and Amuah (1989) also found an overall complementary relationship between butter and margarine (cross-price elasticities of -0.26 and -0.29) using uncompensated price elasticities. The complementary relationship between butter and margarine was somewhat unexpected. However, it might reflect different nutritional properties, consistencies, and flavors between butter and margarine that might contribute to reasons why they are not viewed as appropriate substitutes for each other.

\section{The Demand for Meat in the United States}

The annual per capita consumption of poultry, pork and beef in the United States has changed significantly since the 1970s (Figure 2): poultry consumption has increased significantly while beef consumption has declined. In contrast, per capital pork consumption has remained relatively constant compared to poultry and beef consumption. Again, these results make sense given the changes in the understanding of dietary fats and health that occurred over the period. 
Figure 2. Per Capital Consumption of Meats in the United States (1970-2016)

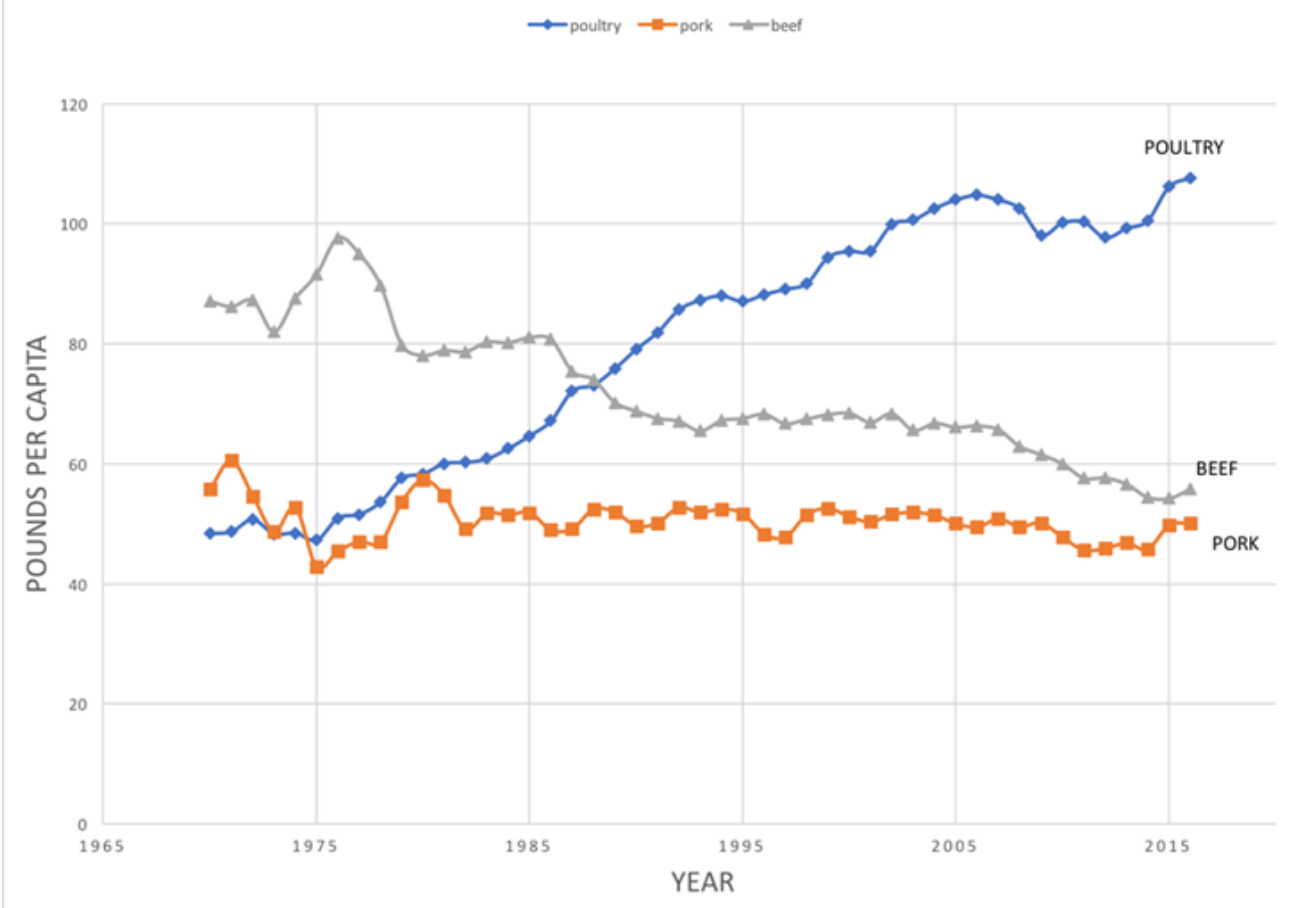

Source: ERS (2017b).

The coefficient estimates for the demand for meats in the United States from 1970 to 2016 are shown in Table 3. The poultry share equation has an $R^{2}$ of 0.966 . The results for the poultry share equation indicate that the price of poultry, pork, and beef and the expenditure variable are significant at the $1 \%$ level. The health claim variable is statistically significant at the 5\% level and indicates that the demand for poultry was, on average, $1.95 \%$ greater after the approval of the "Dietary Saturated Fat and Cholesterol and Risk of Coronary Heart Disease" health claim in 1993.

The $\mathrm{R}^{2}$ for the pork share equation is 0.947 . The results from the pork share equation show that pork's own-price and the price of poultry are statistically significant at the $1 \%$ level. In addition, the time trend is significant at the $1 \%$ level and indicates that, on average, the demand for pork decreased by $0.24 \%$ per year over the sample period.

The $\mathrm{R}^{2}$ for the beef share equation is 0.905 . The results from the beef share equation show that beef's own-price, the price of poultry, and the expenditure variable are significant at the $1 \%$ level. Additionally, the health claim variable in the beef share equation is significant at the $5 \%$ level, which indicates that after the approval of the "Dietary Saturated Fat and Cholesterol and Risk of Coronary Heart Disease" health claim in 1993 the demand for beef was, on average, 2.42\% lower than before the approval. 
Table 3. Coefficient Estimates - Demand for Meats in the United States

\begin{tabular}{|l|c|c|c|}
\hline & \multicolumn{3}{|c|}{ Share Equation } \\
\hline $\begin{array}{l}\text { Independent } \\
\text { Variables }\end{array}$ & Poultry & Pork & Beef \\
\hline Poultry Price & $0.216^{* * *}$ & $-0.052^{* * *}$ & $-0.164^{* * *}$ \\
\hline & $(0.027)$ & $(0.015)$ & $(0.026)$ \\
\hline Pork Price & $-0.052^{* * *}$ & $0.050^{* * *}$ & 0.002 \\
\hline & $(0.015)$ & $(0.012)$ & $(0.010)$ \\
\hline Beef Price & $-0.164^{* * *}$ & 0.002 & $0.162^{* * *}$ \\
\hline & $(0.026)$ & $(0.010)$ & $(0.031)$ \\
\hline Expenditure & $0.148^{* * *}$ & 0.018 & $-0.166^{* * *}$ \\
\hline & $(0.030)$ & $(0.013)$ & $(0.036)$ \\
\hline HC1993 & $0.0195^{* *}$ & 0.0047 & $-0.0242^{* *}$ \\
\hline & $(0.009)$ & $(0.004)$ & $(0.011)$ \\
\hline Time & 0.0014 & $-0.0024 * * *$ & 0.001 \\
\hline & $(0.001)$ & $(0.0004)$ & $(0.001)$ \\
\hline Constant & $-0.924^{* * *}$ & 0.146 & $1.779^{* * *}$ \\
\hline & $(0.238)$ & $(0.103)$ & $(0.285)$ \\
\hline Observations & 47 & 47 & 47 \\
\hline R-squared & 0.966 & 0.947 & 0.905 \\
\hline Stard & & &
\end{tabular}

Standard errors reported in parentheses.

Significance at $* * * 1 \%, * * 5 \%, * 10 \%$ level.

Source: Authors.

The impacts of the "Dietary Saturated Fat and Cholesterol and Risk of Coronary Heart Disease" health claim on poultry (1.95\% increase) and beef ( $2.42 \%$ decrease) demand were as expected and make sense considering poultry is a relatively low source of saturated fats and beef is a relatively higher source (American Heart Association 2017a). In addition, there was a large volume of published research on the impacts of saturated fats and related media attention around the time of this claim (Wansink and Cheney 2005) that likely contributed to the success of this health claim in terms of reducing the consumption of foods higher in saturated fats.

Table 4. Elasticity Estimates - Meats in the United States

\begin{tabular}{|l|c|c|c|}
\hline & \multicolumn{3}{|c|}{ Share Equation } \\
\hline Variables & Poultry & Pork & Beef \\
\hline Poultry Price & $-0.606^{* * *}$ & $-0.243^{* * *}$ & $-0.273^{* * *}$ \\
\hline & $(0.074)$ & $(0.074)$ & $(0.079)$ \\
\hline Pork Price & $-0.220^{* * *}$ & $-0.813^{* * *}$ & $0.118^{* * *}$ \\
\hline Beef Price & $(0.040)$ & $(0.056)$ & $(0.037)$ \\
\hline & $-0.545^{* * *}$ & -0.019 & $-0.383^{* * *}$ \\
\hline Expenditure & $(0.073)$ & $(0.053)$ & $(0.089)$ \\
\hline & $1.372^{* * *}$ & $1.075^{* * *}$ & $0.538^{* * *}$ \\
\hline
\end{tabular}

Standard errors reported in parentheses.

Significance at $* * * 1 \%, * * 5 \%, * 10 \%$ level.

Source: Authors. 
The price and expenditure elasticity estimates are reported in Table 4. All own-price elasticities are inelastic for poultry (-0.606), pork (-0.813), and beef (0.383 ). The cross-price elasticities, poultry, pork, and beef are all complements to each other except for pork, which is a substitute in the beef share equation. As for the expenditure elasticities, all are positive, indicating poultry (1.372), pork (1.075), and beef (0.538) are normal goods and that poultry and pork are income elastic while beef is income inelastic.

The elasticity estimates found in this study are not surprising. The literature typically reports inelastic own-prices and, although there does not appear to be a consensus on which meats are substitutes, the literature typically finds that at least one meat is a substitute to another. In that regard, consistent with the results found here, Brester and Schroeder (1995) also found that poultry (-0.33), pork (-0.69), and beef (-0.56) are own-price inelastic in the United States from 1970 to 1993 and that pork shows the greatest own-price sensitivity relative to poultry and beef. Similarly, Tonsor et al. (2010) found poultry (-0.099), pork (-0.7396), and beef ($0.4199)$ are own-price inelastic and that pork is most sensitive to own-prices in the United States from 1982 to 2007.

Tonsor et al. (2010) also found that poultry and beef are gross complements. The cross-price elasticities for the price of poultry on beef demand is -0.0406 and the price of beef on poultry demand is -0.1113. Similarly, Kinnucan et al. (1997) also found that pork and poultry are complements in the United States from 1976 to 1993. In contrast to the results presented here, Tonsor et al. (2010) found that pork and beef are gross substitutes (0.0163 and 0.0269) while the results here show that beef is a substitute only in the pork equation but not vice versa.

The fact that United States consumers were found to allocate more expenditures towards poultry (1.372) than pork (1.075) and beef (0.538) makes sense because of the negative health aspects of consuming too much red meat due to higher saturated fat and cholesterol levels. In addition, previous research has found similar income elasticities. Adhikari et al. (2006) also found that poultry (1.020) and pork (1.880) are income elastic and that beef (0.404) is income inelastic in the United States using data from 1989 to 2003. In addition, Kinnucan, et al. (1997) found that pork is income elastic (1.005) and beef is income inelastic (0.999) in the United States from 1976 to 1993.

\section{Summary of Findings}

The results from the demand analysis showed that the "Dietary Saturated Fat and Cholesterol and Risk of Coronary Heart Disease (1993)" health claim was successful at influencing the consumption of a healthier diet in the United States Statistically significant findings indicate that the demand for butter $(7.10 \%)$, lard $(1.41 \%)$, and beef $(2.42 \%)$ - products that have relatively higher contents of saturated fats - decreased after the approval of the health claim in 1993. In contrast, the demand for margarine (8.50\%), which was thought to be a better option during the early 1990s because of reduced saturated fat contents, and poultry $(1.95 \%)$ increased after the approval of the United States health claim in 1993. In addition, consumers showed significant changes in consumption patterns 
over time. The demand for pork fell on average by $0.24 \%$ and, consistent with the findings that TFAs have serious health consequences, the demand for margarine showed the largest annual decrease of $1.38 \%$ per year. The demand for butter $(1.31 \%)$ and lard $(0.073 \%)$ increased slightly over the period, which might also reflect changes due to the increased knowledge of the impacts of TFA consumption.

Additionally, the demand analysis revealed important price and expenditure effects. Own-price elasticities for butter (-0.487), margarine (-0.489), and lard $(-0.104)$ were inelastic and consistent with previous findings. Demand for poultry $(-0.606)$, pork (-0.813), and beef (-0.383) were found to be inelastic, which was consistent with previous literature, and all meats were found to be gross complements. Like the findings in this study, a small number of previous findings also have shown gross complementary relationships among poultry, pork and beef. However, more typically, at least one meat is found to be substitute for another. Some studies find pork and beef are substitutes while others find pork and chicken to be substitutes. Also, consistent with previous findings, poultry was most sensitive to change in income (1.372) followed by pork (1.075) and then beef (0.538).

\section{Policy Implications \& Recommendations to Further Improve Health Claims' Efficacy}

\section{Policy Implications}

Research has found that many chronic illnesses are preventable and that the risk of chronic disease can be reduced significantly through the adoption of a healthy lifestyle, which includes a balanced and nutritious diet (CDC 2016, Ippolito and Mathios 1991, Thompson and Moughan 2008, WHO 2003). These illnesses, and many more, place substantial economic burden on society due to the direct public healthcare costs, such as the hospital expenditures and pharmaceutical expenditures, associated with them (Public Health Agency of Canada 2014). In addition, there are considerable indirect costs associated with a loss of productivity and costs that cannot be measured, such as reduction in the quality of life and wellbeing due to the suffering caused by illness.

A second reason the "Dietary Saturated Fat and Cholesterol and Risk of Coronary Heart Disease (1993)" might have been more successful is that there was significant media attention on the issue of dietary fats and heart disease during the 1990s (Wansink and Cheney 2005). It is likely that this media attention facilitated greater consumer awareness and understanding about this health issue.

\section{Conclusion}

Overall, the empirical results suggest that the health claim "Dietary Saturated Fat and Cholesterol and Risk of Coronary Heart Disease (1993)" has been effective at changing the demand for fats and meats in the United States and improvements 
in dietary patterns have coincided with better health outcomes. The empirical results indicate that the health claim was effective at encouraging the consumption of a healthier diet that was lower in saturated fats in the United States. The demand for foods relatively higher in saturated fats decreased after the approval of the health claim in 1993 while the demand for foods lower in saturated fats increased. Specifically, statistically significant results indicated that butter $(7.10 \%)$, lard $(1.41 \%)$, and beef $(2.42 \%)$ demand decreased while margarine $(8.50 \%)$ and poultry $(1.95 \%)$ increased after the approval of the United States health claim in 1993.

Consumers in the United States showed changes in consumption choices over time. On average, the demand for pork ( $0.24 \% /$ year $)$ and margarine $(1.38 \% /$ year $)$ decreased over the period while the demand for butter $(1.31 \% / y e a r)$ and lard (0.073\%/year) increased over the period. Although butter and lard are higher in saturated fats, the increase likely represents adjustments in consumption due to changes in awareness of the relatively more severe negative health consequences of trans fats compared to saturated fats.

Overall, the results from this study suggest that the United States "Dietary Saturated Fat and Cholesterol and Risk of Coronary Heart Disease (1993)" health claim was successful at influencing consumption patterns of fats and meats in the United States.

\section{Limitations of the Study}

This study provides several key insights into the effectiveness of a current health claim at influencing consumption patterns and fostering healthy dietary behaviors. However, a few limitations of the study should be noted as they provide opportunity for improvements in future research. In that regard, the use of aggregated data might not provide sufficient variation to fully analyze the extent at which a specific health claim influences food demand. Further, the current study examines the effects of a health claim on a particular subset of foods; however, there is a possibility for substitution across larger subsets. There is also the potential for additional factors, outside the scope of this study, to influence food demand (e.g., demographic variables, other types of external health information, preference fluctuations, advertising and promotions). More robust results might be achieved with a different of model specification and richer dataset, such as survey or market data.

While these limitations are important for analyzing the effects of current health claims on the demand for fats and oils and meats, data were not available to systematically investigate all the factors associated with changes in food demand. As more data becomes available, the current analysis can be fine-tuned to provide a more comprehensive interpretation of the scope of health claims at influencing dietary behaviors. Understanding the efficacy of health policies aimed at improving dietary patterns and associated public health outcomes is essential given the rising incidence of diet-related chronic illness and related economic burdens in the United States. 


\section{References}

Adhikari M, Paudel L, Houston JE, Paudel KP, Bukenya J (2006) The impact of cholesterol information on meat demand: application of an updated cholesterol index. Journal of Food Distribution Research 37(2): 60-69.

Adhikari M, Paudel L, Paudel K, Houston JE, Bukenya J (2007) Impact of low carbohydrate information on vegetable demands in the United States. Applied Economics Letters 14(13): 939-944.

American Heart Association (2016a) Dietary fats. American Heart Association.

American Heart Association (2016b) Polyunsaturated fats. American Heart Association.

American Heart Association (2017a) Monounsaturated fats. American Heart Association.

American Heart Association (2017b) Saturated fats. American Heart Association.

American Heart Association (2017c) Trans fats. American Heart Association.

Aschemann-Witzel J (2011) The EU health claim regulation in international comparison: Review of the possible impact on food marketing and consumer protection. $C A B$ Reviews: Perspectives in Agriculture, Veterinary Science, Nutrition and Natural Resources 6(33): 1-7.

Boetel, Brenda L., and Donald J. Liu. 2003. Evaluating the effect of generic advertising and food health information within a meat demand system. Agribusiness 19 (3): 34554.

Brester GW, Schroeder TC (1995) The impacts of brand and generic advertising on meat demand. American Journal of Agricultural Economics 77(4): 969-979.

Brown DJ, Schrader LF (1990) Cholesterol information and shell egg consumption. American Journal of Agricultural Economics 72(3): 548-555.

Bureau of Labor Statistics - BLS (2017a) Series ID APU000716114 - Margarine, stick, per $\mathrm{lb}$. (453.6 gm) in U.S. city average, average price, not seasonally adjusted. Occupational Employment Statistics.

Bureau of Labor Statistics - BLS (2017b) Series ID CUUR0000SEFF - Poultry in U.S. city average, all urban consumers, not seasonally adjusted. Occupational Employment Statistics.

Bureau of Labor Statistics - BLS (2017c) Series ID CUURO00OSEFD - Pork in U.S. city average, all urban consumers, not seasonally adjusted. Occupational Employment Statistics.

Bureau of Labor Statistics - BLS (2017d) Series ID CUUROOOOSEFC - Beef and veal in U.S. city average, all urban consumers, not seasonally adjusted. Occupational Employment Statistics.

Canada Food Inspection Agency - CFIA (2016) Health claims. Canada Food Inspection Agency.

Capps O, Schmitz JD (1991) A recognition of health and nutrition factors in food demand analysis. Western Journal of Agricultural Economics 16(1): 21-35.

Centers for Disease Control and Prevention - CDC (2016) Heart disease fact sheet. Centers for Disease Control and Prevention.

Centers for Disease Control and Prevention - CDC (2017) Chronic disease overview. Centers for Disease Control and Prevention.

Centers for Disease Control and Prevention - CDC (2021) Healthy eating for a healthy weight. Centers for Disease Control and Prevention.

Chang H-S, Kinnucan HW (1991) Advertising, information, and product quality: the case of butter. American Journal of Agricultural Economics 73(4): 1195-1203.

Chrysochou P, Grunert KG (2014) Health-related ad information and health motivation effects on product evaluations. Journal of Business Research 67(6): 1209-1217. 
Dedah C, Keithly WR, Kazmierczak RF (2011) An analysis of US oyster demand and the influence of labeling requirements. Marine Resource Economics 26(1): 17-33.

Dietz WH, Douglas CE, Brownson RC (2016) Chronic disease prevention: tobacco avoidance, physical activity, and nutrition for a healthy start. Jama 316(16): 16451656.

Ding YL, Veeman MM, Adamowicz WL (2015) Functional food choices: impacts of trust and health control beliefs on Canadian consumers' choices of canola oil. Food Policy 52(C): 92-98.

Economic Research Services - ERS (2017a) Food availability (per capita) data system. Economic Research Services.

Economic Research Services - ERS (2017b) Table 40 - Margarine (actual weight): supply and disappearance, U.S., 1980-2010. Oil Crops Yearbooks. Economic Research Services.

Economic Research Services - ERS (2017c) Table 42--Lard: supply, disappearance, and price, U.S., 1980-2016. Oil Crops Yearbooks. Economic Research Services.

Economic Research Services - ERS (2017d) Table 43--Butter (actual weight): supply, disappearance, and price, U.S., 1980-2016. Oil Crops Yearbooks. Economic Research Services.

Goddard EW, Amuah AK (1989) The demand for Canadian fats and oils: a case study of advertising effectiveness. American Journal of Agricultural Economics 71(3): 741749.

Heart Foundation (2021) Fats, oils and heart health. Heart Foundation.

Herath D, Cranfield J, Henson S (2008) Who consumes functional foods and nutraceuticals in Canada? Results of cluster analysis of the 2006 survey of Canadians' Demand for Food Products Supporting Health and Wellness. Appetite 51(2): 256-265.

Hobbs JE, Malla S, Sogah EK (2014a) Regulatory frameworks for functional food and supplements. Canadian Journal of Agricultural Economics/Revue Canadienne d'Agroeconomie 62(4): 569-594.

Hobbs JE, Malla S, Sogah EK, Yeung MT (2014b) Regulating health foods: policy challenges and consumer conundrums. Cheltenham, UK: Edward Elgar Publishing Limited.

Huang L, Lu J (2016) The impact of package color and the nutrition content labels on the perception of food healthiness and purchase intention. Journal of Food Products Marketing 22(2): 191-218.

Ippolito PM, Mathios AD (1991) Health claims in food marketing: evidence on knowledge and behavior in the cereal market. Journal of Public Policy \& Marketing 10(1): 1532.

Kinnucan HW, Xiao H, Hsia C-J, Jackson JD (1997) Effects of health information and generic advertising on U.S. meat demand. American Journal of Agricultural Economics 79(1): 13-23.

Malla S, Hobbs JE, Sogah EK (2013) Functional foods and natural health products regulations in Canada and around the world: nutrition labels and health claims. Saskatoon, Saskatchewan, Canada: Report prepared for the Canadian Agricultural Innovation and Regulation Network.

Markosyan A, McCluskey JJ, Wahl TI (2009) Consumer response to information about a functional food product: apples enriched with antioxidants. Canadian Journal of Agricultural Economics 57(3): 325-341.

Mathios AD (2000) The impact of mandatory disclosure laws on product choices: an analysis of the salad dressing market. The Journal of Law \& Economics 43(2): 651678. 
Milner JA (1999) Functional foods and health promotion. Journal of Nutrition 129(7): 1395S-7S.

Moors EHM (2012) Functional foods: regulation and innovations in the EU. Innovation: The European Journal of Social Science Research 25(4): 424-440.

Nichele V (2003) Health information and food demand in France. In WS Chern, S Wen, K Rickertsen, Inc NetLibrary (eds.), Health, Nutrition and Food Demand. Wallingford, UK: CABI Pub.

Peng Y, West GE, Wang C (2006) Consumer attitudes and acceptance of CLA-enriched dairy products. Canadian Journal of Agricultural Economics/Revue Canadienne D'agroeconomie 54(4): 663-684.

Public Health Agency of Canada (2014) Economic burden of illness in Canada, 20052008. Catalogue HP50-1/2013E-PDF, Publication No. 130148. Public Health Agency of Canada.

Raghupathi W, Raghupathi V (2018) An empirical study of chronic diseases in the United States: a visual analytics approach to public health. International Journal of Environmental Research and Public Health 15(3): 431.

Ratnayake WMN, Gagnon C, Dumais L, Lillycrop W, Wong L, Meleta M, et al. (2007) Trans fatty acid content of Canadian margarines prior to mandatory trans-fat labelling. Journal of the American Oil Chemists' Society 84(9): 817-825.

Resnik D (2010) Trans-fat bans and human freedom. The American Journal of Bioethics 10(3): 27-32.

Schleifer D (2012) The perfect solution: how trans fats became the healthy replacement for saturated fats. Technology and Culture 53(1): 94-119.

Teisl MF, Bockstael NE, Levy A (2001) Measuring the welfare effects of nutrition information. American Journal of Agricultural Economics 83(1): 133-149.

Teratanavat R, Hooker NH (2006) Consumer valuations and preference heterogeneity for a novel functional food. Journal of Food Science 71(7): S533-41.

Thompson AK., Moughan PJ (2008) Innovation in the foods industry: functional foods. Innovation 10(1): 61-73.

Tonsor GT, Mintert JR, Schroeder TC (2010) U.S. meat demand: household dynamics and media information impacts. Journal of Agricultural and Resource Economics 35(1): $1-17$.

Urala N, Lähteenmäki L (2004) Attitudes behind consumers' willingness to use functional foods. Food Quality and Preference 15(7): 793-803.

U.S. Food and Drug Administration - FDA (2005) Dietary supplement labelling guide: chapter VI. Claims. U.S. Food and Drug Administration.

U.S. Food and Drug Administration - FDA (2013) Guidance for industry: a food labeling guide (9. Appendix A: definitions of nutrient content claims). U.S. Food and Drug Administration.

U.S. Food and Drug Administration - FDA (2016a) Dietary supplements. U.S. Food and Drug Administration.

U.S. Food and Drug Administration - FDA (2016b) Label claims for conventional foods and dietary supplements. U.S. Food and Drug Administration.

U.S. Food and Drug Administration - FDA (2017) Qualified health claims: letters of enforcement discretion. U.S. Food and Drug Administration.

U.S. Food and Drug Administration - FDA (2018a) Authorized health claims that meet the significant scientific agreement (SSA) Standard. U.S. Food and Drug Administration.

U.S. Food and Drug Administration - FDA (2018b) FDA modernization act (FDAMA) claims. U.S. Food and Drug Administration. 
van Kleef E, van Trijp HCM, Luning P (2005) Functional foods: health claim-food product compatibility and the impact of health claim framing on consumer evaluation. Appetite 44(3): 299-308.

van Trijp HCM, van der Lans IA (2007) Consumer perceptions of nutrition and health claims. Appetite 48(3): 305-324.

Veeman M (2002) Policy development for novel foods: issues and challenges for functional food. Canadian Journal of Agricultural Economics/Revue Canadienne d'agroeconomie 50(4): 527-539.

Verbeke W (2005) Consumer acceptance of functional foods: socio-demographic, cognitive and attitudinal determinants. Food quality and preference 16(1): 45-57.

Wansink B, Cheney MM (2005) Leveraging FDA health claims. Journal of Consumer Affairs 39(2): 386-398.

Wooldridge JM (2010) Econometric analysis of cross section and panel data. Massachusetts: MIT Press.

World Health Organization - WHO (2003) Diet, nutrition, and the prevention of chronic diseases: report of a joint WHO/FAO expert consultation. Volume 916. Geneva: World Health Organization.

Xiong B, Sumner D, Matthews W (2014) A new market for an old food: the U.S. demand for olive oil. Agricultural Economics 45(1): 107-118. 


\section{Appendix 1. United States Health and Nutrient Content Claims}

\section{NLEA Authorized Health Claims}

- Calcium, Vitamin D, and Osteoporosis (2008)

- Stanols/Sterols and Risk of Coronary Heart Disease (2000)

- Soy Protein and Risk of Coronary Heart Disease (1999)

- Soluble Fiber from Certain Foods and Risk of Coronary Heart Disease (1997)

- Dietary Non-cariogenic Carbohydrate Sweeteners and Dental Caries (1996)

- Folic Acid and Neural Tube Defects (1996)

- Dietary Lipids (Fat) and Cancer (1993)

- Dietary Saturated Fat and Cholesterol and Risk of Coronary Heart Disease (1993)

- Fiber-containing Grain Products, Fruits and Vegetables and Cancer (1993)

- Fruits and Vegetables and Cancer (1993)

- Fruits, Vegetables and Grain Products that contain Fiber, particularly Soluble fiber, and Risk of Coronary Heart Disease (1993)

- Sodium and Hypertension (1993)

Source: FDA (2018a).

\section{FDAMA Authorized Health Claims}

- Whole Grain Foods and Risk of Heart Disease and Certain Cancers

- Whole Grain Foods with Moderate Fat Content and Risk of Heart Disease

- Potassium and the Risk of High Blood Pressure and Stroke

- Fluoridated Water and Reduced Risk of Dental Carries

- Saturated Fat, Cholesterol, and Trans Fat, and Reduced Risk of Heart Disease Source: FDA (2018b).

\section{Qualified Health Claims}

- $100 \%$ Whey-Protein Partially Hydrolyzed Infant Formula and Reduced Risk of Atopic Dermatitis. May 24, 2011

- Green Tea and Risk of Breast Cancer and Prostate Cancer. February 24, 2011

- Selenium and a Reduced Risk of Site-specific Cancers. June 19, 2009

- Antioxidant Vitamins C and E and Reduction in the Risk of Site-Specific Cancers. June 19, 2009

- Tomatoes and Prostate, Ovarian, Gastric, and Pancreatic Cancers (American Longevity Petition). November 8, 2005

- Tomatoes and Prostate Cancer (Lycopene Heath Claim Coalition Petition). November 8, 2005

- Calcium and Colon/Rectal Cancer and Calcium and Colon/Rectal Polyps. October 12, 2005

- Selenium and Certain Cancers. April 28, 2003

- Antioxidant Vitamins and Risk of Certain Cancers. April 1, 2003

- Oleic Acid and Coronary Heart Disease (Corbion Biotech Petition). November 19, 2018

- Folic Acid, Vitamin B6, and Vitamin B12 and Vascular Disease. November 28, 2000

- Macadamia Nuts and Reduced Risk of Coronary Heart Disease. July 24, 2017 
- Walnuts and Coronary Heart Disease. March 9, 2004

- Nuts and Coronary Heart Disease. July 14, 2003

- Omega-3 Fatty Acids and Reduced Risk of Coronary Heart Disease. September 8, 2004

- Soybean Oil and Reduced Risk of Coronary Heart Disease. July 31, 2017

- Corn Oil and Corn Oil-Containing Products and a Reduced Risk of Heart Disease. March 26, 2007

- Unsaturated Fatty Acids from Canola Oil and Reduced Risk of Coronary Heart Disease. October 6, 2006

- Monounsaturated Fatty Acids from Olive Oil and Coronary Heart Disease. November 1, 2004

- Phosphatidylserine and Cognitive Dysfunction and Dementia. May 13, 2003

- High-Amylose Maize Starch and Reduced Risk Type 2 Diabetes Mellitus. December 12, 2016

- Psyllium Husk and a Reduced Risk of Type 2 Diabetes. External Link Disclaimer June 24, 2014

- Whole Grains and a Reduced Risk of Diabetes Mellitus Type 2. September 11, 2013

- Chromium Picolinate and a Reduced Risk of Insulin Resistance, Type 2 Diabetes. August 25, 2005

- Eicosapentaenoic Acid and Docosahexaenoic Acid and Reduction of Blood Pressure in the General Population. June 19, 2019

- Calcium and Hypertension, Pregnancy-Induced Hypertension, and Preeclampsia. October 12, 2005

- Folic Acid and Neural Tube Defects. April 3, 2007

- $\quad$ Ground Peanuts and Reduced Risk of Developing Peanut Allergy. September 7, 2017

Source: FDA (2017).

Nutrient Content Claim Categories (United States)

- Calories Claims

- Total Fat Claims

- Saturated Fat Claims

- Cholesterol Claims

- Sodium Claims

- Sugars Claims

Source: FDA 2013. 
Appendix 2. Descriptions and Sources of Price and Quantity Data

\begin{tabular}{|c|c|c|c|}
\hline $\begin{array}{l}\text { Demand } \\
\text { System }\end{array}$ & Commodity & $\begin{array}{l}\text { Quantity Data } \\
\text { Description }\end{array}$ & Price Data Description \\
\hline \multirow[t]{3}{*}{$\begin{array}{l}\text { Fats (United } \\
\text { States) }\end{array}$} & Butter & $\begin{array}{l}\text { Annual pounds of butter } \\
\text { available per capita } \\
\text { Source: ERS (2017d) }\end{array}$ & $\begin{array}{c}\text { Consumer price index for } \\
\text { poultry } \\
\text { Source: BLS }(2017 \mathrm{a})\end{array}$ \\
\hline & Margarine & $\begin{array}{c}\text { Annual pounds of } \\
\text { margarine available per } \\
\text { capita } \\
\text { Source: ERS (2017b) }\end{array}$ & $\begin{array}{l}\text { Consumer price index for } \\
\text { fresh or frozen pork } \\
\text { Source: ERS (2017b) }\end{array}$ \\
\hline & Lard & $\begin{array}{l}\text { Annual pounds of lard } \\
\text { available per capita } \\
\text { Source: ERS (2017c) }\end{array}$ & $\begin{array}{c}\text { Consumer price index for } \\
\text { beef and veal } \\
\text { Source: ERS }(2017 \mathrm{c})\end{array}$ \\
\hline \multirow[t]{3}{*}{$\begin{array}{l}\text { Meats (United } \\
\text { States) }\end{array}$} & Poultry & $\begin{array}{c}\text { Annual pounds of } \\
\text { chicken, broilers and } \\
\text { turkey available per } \\
\text { capita on an eviscerated } \\
\text { weight basis } \\
\text { Source: } \text { ERS (2017a) }\end{array}$ & $\begin{array}{c}\text { Consumer price index for } \\
\text { poultry } \\
\text { Source: BLS (2017b) }\end{array}$ \\
\hline & Pork & $\begin{array}{l}\text { Annual pounds of pork } \\
\text { available per capita on a } \\
\text { retail weight basis } \\
\text { Source: } \text { ERS }(2017 \mathrm{a})\end{array}$ & $\begin{array}{l}\text { Consumer price index for } \\
\text { fresh or frozen pork } \\
\text { Source: BLS }(2017 \mathrm{c})\end{array}$ \\
\hline & Beef & $\begin{array}{l}\text { Annual pounds of beef } \\
\text { and veal available per } \\
\text { capita on a retail weight } \\
\text { basis } \\
\text { Source: } \text { ERS (2017a) }\end{array}$ & $\begin{array}{c}\text { Consumer price index for } \\
\text { beef and veal } \\
\text { Source: BLS (2017d) }\end{array}$ \\
\hline
\end{tabular}

Source: Authors. 

Athens Journal of Business \& Economics -

Volume 8, Issue 2, April 2022 -Pages 119-138

\title{
Rural Structural Transformation and Agricultural Productivity in Nigeria
}

\begin{abstract}
By Abidemi Abiola* \& Rasak A. Adefabi $i^{ \pm}$
Rural structural transformation is best defined as structural changes in the rural areas occasioned by government policies and programmes with the intention of altering the contributions of major sector of the economy for the enhancement of agricultural sector. The study aimed at investigating the impact of rural structural transformation on agricultural productivity in Nigeria. The methodology adopted for the study was Structural Autoregression (SVAR). Six variables of expenditure on education (EXPE), expenditure on health (EXPH), expenditure on electricity (EXPEL), expenditure on telecommunication (EXPTC), expenditure on roads and construction (EXPRC) and expenditure on agriculture (EXPA). Of the six explanatory variables only expenditure on agriculture was found to be negatively related to agricultural productivity, while the others were positively related to it. Several reasons of which of official corruption by the handlers of agricultural funds could possibly be one of the reasons for the negative relationship between expenditure on agriculture and agricultural productivity. Among many other recommendations was the need to provide clinics and health centres to the rural areas, provision of good and accessible roads, provision of electricity and internet facilities. This will act as motivating factors in curbing rural-urban migration, and by extension improve the lots of agricultural productivity in Nigeria.
\end{abstract}

Keywords: rural, structural transformation, agricultural productivity, agricultural policies and structural VAR

\section{Introduction}

That agriculture is about most important sector in any given economy is to over-emphasise the obvious. Even with the best of the industrialised economy, agricultural sector cannot be regarded as secondary (Alvarez-Cuadrado and Poschke 2009). It is always at the front burner of national discourse. In most economies and especially the developing economies, agriculture is chief employer of labour. In Nigeria with the entire Dutch disease syndrome that saw many employees moving from agricultural sector to the manufacturing, industrial and oil sector, the sector still remains the largest employer of labour, accounting for about $70 \%$ of the labour force (World Bank 2018). The sector's contribution to food production, the most fundamental of human wants, the production of raw materials for many industries, contribution to the nation's gross domestic product, provision of jobs as means of livelihood of many are pointers to the importance of the sector to the economy.

${ }^{*}$ Senior Lecturer, Department of Economics, Ajayi Crowther University, Nigeria.

${ }^{ \pm}$Chief Lecturer, Department of Economics, Emmanuel Alayande College of Education, Nigeria. 
The sector is an umbrella body for four other subsectors of crop production, animal husbandry (livestock), fishery and forestry. While not demeaning the importance of the other three subsectors, the contribution of the crop production must be emphasized as the subsector is the largest contributor to the nation's gross domestic product, accounting for 88\% in the last quarter of 2016 (CBN 2018). According to Adikwu (2016), about $70 \%$ of the crop production is done at the rural areas where farmers lived in penury, thatched houses in squalid state, and lack basic amenities such as quality health care, electricity, portable water and inaccessible roads. Farmers in most of these developing economies are largely subsistence, depend on rain for irrigation, use simple crude tools for production which deny them the opportunity for large scale production. Compounding these problems for those who still manage to produce under these strenuous conditions is the little or no access to markets on account of poor conditions of the roads. The effect of which is the acceptance of peanuts as factor payments to the farmers for participating in the production process. A further effect of which is that all most all the rural areas are populated by aged population who are constrained on account of age to remain at the areas while the active youths that are capable of enhancing agricultural productivity migrate to the urban centres in search of greener pastures.

For reasons of general to specific, debate and topical issues on the importance of agricultural sector will continue unabated now and in the nearest future (Gangopadhyay and Mondal 2017). From the structural change Lewis theory of development (Todaro and Smith 2009), the importance of agricultural sector to national development in a developing economy with surplus labour in the traditional agricultural sector existing side by side with high-productivity modern urban industrial sector has long been noticed. The African Union Comprehensive African Agriculture Development Programme (CAADP) that advises governments in Africa countries to earmark $10 \%$ of their annual budget to agriculture, also underscore the importance of agricultural sector. The CAADP is a growth-oriented agricultural development agenda, aimed at increasing agriculture growth rates to a minimum of $6 \%$ per year to create the wealth needed for rural communities and households in Africa to prosper (Adeyinka et al. 2013). In the Nigerian context, programmes and policies have been put in place by successful governments to better the lots of agricultural sector in the country. The Farm Settlement Programme (FSP) introduced by the Western government in 1959, the National Accelerated Food Production Programme (NAFPP) initiated in 1972, the Agricultural Development Programme (ADPs) established by the Northern state governments in 1974, the Operation Feed the Nation (OFN) of 1976, the River Basin Development Authorities (RBDA) of 1976, the Green Revolution (GR) of 1980, the Directorate of Food Road and Rural Infrastructure (DFRRI) of 1986 have all at one time or the other established to address the myriad of problems facing agricultural sector.

The failure or not too felt impact of these programmes is not unconnected with the lip service implementation methods of those programmes. This is coupled with the fact that attention has been shifted to the money spinning oil sector in the country since the discovery of oil in commercial quantity in the late 60s. Efforts at revamping the agricultural sector according to (Ogbe 2018) however became more 
prominent the last decade in the country beginning from the Agricultural Transformation Agenda (2011) of Jonathan administration, the Economic Recovery and Growth Plan (2017-2020) of Buhari administration that encompasses Agricultural Promotion Policy (APP) alternatively called the "Green Alternative" (2016-2020) and Agricultural Sector Food Security and Nutrition Strategy (20162025).

\section{Statement of the Problem}

As observed in the previous section, a lot of programmes and policies have been put in place to revamp agricultural sector in Nigeria. The reasons for revamping according to Abiola (2017) stem from the apparent manifestation of the danger in monocultural nature of a given economy. The warning from oil experts on the possible exhaustion of oil deposits in the country in the nearest future and of course the increasing need for the nation to diversify her economy. From general macroeconomic policies to agricultural specific policies and programmes, efforts at concentrating on agricultural sector have gathered momentum in the recent past. These policies and programmes however have not produced the much desired results in terms of food sufficiency, adequate agricultural productivity to meet local consumption talkless of export.

According to World Bank (2018), the country's agricultural export's earning was $\$ 1,116,083.44$ as against import's payment of $\$ 2,554,896.19$. This staggering difference between the export and import is a major indication of the failure of the policies and programmes in achieving the expected agricultural output results (Yakubu and Akanegbu 2015). One striking feature of the country's agricultural import according to Food and Agricultural Organisation (FAO) (2011) is that a larger percentage of the country's agricultural import is on food. Nigeria's total food and agricultural imports are growing and estimated at more than $\$ 10$ billion in 2015. Wheat, rice, brown sugar, frozen fish, dairy products, vegetable oil, intermediate and consumer-oriented products are the largest imports. By continent, Nigeria imported goods mostly from Asia (44.6 percent), EU (33.6 percent), Americas (14.1), Africa (6.5 percent), and others (1.2 percent). By country, Nigeria's most significant suppliers include China (23 percent), United States (10 percent), India ( 8 percent), Belgium (6 percent), Netherlands (6 percent), and others countries across the world ${ }^{3}$.

The questions that arose are despite trade policies like imports substitution strategy for production of more rice in the country, quota ban on rice importation, exchange rate restrictions that affect the importation of wheat, establishment of bank of agriculture to facilitate accessibility of local farmers to credit facilities, a lot of agricultural programmes like the FADAMA I, II and III, all for the purpose of boosting agricultural productivity in the country, why is the country still not sufficient in food production, general agricultural productivity and value addition to agriculture. While the answer to the question could be viewed from far and

${ }^{3}$ USDA 2016. Retrieved from: www.fas.usda.gov/data/world-agricultural-production. [Accessed 8 February 2021] 
remote causes, the glaring immediate cause could be traced to the state of most rural areas in the country as well as the mode of operations of agricultural services. Why are there no social amenities like good roads, electricity, pipe borne water, hospitals and clinics, recreation facilities, internet facilities, etc., in the rural areas. Is there any impact these amenities have on the performance of agricultural productivity? Is there any link between the absence of these amenities and the absence of young able bodied men to engage in agricultural production in the rural areas? What of the orthodox method of agricultural production that is archaic as far as modern method of farm practices are concerned? What programmes and policies are in place to transform the entire structure of rural settings to make agriculture more attractive to teeming unemployed people? These and many more questions form the basis of the research study. The broad objective of the study therefore is to investigate the impact of rural structural transformation on agricultural productivity in Nigeria. Specifically the study will examine the present rural structure vis-à-vis the present agricultural productivity, as well as investigating the possible effects of increasing funding to agricultural sector on agricultural productivity in Nigeria.

\section{Literature Review}

Structural transformation according to Eboh (2014) connotes progressive decline in the share of primary production (agriculture and minerals) in national output as the economy modernises and grows, while manufacturing and services sectors grow increasingly. Another correlate of structural transformation is the reallocation of the labour force through specialisation (in products and skills) and market differentiation (Kendrick 1977). Specialisation and technological change are the driving forces that transform an agrarian economy into a diversified economy. Structural change is caused by changes in consumer demand and varied increases in productivity in the different sectors of the economy, due to specialisation and division of labour associated with scientific and industrial advances (Timmer and Akkus 2008).

Conceptually, a distinction between two closely related terms of structural transformation (ST) and rural transformation (RT) is imperative for analytical purpose. According to Omamo et al. (2016), structural transformation reflects changes in the relative contributions of agriculture, services, and manufacturing in an economy, while rural transformation (RT) is defined as a process of change in rural areas, which depends on many factors and dynamics. Rural transformation is embedded within structural transformation, as rural people change their occupations, invest, diversify livelihoods, and relate differently to each other within their families, communities, and social institutions (Losch et al. 2012). In semantic parlance therefore, rural structural transformation is seen as structural changes in the rural areas occasioned by government policies and programmes with the intention of altering the contributions of major sector of the economy in favour of agricultural sector (Naseem et al. 2107). 
Diao (2010) examines the success story of Ghana in terms of steady economic growth and poverty reduction and the likelihood of Ghana moving in the direction of most Asian countries that placed less premium on agriculture over and above other sectors of the economy. The study adopted a dynamic Computable General Equilibrium model with a view of examining which of the sectors of Ghanian economy will achieve a faster increase in national income and poverty reduction. The forward looking analysis of the dynamic CGE model shows that, even with much higher growth in the non-agricultural sector, agriculture will continue to be an important sector in terms of its size in the economy. Rapid growth in the manufacturing and export services can only occur when these sectors significantly improve their international competitiveness. However, with high dependency on imports for manufacturing, such growth also implies to lower prices for manufacturing goods produced domestically, which leads to lower the share of this sector in total GDP. Domestically oriented industry (e.g., construction) and services can only grow with income growth for a majority of households and rapid urbanization. Hence, rapid growth in non-traded industry and services is rather an outcome of broad-based growth, including growth in agriculture, and it will be unlikely to become a main driver to lead the economy wide growth. Moreover, the initial conditions of the structures and competition capacity of industry and services indicate that Ghana will unlikely become an African "Tiger" in next 10 years and will unlikely to observe rapid structural change in its economy. Agriculture will continue to be an important and big economic sector even when Ghana manages to become a middle income country in the next 10 years.

The study of Briones and Felipe (2013) is on Asia. The paper exposes that relative to other developing regions, developing Asia has experienced a slower decline in employment share in agriculture, compared to its output share; a rapid growth in labor and land productivity; and a shift from agricultural output from traditional to high-value products. The most successful Asian economies have pursued an agricultural development-led industrialization pathway. Nevertheless, agriculture remains the largest employer in many large Asian countries, hence future structural transformation must take into account agricultural transformation. Extrapolating from past trends, and taking to account emerging conditions, many countries of developing Asia will be expected to move on to the next phase of agricultural development; however even in the long term, agriculture's employment share will continue to be sizable relative with the output share. The paper concludes among others that to expedite transformation, many Asian countries will still need to promote long term productivity growth in agriculture and facilitate upgrading of their farms and agroenterprises within the global value chain.

The central theme of Lopes (2015) was on the imperativeness of agriculture as part of Africa's structural transformation. The paper buttresses its position with evidence that suggests that countries that have increased productivity across the globe benefited from economic growth sustained by agricultural transformation. Africans have an opportunity, now more than at any time before, to change their lives through increased agricultural productivity and enhanced agribusiness that connects smallholders to national, regional and global value chains. Food security has been given rightful prominence in the debate but cannot be a replacement for 
real transformation. It is important to renew the building blocks that are necessary for a deeper discussion of the connection to be made between agriculture and industrialisation. This paper proposes a six-point strategy to address major obstacles hampering African agricultural transformation. These include among others; the need to re-emphasise strategies and policies aimed at structural transformation; and the need to reduce the vulnerability of millions of African small scale farmers to high, volatile prices while increasing resilience to shocks. Oboh and Adeleke (2016) were on inclusive agricultural growth in Nigeria. The paper observed that agriculture has been identified as a critical sector with huge potential for promoting inclusive growth by stimulating economic growth, reducing poverty, and creating employment for a large number of people in developing countries. Against this backdrop, the paper assessed the sector's potential in accelerating sustainable broad-based growth and examined key strategies for realizing inclusive agricultural growth in Nigeria. Using data, covering 1981-2015, the results indicate agriculture's significant contribution to economic growth which is a necessary (but not sufficient) condition for achieving inclusive growth. Results of employment elasticity computed for the three major sectors suggested that agriculture led others (1.88) followed by services sector (1.18) and industry (0.33) in contributing to employment. Based on the analysis, the paper recommended policies such as increased public investment, access to farm inputs, youth-friendly and price stabilization programmes in order to accelerate inclusive growth in the agriculture sector.

Omamo et al. (2016) extended their work beyond the shores of Nigeria as the paper takes a look at the structural transformation of agriculture in Africa. The paper is of the opinion that any successful long-term structural transformation will start from agriculture and move through services and then to a more diversified manufacturing sector, thereafter reverting to expansion of highly skilled services. It also observed that comprehensive rural transformation in agriculturally dependent countries is constrained when not led by technical dynamism. With few exceptions, such dynamism is weak in African agriculture despite recent acceleration. In addition, mobility of factors (especially land) among alternative uses constrains rural transformation. Using descriptive analysis, the paper offer suggestions which include: public policy and investment must focus on two elements: leveraging burgeoning demand emanating from urbanization and dietary diversification to deepen employment in the rural nonfarm economy, and developing inclusive food supply chains to provision ever-increasing numbers of consumers. Rural suppliers need to sell to sources of dynamic, growing demand, especially to domestic urban markets. Broad objectives and priorities for policy and investment include improving market performance and meeting new demands, enhancing access to land and tenure security for smallholders and investors, financing agribusiness, upgrading infrastructure, using public-private partnerships where possible, building skills and entrepreneurship, particularly among young people, and making agribusiness inclusive by integrating market-oriented smallholders and rural communities into dynamic value chains.

Barrett et al. (2017) are more of the extension of Omamo et al. (2016). The paper pointed out that from 2000 to 2014, per capita GDP in sub-Saharan Africa 
increased by almost $35 \%$ in real terms, doubling in some countries. The irony of such progress is that agricultural productivity growth remained low in the aggregate, despite some bright spots, and poverty reduction has been steady but discouragingly slow. This paper argues that ending extreme poverty will require structural change in agriculture and in rural African economies more broadly. Drawing on a range of recent research, this paper outlines broad priority areas for policy actions to accelerate productivity and initiate structural change in the agriculture sector and the rural non-farm economy.

Nwankpa (2017) paper examines the agricultural transformation via-a-vis hunger and poverty eradication as a means of sustaining economic growth and development in Nigeria. The paper tries to highlight the importance of agricultural sector in terms of its contribution to the means of livelihood of a larger percentage of Nigeria and in terms of its contribution to the country's economic growth. The study went on to discuss the twist in economic fortune of the sector as a result of the discovery of oil in commercial quantity in 1968. The paper exposes among other things that despite the humongous amount of wealth that is realized from the sale of crude in the country since that period, about 53 million Nigerians, which represents about $30 \%$ of the nation's population are still undernourished, while about 118.2 million which represents about $72 \%$ of the total population still live below the poverty line. Using qualitative analysis of technique, the paper emphasizes significant improvements and effective harnessing of agricultural sector for meaningful and adequate food production and other socio-economic developments through agricultural reforms. Specifically, the study limits itself to the important role of agricultural transformation in engendering sustainable development and significant levels of hunger and poverty reduction in South Western Nigeria.

\section{Theoretical Framework and Model Specification}

This study adopts the traditional two factor neo-classical theory of production in which land (and perhaps capital) is fixed, labor is the only variable input, and profit is maximized. Specifically, the theory provides an economic rationale for the observed low productivity of traditional agriculture in the form of the law of diminishing marginal productivity ${ }^{4}$. The relevance of this theory is stemmed from the subsistence nature of farming system in Sub-Saharan Africa. Unfortunately, this theory according to Todaro and Smith (2009) does not satisfactorily explain why small-scale farmers are often resistant to technological innovation in farming techniques or to the introduction of new seeds or different cash crops. According to the standard theory, a rational income or profit-maximizing farm or firm will always choose a method of production that will increase output for a given cost (in this case, the available labor time) or lower costs for a given output level. But the theory is based on the crucial assumption that farmers possess "perfect knowledge" of all technological input-output relationships as well as current information about prevailing factor and product prices.

\footnotetext{
${ }^{4}$ An exposition made by Weitz (1971).
} 
Given the above theoretical background, the study applies the Cobb-Douglas production function in Abiola (2010), where;

$Q=A K^{\alpha} L^{\beta}$

where $\mathrm{Q}=$ the output

$\mathrm{A}=$ Efficiency parameter

$\mathrm{K}=$ Fixed input of Capital

$\mathrm{L}=$ Variable input of Labour

Equation 1 is not a convenient form for direct estimation by least squares methods; it is therefore usually converted into a logarithmic form:

$\log Q=\log A+\alpha \log K+\beta \log L+\mu$

so that the residual $\mu$ is added in the multiplicative form $e^{\mu}$.

A priori expectation suggests that both $\alpha$ and $\beta$ are greater than zero but less that one. That is, $0<\alpha<1$ and $0<\beta<1$. In the case where constant returns to scale is present, then $\alpha+\beta=1$. Alternatively, constant returns to scale may be imposed by putting $\beta=1-\alpha$, so that (1) can be rewritten as:

$Q=A K^{\alpha} L^{1-\alpha} e^{\mu} \Rightarrow Q=A\left(\frac{K}{L}\right)^{\alpha} L e^{\mu}$

or

$$
\frac{Q}{L}=A\left(\frac{K}{L}\right)^{\alpha} e^{\mu}
$$

and taking logarithms of both sides gives

$$
\log \left(\frac{Q}{L}\right)=\log A+\alpha \log \left(\frac{K}{L}\right)+\mu
$$

This second form avoids multicollinearity between $\log \mathrm{K}$ and $\log \mathrm{L}$ and also reduces heteroscedasticity if the variance of $\mathrm{K}$ is correlated with $\mathrm{L}$ (Wynn and Holden 1974).

Given the generic production function stated in 1 , the model for the study is specified as:

$Q=A X_{1}^{\alpha} X_{2}^{\beta} X_{3}^{\delta} X_{4}^{\lambda} X_{5}^{\sigma} X_{6}^{\pi}$

Where,
$Q=\mathrm{AGDP}=$
Agricultural Gross Domestic Product
$X_{1}=\quad \mathrm{EXPE}=$
Expenditure on Education 
$X_{2}=\mathrm{EXPH}=\quad$ Expenditure on Health

$X_{3}=$ EXPEL $=\quad$ Expenditure on Electricity

$X_{4}=$ EXPTC $=$ Expenditure on Telecommunication

$X_{5}=$ EXPRC $=\quad$ Expenditure on Road and Construction

$X_{6}=$ EXPA $=\quad$ Expenditure on Agriculture

In linear form, this can be expressed as:

$\log Q=\log A+\alpha \log X_{1}+\beta \log X_{2}+\delta \log X_{3}+\lambda \log X_{4}+\sigma \log X_{5}+\pi \log X_{6}+\mu$

\section{Estimation Procedure}

A study of agricultural productivity in economic literature shows that the methodologies adopted range from the descriptive analysis, most of which are qualitative in nature to econometric analyses. The econometric analyses involve the use of ordinary least square (OLS), the co-integration analyses and the error correction model (ECM), the two-stage least square for the ones involving simultaneous equations, the Generalized Method of Moments (GMM) panel estimation for the ones involving panel data, the generalized autoregressive conditional heteroskedasticity $(\mathrm{GARCH})$ and the vector error correction model (VECM).

In spite of the advantages of each method mentioned above, this model has adopted the methodology of Structural Vector Autoregression (SVAR). The advantages of SVAR according Kilian (2011) are classified under four main applications. First, they are used to study the average response of the model variables to a given one-time structural shock. Second, they allow the construction of forecast error variance decompositions that quantify the average contribution of a given structural shock to the variability of the data. Third, they can be used to provide historical decompositions that measure the cumulative contribution of each structural shock to the evolution of each variable over time. Finally, structural VAR models allow the construction of forecast scenarios conditional on hypothetical sequences of future structural shocks.

A typical estimation procedure for SVAR model involves the some steps. First is the examination of the stationarity or otherwise of the time series data included in the model. One important notice is that SVAR models involve high frequency data and as such annual time series data may not adequately capture the kind of expected result. Therefore it is advisable as much as possible that quarterly data of the series included in the model are used rather than the annual series. Where quarterly data are not easily available in some series, this problem may be overcome by disaggregating the data using different types of techniques available in many of the econometric packages.

The next step involves the estimation of the reduced form VAR, ensuring that adequate length have been taken into consideration. What constitutes adequate lag 
length can be taken care of by the use of lag length criteria available in econometric packages. Prominent among these lag length criteria are the Akaike, Schwartz and Hannan-Quinn information criteria. According to Gutierrez et al. (2007), an important aspect of empirical research in the specification of the VAR models is the determination of the lag order of the autoregressive lag polynomial, since all inference in the VAR model depends on the correct model specification. In several contributions, the effect of lag length selection has been demonstrated. Lütkepohl (1993) indicates that selecting a higher order lag length than the true lag length causes an increase in the mean square forecast errors of the VAR and that under fitting the lag length often generates autocorrelated errors. Braun and Mittnik (1993) show that impulse response functions and variance decompositions are inconsistently derived from the estimated VAR when the lag length differs from the true lag length. When cointegration restrictions are considered in the model, the effect of lag length selection on the cointegration tests has been demonstrated. For example, Johansen (1991) and Gonzalo (1994) point out that VAR order selection may affect proper inference on cointegrating vectors and rank.

In this study, one broad equation as contained in equation 7 was estimated. The equation that was used to estimate the aggregate agricultural output has seven variables. Q was used to represent agricultural output, APRC represented average price of the aggregate agricultural output, ACR was used to represent acreage while $\mathrm{LAB}$ was used to represent labour force in the agricultural sector. The other variables are as previously defined. Following the Cholesky ordering and based on economic theory; equation 6 can be represented as follows:

Taking a cue from the Structural VAR equations above, $n\left(\frac{n+1}{2}\right)=7\left(\frac{7+1}{2}\right)=28$ restrictions on the model, and hence, $7^{2}-28=21$ more restrictions are required to identify the structural matrix $B$

$$
\tilde{Y}=\left[\begin{array}{lllllll}
b_{11} A G D P & +b_{12} E X P H & +b_{13} E X P E & +b_{14} E X P E L & +b_{15} \text { EXPRC } & +b_{16} \text { EXPTC } & +b_{17} E X P A \\
b_{21} A G D P & +b_{22} E X P H & +b_{23} E X P E & +b_{24} E X P E L & +b_{25} E X P R C & +b_{26} E X P T C & +b_{27} E X P A \\
b_{31} A G D P & +b_{32} E X P H & +b_{33} E X P E & +b_{34} E X P E L & +b_{35} E X P R C & +b_{36} E X P T C & +b_{37} E X P A \\
b_{41} A G D P & +b_{42} E X P H & +b_{43} E X P E & +b_{44} E X P E L & +b_{45} E X P R C & +b_{46} E X P T C & +b_{47} E X P A \\
b_{51} A G D P & +b_{52} E X P H & +b_{53} E X P E & +b_{54} E X P E L & +b_{55} E X P R C & +b_{56} E X P T C & +b_{57} E X P A \\
b_{61} A G D P & +b_{62} E X P H & +b_{63} E X P E & +b_{64} E X P E L & +b_{65} E X P R C & +b_{66} E X P T C & +b_{67} E X P A \\
b_{71} A G D P & +b_{72} E X P H & +b_{73} E X P E & +b_{74} E X P E L & +b_{75} E X P R C & +b_{76} E X P T C & +b_{17} E X P A
\end{array}\right]
$$

This matrix can be represented as follows: 
$\left[\begin{array}{lllllll}b_{11} & b_{12} & b_{13} & b_{14} & b_{15} & b_{16} & b_{17} \\ b_{21} & b_{22} & b_{23} & b_{24} & b_{25} & b_{26} & b_{27} \\ b_{31} & b_{32} & b_{33} & b_{34} & b_{35} & b_{36} & b_{37} \\ b_{41} & b_{42} & b_{43} & b_{44} & b_{45} & b_{46} & b_{47} \\ b_{51} & b_{52} & b_{53} & b_{54} & b_{55} & b_{56} & b_{57} \\ b_{61} & b_{62} & b_{63} & b_{64} & b_{65} & b_{66} & b_{67} \\ b_{71} & b_{72} & b_{73} & b_{74} & b_{75} & b_{76} & b_{77}\end{array}\right]\left[\begin{array}{c}A G D P \\ E X P H \\ E X P E \\ E X P E L \\ E X P R C \\ E X P T C \\ E X P A\end{array}\right]=\left[\begin{array}{c}\varepsilon_{1} \\ \varepsilon_{2} \\ \varepsilon_{3} \\ \varepsilon_{4} \\ \varepsilon_{5} \\ \varepsilon_{6} \\ \varepsilon_{7}\end{array}\right]$

To arrive at the recursive restriction matrix, the followings restrictions were made to retrieve the structural shocks.

1. Agricultural output (AGDP) is affected by all the variables in the model. This is in consonance with the production function specified in equation 6 .

2. Expenditure on health (EXPH) is affected by expenditure on education (EXPE). They are both variables of human capital development. These variables, if present at the rural areas are capable of stemming the ruralurban influx.

3. The expenditure on education (EXPE) is affected by only EXPH. The reason as stated in 2 .

4. Expenditure on electricity (EXPEL) is affected by expenditure on road and construction (EXPRC) and expenditure on telecommunication (EXPTC). They are both variables of social amenities, the presence of which makes life comfortable for rural dwellers and debar them from moving en-masse to the cities.

5. Expenditure on road and construction (EXPRC) is affected by expenditure on electricity (EXPEL) and expenditure on telecommunication (EXPTC). Reason as stated in 4.

6. Expenditure on telecommunication (EXPTC) is affected by expenditure on road and construction (EXPRC) and expenditure on electricity (EXPEL).

7. Expenditure on agriculture is affected by all the other variables with the exception of agricultural gross domestic product.

From the assumptions above, the following are applicable. In the case of EXPE and EXPH, that are assumed to be affected by one and other, $\mathrm{b}_{21}=\mathrm{b}_{24}=\mathrm{b}_{25}=\mathrm{b}_{26}=\mathrm{b}_{27}=\mathrm{b}_{31}=\mathrm{b}_{34}=\mathrm{b}_{35}=\mathrm{b}_{36}=\mathrm{b}_{37}=0$. On the restriction placed on EXPEL, EXPRC and EXPTC the implication is that other variables of AGDP, EXPH, EXPE and EXPA do not affect them. Therefore, $b_{41}=b_{42}=b_{43}=b_{47}=b_{51}=$ $b_{52}=b_{53}=b_{57}=b_{61}=b_{62}=b_{63}=b_{67}=0$. Expenditure on agriculture (EXPA) is affected all other variables with the exception of agricultural gross domestic product, therefore $b_{71}=0$. Based on these restrictions, the resultant recursive matrix is presented thus: 
Vol. 8, No. 2 Abiola \& Adefabi: Rural Structural Transformation and Agricultural...

$$
B_{0}=\left[\begin{array}{ccccccc}
b_{11} & b_{12} & b_{13} & b_{14} & b_{15} & b_{16} & b_{17} \\
0 & b_{22} & b_{23} & 0 & 0 & 0 & 0 \\
0 & b_{32} & b_{33} & 0 & 0 & 0 & 0 \\
0 & b_{42} & b_{43} & b_{44} & 0 & 0 & 0 \\
0 & b_{52} & b_{53} & b_{54} & 0 & 0 & 0 \\
0 & b_{62} & b_{63} & b_{64} & 0 & 0 & 0 \\
0 & b_{72} & b_{73} & b_{74} & b_{75} & b_{76} & b_{77}
\end{array}\right]
$$

Expressing the restrictions in linear form, we have:

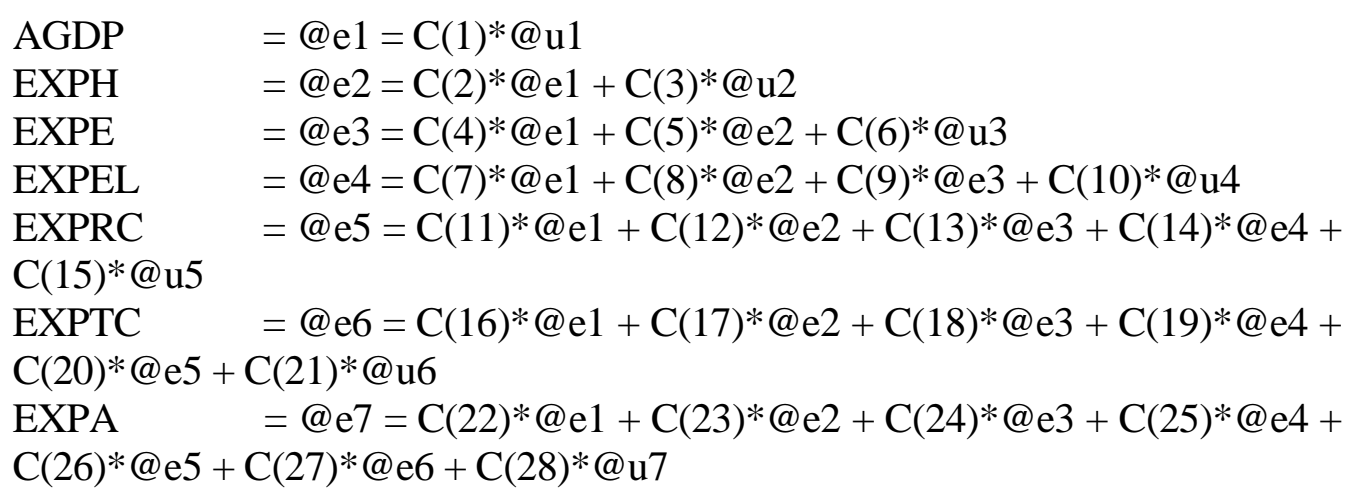

\section{Results and Discussion}

Table 1 presents the statistical properties of the series used for the models. The table provides information about the mean, the median, standard deviation, the maximum value, the minimum value, the skewness as well as the Jarque-Bera of each variable. The table shows the logarithm of the observed value of each variable. The mean values of the logarithm of agricultural gross domestic product (AGDP) and that of expenditure on education (EXPE) are 1.47 and 1.37 respectively. The implication of this is that of the other variables under consideration, the observed data of both the AGDP and EXPE appears to have biggest values throughout the period of observation. Expenditures on agriculture and telecommunication have the lowest means of 1.33 each. This is implies that both AGDP and EXPE have the lowest observed value in the series that make up the model. One important statistical characteristic of the variables in Table 1 is the near equality of both the mean and the median for all the variables. This implies a near perfect normal distribution data sets, a common assumption underlying many statistical tests. 
Table 1. Summary Statistics of the Series

\begin{tabular}{|l|c|c|c|c|c|c|c|}
\hline & AGDP & EXPA & EXPE & EXPEL & EXPH & EXPRC & EXPTC \\
\hline Mean & 1.47 & 1.33 & 1.37 & 1.35 & 1.35 & 1.35 & 1.33 \\
\hline Median & 1.47 & 1.36 & 1.39 & 1.36 & 1.37 & 1.36 & 1.35 \\
\hline Maximum & 1.48 & 1.40 & 1.43 & 1.42 & 1.42 & 1.41 & 1.40 \\
\hline Minimum & 1.45 & 1.21 & 1.28 & 1.24 & 1.24 & 1.26 & 1.24 \\
\hline Std. Dev. & 0.01 & 0.06 & 0.05 & 0.06 & 0.06 & 0.05 & 0.05 \\
\hline Skewness & 0.17 & -0.74 & -0.56 & -0.30 & -0.42 & -0.24 & -0.56 \\
\hline Kurtosis & 1.50 & 2.11 & 1.88 & 1.85 & 1.70 & 1.71 & 1.96 \\
\hline Jarque-Bera & 14.70 & 18.45 & 15.69 & 10.52 & 14.77 & 11.76 & 14.57 \\
\hline Probability & 0.00 & 0.00 & 0.00 & 0.01 & 0.00 & 0.00 & 0.00 \\
\hline Sum & 218.86 & 198.14 & 203.87 & 200.45 & 201.52 & 200.75 & 198.60 \\
\hline Sum Sq. Dev. & 0.01 & 0.55 & 0.40 & 0.53 & 0.47 & 0.35 & 0.39 \\
\hline Observations & 149 & 149 & 149 & 149 & 149 & 149 & 149 \\
\hline
\end{tabular}

Source: Author's Computation from E-Views 9. Data source: CBN 2018.

\section{Correlation}

Table 2 displays correlations between logarithm of agricultural gross domestic product (AGDP) and its determinants. This was done to avoid inconsistency in the regression analysis by establishing the substitutability of the variables. As a result, they provide a useful guide in the specification of the models. The simple correlations suggest that there was a positive correlation between logarithm of AGDP and the logarithm of all the determinants with the exception of that of inflation rate. In all the cases, the correlation appears to be strong, as the coefficients of the correlation are more than $80 \%$.

Table 2. Correlations

\begin{tabular}{|l|c|c|c|c|c|c|c|}
\hline & AGDP & EXPA & EXPE & EXPEL & EXPH & EXPRC & EXPTC \\
\hline AGDP & 1.00 & 0.89 & 0.93 & 0.95 & 0.95 & 0.97 & 0.90 \\
\hline EXPA & 0.89 & 1.00 & 0.98 & 0.96 & 0.97 & 0.97 & 0.98 \\
\hline EXPE & 0.93 & 0.98 & 1.00 & 0.97 & 0.99 & 0.97 & 0.96 \\
\hline EXPEL & 0.95 & 0.96 & 0.97 & 1.00 & 0.98 & 0.98 & 0.95 \\
\hline EXPH & 0.95 & 0.97 & 0.99 & 0.98 & 1.00 & 0.97 & 0.96 \\
\hline EXPRC & 0.97 & 0.97 & 0.97 & 0.98 & 0.97 & 1.00 & 0.96 \\
\hline EXPTC & 0.90 & 0.98 & 0.96 & 0.95 & 0.96 & 0.96 & 1.00 \\
\hline
\end{tabular}

Source: Author's Computation from E-Views 9 Data source: CBN 2018.

\section{Stationarity Property of the Series}

The data used for the analysis is time series. The major problem associated with that type of data is the serial or autocorrelation problem. If this problem is not taken care of, the results obtained from it will be spurious or nonsense. Testing for the stationarity or otherwise of a series involves testing for the unit root. This study tested for unit root using the Augmented Dickey Fuller approach. 
Table 3. Augmented Dickey Fuller Unit Root Test

\begin{tabular}{|l|c|c|c|c|}
\hline Variables & Level & $\mathbf{1}^{\text {st }}$ Difference & $\mathbf{2}^{\text {nd }}$ Difference & $\begin{array}{c}\text { Order of } \\
\text { Integration }\end{array}$ \\
\hline AGDP & -0.7361 & $-3.0857^{* *}$ & & $\mathrm{I}(1)$ \\
\hline EXPE & -1.5127 & $-4.4779^{*}$ & & $\mathrm{I}(1)$ \\
\hline EXPH & -1.3804 & $-4.1320^{*}$ & & $\mathrm{I}(1)$ \\
\hline EXPEL & -1.3551 & $-3.3491^{* *}$ & & $\mathrm{I}(1)$ \\
\hline EXPTC & -1.7160 & $-4.3938^{*}$ & & $\mathrm{I}(1)$ \\
\hline EXPRC & -1.9660 & $-3.4076^{* *}$ & & $\mathrm{I}(1)$ \\
\hline EXPA & -2.3724 & $-3.2283^{* *}$ & & $\mathrm{I}(1)$ \\
\hline
\end{tabular}

Critical Statistics: $1 \%=-3.4778,5 \%=-2.8823,10 \%=-2.5779$

*Significant@1\%,**Significant@5\%,***Significant@10\%

Source: Author's Computation from E-Views 9 Data source: CBN 2018.

Table 3 shows the unit root test results using Augmented Dickey Fuller (intercept) approach. From the results all the series that make up the model were non stationary. To make them stationary, they were all made stationary after first differencing. Since the stationary properties of the series had been determined, we proceeded to estimate the Vector Autoregression by first examining the lag length needed for the estimation. The results are presented in Table 4.

Table 4. Lag Selection Criteria

\begin{tabular}{|c|c|c|c|c|c|c|}
\hline & & VAR Las & Order Selec & tion Criteria & & \\
\hline Endoge & us variables: & AGDP EXP & EXPE EXP & EL EXPH EX & PRC EXPTC & \\
\hline Exogen & S variables: & & & & & \\
\hline Sample & 9812018 & & & & & \\
\hline Include & bservations: & & & & & \\
\hline Lag & $\log L$ & LR & FPE & AIC & SC & HQ \\
\hline 0 & 786.1064 & NA & $3.76 \mathrm{e}-28$ & -43.28369 & -42.97578 & -43.17622 \\
\hline 1 & 934.5866 & 230.9692 & $1.58 \mathrm{e}-30$ & -48.81037 & $-46.34711 *$ & -47.95063 \\
\hline 2 & 1015.171 & $94.01487 *$ & $3.77 \mathrm{e}-31 *$ & $-50.56504 *$ & -45.94645 & $-48.95303^{*}$ \\
\hline$*$ indic & s lag order $\mathrm{s}$ & lected by the & riterion & & & \\
\hline LR: sec & ential modifi & d LR test sta & stic (each tes & $t$ at 5\% level) & & \\
\hline FPE: F & l prediction & error & & & & \\
\hline AIC: A & ike informat & on criterion & & & & \\
\hline SC: $\mathrm{Sc}$ & arz informa & on criterion & & & & \\
\hline HQ: $\mathrm{H}$ & an-Quinn in & formation c & & & & \\
\hline
\end{tabular}

The results above show that of the five criteria available for choosing the lag length, four chose lag length 2. This forms the basis for the estimation of our Vector Autoregression. 
Table 5. Structural VAR Estimates of the Foreign Direct Investment Equation

\begin{tabular}{|c|c|c|c|c|}
\hline & Coefficient & Std. Error & z-Statistic & Prob. \\
\hline C(1) & 0.000937 & 0.000110 & 8.485281 & 0.0000 \\
\hline $\mathrm{C}(2)$ & 0.776511 & 2.460008 & 0.315654 & 0.7523 \\
\hline $\mathrm{C}(3)$ & 0.013827 & 0.001630 & 8.485281 & 0.0000 \\
\hline $\mathrm{C}(4)$ & 3.380533 & 1.788611 & 1.890033 & 0.0588 \\
\hline $\mathrm{C}(5)$ & 0.395911 & 0.121012 & 3.271674 & 0.0011 \\
\hline C(6) & 0.010040 & 0.001183 & 8.485281 & 0.0000 \\
\hline $\mathrm{C}(7)$ & -0.094106 & 1.294108 & -0.072718 & 0.9420 \\
\hline $\mathrm{C}(\mathbf{8})$ & -0.020724 & 0.095118 & -0.217873 & 0.8275 \\
\hline $\mathrm{C}(9)$ & 0.222752 & 0.115016 & 1.936702 & 0.0528 \\
\hline $\mathrm{C}(10)$ & 0.006928 & 0.000817 & 8.485281 & 0.0000 \\
\hline $\mathrm{C}(11)$ & 2.544275 & 0.969888 & 2.623266 & 0.0087 \\
\hline $\mathrm{C}(12)$ & -0.104364 & 0.071329 & -1.463124 & 0.1434 \\
\hline $\mathrm{C}(13)$ & 0.809631 & 0.090573 & 8.938959 & 0.0000 \\
\hline $\mathrm{C}(14)$ & 0.305774 & 0.124902 & 2.448116 & 0.0144 \\
\hline $\mathrm{C}(15)$ & 0.005192 & 0.000612 & 8.485281 & 0.0000 \\
\hline $\mathrm{C}(16)$ & 2.308275 & 1.341442 & 1.720741 & 0.0853 \\
\hline $\mathrm{C}(17)$ & 0.587530 & 0.093042 & 6.314680 & 0.0000 \\
\hline $\mathbf{C}(18)$ & -0.033960 & 0.205952 & -0.164894 & 0.8690 \\
\hline $\mathrm{C}(19)$ & 0.185460 & 0.170952 & 1.084869 & 0.2780 \\
\hline $\mathrm{C}(20)$ & -0.251444 & 0.211210 & -1.190491 & 0.2339 \\
\hline $\mathrm{C}(21)$ & 0.006580 & 0.000775 & 8.485281 & 0.0000 \\
\hline $\mathbf{C}(22)$ & 3.570696 & 1.250473 & 2.855477 & 0.0043 \\
\hline $\mathbf{C}(23)$ & 0.123914 & 0.121036 & 1.023776 & 0.3059 \\
\hline $\mathrm{C}(24)$ & 0.214564 & 0.184616 & 1.162218 & 0.2451 \\
\hline $\mathrm{C}(25)$ & -0.384104 & 0.155667 & -2.467469 & 0.0136 \\
\hline $\mathrm{C}(26)$ & -0.223016 & 0.192947 & -1.155841 & 0.2477 \\
\hline $\mathrm{C}(27)$ & 0.489251 & 0.149344 & 3.276000 & 0.0011 \\
\hline $\mathrm{C}(28)$ & 0.005896 & 0.000695 & 8.485281 & 0.0000 \\
\hline
\end{tabular}

Source: Author's Computation from E-Views 9. Data source: CBN 2018.

Table 5 displays the estimates of the SVAR model for the determinants of agricultural productivity on the basis of rural structural transformation in Nigeria. These were the results of the model specified and estimated with the objective of investigating the impact of the expenditure on rural structural transformation on agricultural productivity in Nigeria. The 28 coefficients gave an insightful depiction of the kind of cross relationships among the variables that make up the model. The coefficients of major concern to this analysis are $\mathrm{C}(2), \mathrm{C}(3), \mathrm{C}(4)$, $\mathrm{C}(5), \mathrm{C}(6)$ and $\mathrm{C}(7)$. These are the coefficients of expenditures on education (EXPE), health (EXPH), electricity (EXPEL), telecommunication (EXPTC), road and construction (EXPRC) and agriculture (EXPA). All the variables were found to be positively related to agricultural productivity with the exception of the coefficient 7 , the coefficient associated with agriculture. The implication of the results is that they all follow the a priori expectation with the exception of agriculture which was found to be negative as against the expected positive relation. The results however is a manifestation of sharp practices from those in 
charge of funds relating to agricultural sector. This mostly as it concerns the diversion of funds for agricultural development for personal uses, engaging in the sales of fertilizers meant for distribution to farmers and a lot of corrupt practices among high level personnel handling agricultural issues in the country. The impulse response function of the SVAR is presented in Figure 1.

Figure 1. Agricultural Productivity Impulse Response Function

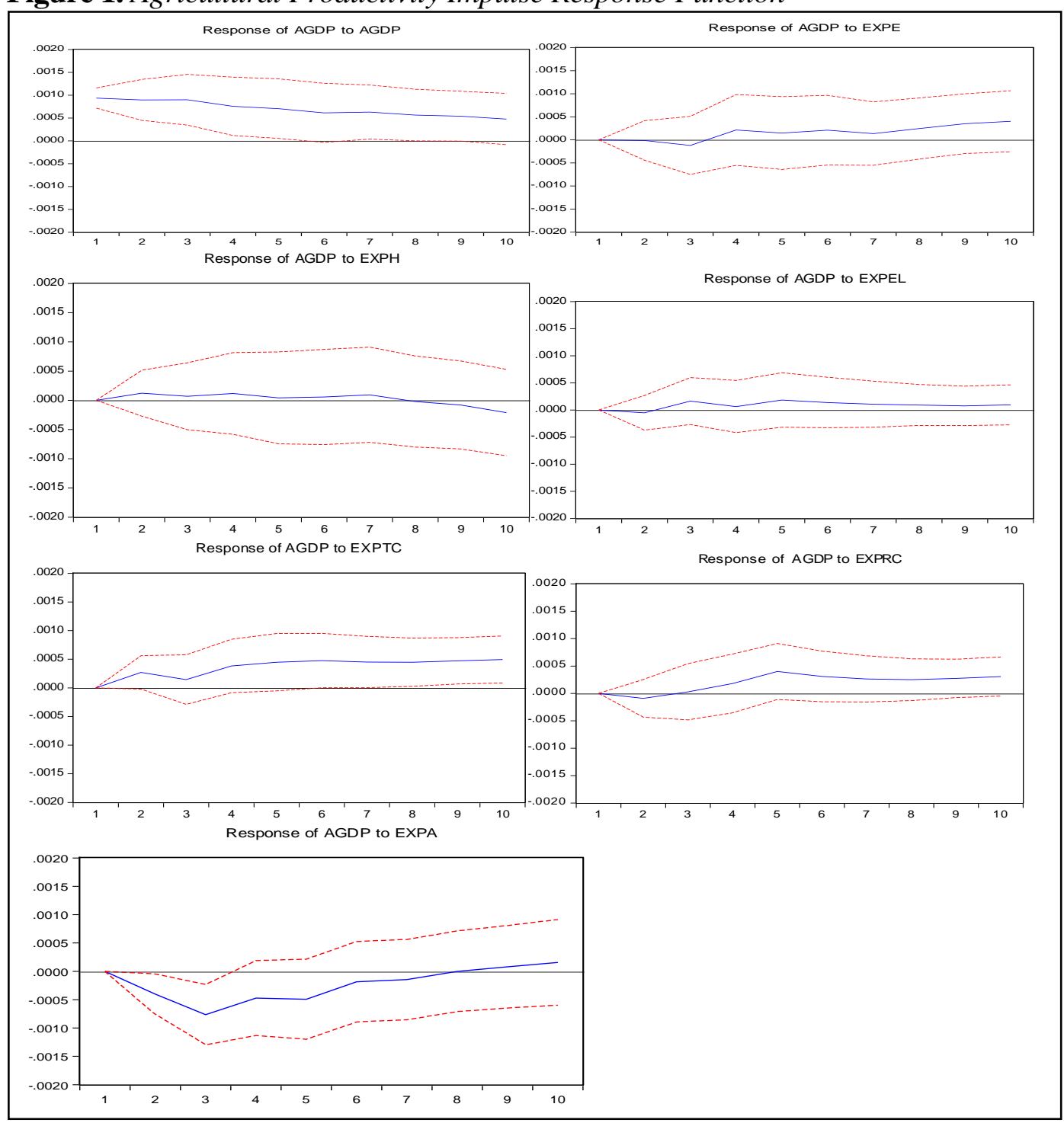

The first figure of Figure 1 shows the response of AGDP to its own shock. A one standard deviation shock to AGDP led to a rise in AGDP from period one all through to period ten, albeit positive movement. The second figure (north-east corner) shows the response of AGDP to the shock from expenditure on inflation. With an impulse from expenditure on education, the AGDP was unresponsive from period one to two, before a positive response was observed from period two to ten. The positive trend responsive was similar for expenditure on health, electricity, telecommunication and road and construction. In the case of impulse 
from agriculture, the response of AGDP was negative from period one to 8, before a positive response was observed for periods 8 to 10 .

Table 6. Variance Decomposition of AGDP

\begin{tabular}{|l|c|c|c|c|c|c|c|c|}
\hline \multicolumn{10}{|c|}{ Variance Decomposition of AGDP } \\
\hline Period & S.E. & AGDP & EXPA & EXPE & EXPEL & EXPH & EXPRC & EXPTC \\
\hline $\mathbf{1}$ & 0.000937 & 100.0000 & 0.000000 & 0.000000 & 0.000000 & 0.000000 & 0.000000 & 0.000000 \\
\hline $\mathbf{2}$ & 0.001394 & 86.56125 & 1.421501 & 0.291091 & 0.003920 & 0.431917 & 5.963038 & 5.327285 \\
\hline $\mathbf{3}$ & 0.001846 & 73.12613 & 6.096622 & 0.424673 & 0.789201 & 0.526256 & 14.68152 & 4.355593 \\
\hline $\mathbf{4}$ & 0.002108 & 68.89497 & 4.772531 & 1.301817 & 0.835168 & 0.537266 & 19.15342 & 4.504831 \\
\hline $\mathbf{5}$ & 0.002367 & 63.53720 & 4.243597 & 1.149540 & 1.311566 & 0.426677 & 25.46160 & 3.869825 \\
\hline $\mathbf{6}$ & 0.002530 & 61.47988 & 5.557273 & 1.048348 & 1.544535 & 0.449193 & 26.13886 & 3.781908 \\
\hline $\mathbf{7}$ & 0.002671 & 60.74969 & 6.172287 & 0.941013 & 1.676605 & 0.580307 & 26.10150 & 3.778594 \\
\hline $\mathbf{8}$ & 0.002790 & 59.77258 & 8.181866 & 0.880339 & 1.642435 & 0.548168 & 25.23365 & 3.740961 \\
\hline $\mathbf{9}$ & 0.002918 & 58.07223 & 11.33034 & 0.892784 & 1.540136 & 0.501565 & 24.02397 & 3.638977 \\
\hline $\mathbf{1 0}$ & 0.003053 & 55.49299 & 15.50192 & 0.886023 & 1.416573 & 0.561579 & 22.67054 & 3.470373 \\
\hline
\end{tabular}

Source: Author's Computation. Data source: CBN 2018.

Table 6 shows the results of variance decomposition of the first ten periods' horizon into the future. The results show that in the first period, variations in AGDP were wholly explained by own shocks. This implies that variations in AGDP were hardly affected by other variables in the first period. The results also show that beside own contribution, variations in AGDP was mainly attributed to expenditure on agriculture, road and construction as well as expenditure on telecommunication. The expenditures on other social amenities like health, electricity and education marginally attribute to changes in variations in agricultural gross domestic product. Expenditures on agriculture and road and construction that contribute mostly to agricultural productivity accounted $1.4 \%$ and $6.0 \%$ respectively in period 1 , and by period 10 , it had risen to $15.5 \%$ and $22.7 \%$ respectively.

\section{Conclusion}

From the above analysis, it is confirmed that along the line of rural structural transformation, expenditures on social amenities plays very important roles. These social amenities are indirectly related to agricultural productivity in the country. Of the push factors that draw away productive agricultural labour force from the rural areas to urban areas are the absence of basic social facilities that can make life comfortable for the rural dwellers. Transforming rural area structurally entails the provision of these facilities. This study therefore made use of six explanatory variables of rural structural transformation to explain agricultural productivity in Nigeria. Of the six variables, expenditures on education, health, electricity, road and construction and telecommunication were found to be positively related to agricultural productivity, while expenditure on agriculture was found to be negatively related to its productivity. Although the relationship between expenditure on agriculture and its productivity was negative, the results of the 
variance decomposition shows that the variable has the strongest impact on agricultural productivity than any of the other variables under consideration.

\section{Recommendations}

On the bases of the above analysis and findings, it is highly recommended that government should expend more on those social and basic amenities for people of rural areas, so as to act as motivation and incentives for them to staying in the rural villages and make career out of the farming profession. New roads should be constructed for them, existing ones to be rehabilitated so that it will be motorable for the rural dwellers to transport themselves as well as their goods. Electricity should be provided to have a feel of life in the cities. Internet facilities should be made available for them to get themselves acquainted with happenings in the world and be educated about the current methods of agricultural production. Hospitals, clinic and maternity centres should be provided to improve on their health status, while schools should be provided to at least cater for their basic educational needs. All these when provided, will act as impetus for the rural farmers to be more productive and this will ultimately lead to improve agricultural productivity in the country.

\section{References}

Abiola A (2010) Capital-labour substitution and banking sector performance in Nigeria (1960-2008), Central Bank of Nigeria, Economic and Financial Review 48(2): 109130

Abiola A (2017) Agricultural supply response to trade and exchange rate reforms in Nigeria. Unpublished $\mathrm{PhD}$ Thesis. Ibadan, Nigeria: Department of Economics, University of Ibadan.

Adeyinka A, Salau S, Vollrath D (2013) Structural change in the Nigerian economy. Working Paper 24. International Food Policy Research Institute.

Adikwu S E (2016) The need for agricultural transformation. The Sun Newspaper, May 31.

Alvarez-Cuadrado F, Poschke M (2009) Structural change out of agriculture, labour push versus labour pull. Discussion Paper 4247. Germany: Institute for the Study of Labour (IZA).

Barrett CB, Christiaensen L, Sheahan M, Shimeless A (2017) On the structural transformation of rural Africa. Journal of African Economies 26(1): 11-35.

Braun PA, Mittnik S (1993) Misspecifications in vector autoregressions and their effects on impulse responses and variance decompositions. Journal of Econometrics 59(3): 319-341.

Briones R, Felipe J (2014) Agriculture and structural transformation in developing Asia: review and outlook. Working Paper Series 363. Asian Development Bank Economics.

Central Bank of Nigeria - CBN (2018) Statistical bulletin. CBN. Retrieved from: www. cbn.gov.ng/documents/Statbulletin.asp. [Accessed 8 February 2021] 
Diao X (2010) Economic importance of agriculture for sustainable development and poverty reduction: findings from a case study of Ghana. In Global Forum on Agriculture. November 29-30. Paris: OECD.

Eboh EC (2014) Agricultural economics of Nigeria: paradoxes and crossroads of multimodal nature. Nsukka: University of Nigeria.

Food and Agricultural Organisation - FAO (2011) The future of food and agriculture. Retrieved from: http://www.fao.org/3/i6583e/i6583e.pdf. [Accessed 8 February 2021]

Gangopadhyay K, Mondal D (2017) Agricultural productivity and structural change: a falsifiable approach to explain structural break in relative price of manufacturing. Indian Institute of Management.

Gonzalo J (1994) Five alternative methods of estimating long run equilibrium relationships. Journal of Econometrics 60(1-2): 203-233.

Gutierrez CEC, Souza RC, Gullen OT (2007) Selection of optimal lag length in cointegrated var models with weak form of common cyclical features. Working Paper 139. Banco Central Do Brasil.

Johansen S (1991) Estimation and hypothesis testing of cointegration vectors in guassian vector autoregresive models. Economtrica 59(6): 1551-1580.

Kendrick JW (1977) Understanding productivity: an introduction to the dynamic of productivity change. Baltimore: The John Hopkins University, Press.

Kilian L (2011) Structural vector autoregressions. Mimeo, University of Michigan.

Lopes C 2015 Agriculture as part of Africa's structural transformation, Journal of African Transformation 1(1): 43-61.

Losch B, Freguin-Gresh S, White EC (2012) Structural transformation and rural change revisited. Agence Francaise de Developpement and the World Bank.

Lutkepohl H (1993) Introduction to multiple time series analysis. New York: Springer.

Naseem A, Oehmke JF, Anderson J, Mbaye S, Pray C, Nagarajar L et al. (2017) Measuring agricultural and structural transformation. In 2017 Agricultural and Applied Economics Association Annual Meeting. Chicago, Illinois.

Nwankpa NN (2017) Sustainable agricultural development in Nigeria: a way out of hunger and poverty. European Journal of Sustainable Development 6(4): 175-184.

Oboh VU, Adeleke AI (2016) Accelerating inclusive agricultural growth in Nigeria: an examination of strategic issues, challenges and policy options. International Journal of Development and Economic Sustainability 4(6): 1-25.

Ogbe A (2018) Nigeria must mainstream food security in its agricultural production. Federal Ministry of Agriculture and Rural Development.

Omano S, Benfica R, Brooks K, Suttie D (2016) Structural and rural transformation in Africa: challenges, opportunities and implications for policy and investments. Rural Development Report's Africa Chapter on Inclusive Rural Transformation. IFAD.

Timmer CP, Akkus S (2008) The structural transformation as a pathway out of poverty: analytics, empirics and politics. Working Paper 150. Centre for Global Development.

Todaro MP, Smith SC (2009) Economic development. $10^{\text {th }}$ Edition. USA: Addison Wesley Publishing.

Weitz R (1971) From peasant to farmer: a revolutionary strategy for development. New York: Columbia University Press.

World Bank (2018) Indicators. Retrieved from: https://data.worldbank.org/indicator. [Accessed 8 February 2021]

Wynn RF, Holden K (1974) An introduction to applied econometric analysis. New York: Macmillian Publications.

Yakubu M, Akanegbu B (2015) Neglecting agriculture and its consequences to the Nigerian economy: an analytical synthesis. European Journal of Research in Social Sciences 3(3): 18-27. 



\title{
Assessment of the University Vision, Goals, Mission and Program Objectives: A Management Protocol for Quality Assurance
}

\author{
By Bretel B. Dolipas", Julie A. Buasen ${ }^{ \pm}$, Maria Azucena B. Lubrica ${ }^{\ddagger}$, \\ Phil S. Ocampo ${ }^{+}$, Kenneth B. Pakipac ${ }^{\S}$, Marycel T. Sajise \& \\ Precious M. Valentin
}

\begin{abstract}
This study measured the level of awareness, understanding, acceptability, clarity and consistency by the Benquet State University's personnel of the University, College and Department's vision, goals, mission and objectives (VGMO). The study also determined the manner by which the VGMOs were disseminated. The results of the study showed that brochures are the most frequent manner of disseminated materials that display the University's VGMOs, leading to higher levels of awareness of them. The level of awareness, understanding, acceptability, and consistency of the University's VGMOs, the College's goals and objectives and the Department's program objectives were analog for both male and female personnel, but the clarity levels differed significantly. Faculty members, compared to non-faculty members, have higher levels of awareness, understanding, acceptability, clarity and consistency in their recognition of $B S U$ 's VGMOs.
\end{abstract}

Keywords: university vision, mission, goals, objectives, awareness, personnel

\section{Introduction}

An institution has an identity which serves as a guide and inspiration to its existence. Institutions are expected to live up to the expectations mandated by their respective charter. The university considered in this study is one such institution established by virtue of PD 2010 signed on January 12, 1986. The mandate of Benguet State University (BSU), as provided by its charter, states that the University shall provide graduate and undergraduate courses in the arts, sciences, humanities and professional fields in agriculture, natural sciences, technology, and other technical professional courses as the Board of Regents may determine and deem proper. It shall promote research, extension, agribusiness and advanced studies and progressive leadership in its field of specialization. The University envisions a premier state university in Asia and its missions are to develop people

\footnotetext{
${ }^{*}$ Professor, Benguet State University, Philippines.

${ }^{ \pm}$Associate Professor, Benguet State University, Philippines.

*Professor, Benguet State University, Philippines.

${ }^{+}$Assistant Professor, Benguet State University, Philippines.

${ }^{\S}$ Assistant Professor, Benguet State University, Philippines.

${ }^{\diamond}$ Associate Professor, Benguet State University, Philippines.

'Instructor, Benguet State University, Philippines.
} 
imbued with academic excellence; social conscience and productivity; and actively generate and promote environment-friendly, useful technologies to improve quality of life.

The College of Arts and Sciences at Benquet State Univeristy was created on May 8, 1984 under Administrative Order No. 17, s. 1984, geared towards the preparation of students for responsible leadership and for creative and useful membership of society. Specifically, education in the arts and sciences aims to 1) develop the ability to think critically, 2) establish the essential foundation for the development of productive and well-rounded citizens, 3) acquire the ability to investigate and analyze questions and problems intellectually and to present clearly ideas which are based on solid data and study, 4) attain a broad liberal education in the humanities, the natural and physical sciences and social sciences, and develop professional competence on a chosen field of specialization, 5) develop appreciation for human values and cultural heritage, and 6) develop ideals and acquire attributes and habits desirable for one's development as a human being.

Every institution is guided by its vision, goals, mission and objectives (VMGO). This study was conceptualized in the context that appropriate evaluation procedures and effective followup measures should be provided in any institution in order to make development programs efficient, effective, relevant and responsive to the needs of their stakeholders. There are activities that are directed towards attaining the University's VMGOs. In the end, these VGMOs become the unifying factor of the different components of the educational system. Students must therefore be aware of these vision, mission, goals and objectives and must have an experience of the overall operations of the educational system to have a valid perception on the effectiveness of the institution along its areas of concern.

It is the purpose of this study to assess and highlight the personnel's level of awareness, acceptability, understanding and consistency of the Vision, Mission, Goals and Objectives of Benguet State University, the goals of the College of Arts and Sciences, and the objectives of the Mathematics-Physics-Statistics Department degree programs. The findings of this study could help the department revisit its programatic objectives in order to identify and recognize areas of improvements.

The result of this study will provide relevant information to the faculty of the College of Arts and Science at BSU which will hopefully challenge them to contribute along their fields of specialization in ways and means to maintain quality service education. Results of this study would create awareness, as well as commitment for the administrators to give their full support to the programs of the college in order to deliver its services effectively to the students and its service area.

The respondents of the study were university personnel under the College of Arts and Sciences, categorized as either teaching or non-teaching personnel. A questionnaire checklist was used to gather relevant data on the vision, mission, goals and objectives of the University, the College of Arts and Sciences, and the Mathematics-Physics-Statistics Department programs respectively. The items in the questionnaire were arranged according to the objectives of the study. 


\section{Literature Review}

1. The vision, mission, goals, objectives and core values are statements that are usually the result of several key process steps found in strategic planning. However, despite their implication, educational leaders and practitioners can sometimes have a rather skeptical outlook about them. Such outlooks may stem from the thought that statements of the VMGOs and values are too broad or deliberately too vague, therefore stakeholders cannot find any real-world meaning in them and may find them synonymous with being immeasurable (Calder 2014).

2. According to Tromp and Ruben, as stated by Calder (2014), attention to ongoing evaluation practices is indispensable with monitoring the progress of planning and gauging the results. Without thoughtful consideration in identifying the proper factors to assess and the appropriate procedures for doing so, information about institutional statements of purpose, strategic direction, and value-based decision making are of little importance.

3. Evaluation of the achievement of VMGOs, therefore, can become vague for any meaningful measure of how close or how far away an institution is from a preferred future (its vision), sense of purpose (its mission), as well as assessing institutional values' claims. Of course, the clearer and more concise these statements are, the better they can be evaluated, understood, and recognized.

4. Also, according to Tromp and Ruben, as cited by Calder (2014), institutional success is ultimately about upholding its values and realizing a vision and mission even through the most demanding times. An assessment process develops an institution's ability to meet and hopefully exceed the standards set out by VMGO's statements, all of which helps an institution look at its own bearing, progress, and possibly determine if it is indeed the finest it can be.

It is the purpose of this study to assess and highlight the acceptability, understandability, clarity, consistency and congruency of the vision, mission, goals and objectives of the University; the College of Arts and Sciences (CAS) and the Mathematics-Physics-Statistics (MPS) Department degree programs.

In as much as the MPS department is concerned, it intends to revisit its program objectives statement to assess acceptability in order to identify and recognize areas of improvements when considering refinement of such in the future.

Galangco (1997) stated that vision does not just happen. As a result of conflict and negotiation, vision is developed in a dynamic way. There is a mission statement formulating some images of the school integrating different strengths. This statement has been discussed and approved by the staff; the head frequently refers to the mission statement; the head is supported in his integrative endeavors as manifested by representations of the parents, and teachers' associations; and an open and fruitful communicative climate of the school is considered by the people. The vision provides a guiding framework for the school as a whole and does not deny the personal values of individual teachers. In September 1996, the issue of The Journal of Teaching and Teacher Education mentioned that schools show a high level of teacher-quality. Student achievement is characterized by a vision and 
is based on strong shared values.

Mission is a set of very broad statements that spell out what the institution is all about and how it intends to carry out vision in its educational effort (Palma 1992). According to Palma, vision is the end product envisioned at the conclusion of the educational effort based on shared beliefs and values derived from one's philosophy. It provides a focal point of unifying elements according to which the institution staff behave or perform individually or collectively (Cawaon and Aquitania 1996). The mandate of a university/college is contained in its mission statement; it declares the purpose of its existence and its accountability (Cawaon and Aquitania 1996).

The school in this study has a powerful link with the community. Since the school has its mandated mission, goal and objectives, these should be defined in order to effectively meet the demands and needs of the community. According to Cawaon and Aquitania (1996) goals are specific targets for accomplishments which can be verified at a certain time and under specifiable conditions.

Dolipas et al. (2006) conducted research that assessed the awareness and acceptability of BSU's VGMOs among students, faculty, administrators, alumni, parents of students, and staff of the University. Results of the study revealed that the majority of the respondents agree that they are aware of the VGMOs of the University, College, Department and Programs. Also, the majority of the respondents agreed that the VGMOs are acceptable to them, and that the VGMOs of the University are consistent with those of the College, Department, and Programs. The top three ways by which the respondents are able to access information on the VGMOs were through bulletin board displays, brochures and school activities. This study has a direct bearing on the proposed study which considers the new VGMOs of the University.

\section{Vision, Mission, Goals and Objectives of the University}

The vision, mission, goals and objectives of the University refers to the approved VMGOs as per BOR Resolution No. 2494, s. 2016 dated June 22, 2016. The vision reads: A PREMIER UNIVERSITY delivering world-class education that promotes sustainable development amidst climate change. The Mission: to provide quality education to enhance food security, sustainable communities, industry innovation, climate resilience, gender equality, institutional development and partnerships. The University has 5 goals with identified specific objectives under each goal.

The goals and objectives of the University are as follows:

GOAL I. To develop proactive programs to ensure relevant quality education.

Objectives:

1. To benchmark curricular and co-curricular programs with national and international standards.

2. To develop alternative learning experiences to enhance skills that match industry needs.

3. To develop innovative and relevant curricular and co-curricular programs 
4. To enhance proactive student welfare and development programs.

GOAL II. To develop proactive programs for quality service.

Objectives:

1. To enhance relevant human resource development programs.

2. To develop effective and efficient innovative platforms for cascading information.

3. To enhance and develop employee welfare programs.

GOAL III. To enhance responsive systems and procedures for transparent institutional development.

Objectives:

1. To enhance and develop innovative financial management systems.

2. To ensure transparency in all transactions in the university.

3. To ensure inclusive and consultative decision making.

GOAL IV. To develop relevant and gender sensitive research and extension programs for institutional development, sustainable communities, climate resilience, industry innovation, and partnerships.

Objectives:

1. To develop relevant multimedia tools in disseminating technology, knowledge and information generated from RDE programs.

2. To develop relevant RDE activities that will address current problems and support cultural advocacy.

3. To partner with strategic local, regional, national and international entities.

GOAL V. To strengthen and expand public-private partnership.

Objectives:

1. Sustain and pursue functional University-relation with the alumni and other organizations both in the government and nongovernment entities.

2. To strengthen the linkage among academe, industries, LGUs and community.

\section{Goals of the College}

The school has a powerful link with the community. Since the school has its mandated vision, mission, goals and objectives, these should be defined in order to effectively meet the demands and needs of the community.

The goals of the Colleges are being revised or enhanced whenever there are new University VMGOs. Part of the strategic planning of the College is to revisit the existing goals of the College and to align it by revising or enhancing it to be consistent with the new University VMGOs. The goals of the College refer to the 
2016 approved CAS goals by the CAS Academic Council. The goals are as follows: a) Promote dynamic teaching and learning engagements, research and extension activities towards climate change adaptation and resilience for sustainable development; b) Produce globally-competent and gender sensitive graduates imbued with value systems in the preservation and respect of cultural and environmental heritage; c) Establish collaborative research and disseminate scholarly outputs through relevant platforms towards innovation and product development; and d) Design and deliver mentoring expertise, management programs and leadership in community affairs.

\section{Objectives of the Programs}

The objectives of the programs refer to the specific statements of what students will become when they finish the program. The Department of Mathematics Physics - Statistics is currently offering one undergraduate program and four graduate programs. The objectives of the different programs were revised by the Department last April 2016. The following are the programs with their corresponding objectives:

\section{Bachelor of Science in Applied Statistics}

The Bachelor of Science in Applied Statistics graduates are expected to:

1. Apply concepts in statistics from research design stage to data analysis and interpretation of results and provide needed expertise in the academe, industry and community.

2. Work with precision and accuracy in the statistical consultancy while upholding the moral and ethical standards.

3. Demonstrate student/client-centeredness, leadership, integrity, diversity, efficiency and service in the practice of profession.

4. Manifest aesthetic principles and promote cultural values.

5. Exhibit life-long learning by pursuing advanced education and/or trainings in statistics or in related fields.

\section{Master of Arts in Applied Statistics}

The Master of Arts in Applied Statistics graduates are expected to:

1. Demonstrate comprehensive and in-depth knowledge on advanced statistical concepts and methodologies.

2. Apply necessary skills in research conceptualization, data management, analysis, interpretation and communication of results to end-users.

3. Conduct, publish and extend outstanding researches while promoting the solid practice of statistics in uplifting socio-cultural, economic, environmental and technical status of the academe, industry and community.

4. Manifest aesthetic principles and promote cultural values.

5. Demonstrate student/client-centeredness, leadership, integrity, diversity, efficiency and service in the practice of profession. 


\section{Master of Arts in General Science}

Graduates of Master of Arts in General Science are expected to:

1. Demonstrate competence in advanced knowledge and skills in General Science.

2. Conduct cross disciplinary researches, extension, and production activities that will contribute scientifically, socially, aesthetically, and culturally relevant outcomes for the workplace and the community.

3. Manifest student/client-centeredness, leadership, integrity, diversity, efficiency and service in the practice of profession.

\section{Master of Arts in Mathematics}

Graduates of Master of Arts in Mathematics are expected to:

1. Apply advanced and in-depth knowledge and skills in Mathematics and extend practical and relevant Mathematics competencies to the academe, industry, and community.

2. Generate innovations that will lead to efficient solutions to existing and emerging problems.

3. Manifest aesthetic principles and promote cultural values.

4. Demonstrate student/client-centeredness, leadership, integrity, diversity, efficiency and service in the practice of profession.

\section{Master of Arts in Physics}

Graduates of Master of Arts in Physics are expected to:

1. Demonstrate advanced knowledge and skills competence in Physics.

2. Conduct cross disciplinary researches, extension, and production activities that will contribute scientifically, socially, aesthetically, and culturally relevant outcomes for the workplace and the community.

3. Manifest student/client-centeredness, leadership, integrity, diversity, efficiency and service in the practice of profession.

It is the purpose of this study to assess and highlight the personnel's level of awareness, acceptability, understanding and consistency of the vision, mission, goals and objectives of Benguet State University, the goals of the College of Arts and Sciences, and the objectives of the Mathematics-Physics-Statistics Department degree programs. Also, result of this study could help the Department revisit its program objectives statement in order to identify and recognize areas of improvements.

The study was conceptualized based on the context that appropriate evaluation procedures and effective follow up measures should be provided in the institution to make programs efficient, effective, relevant and responsive to the needs of the clients. Undertakings in the University are directed towards attaining the goal and objectives of the institution. Figure 1 presents the paradigm of the study.

Figure 1. Paradigm of Study 


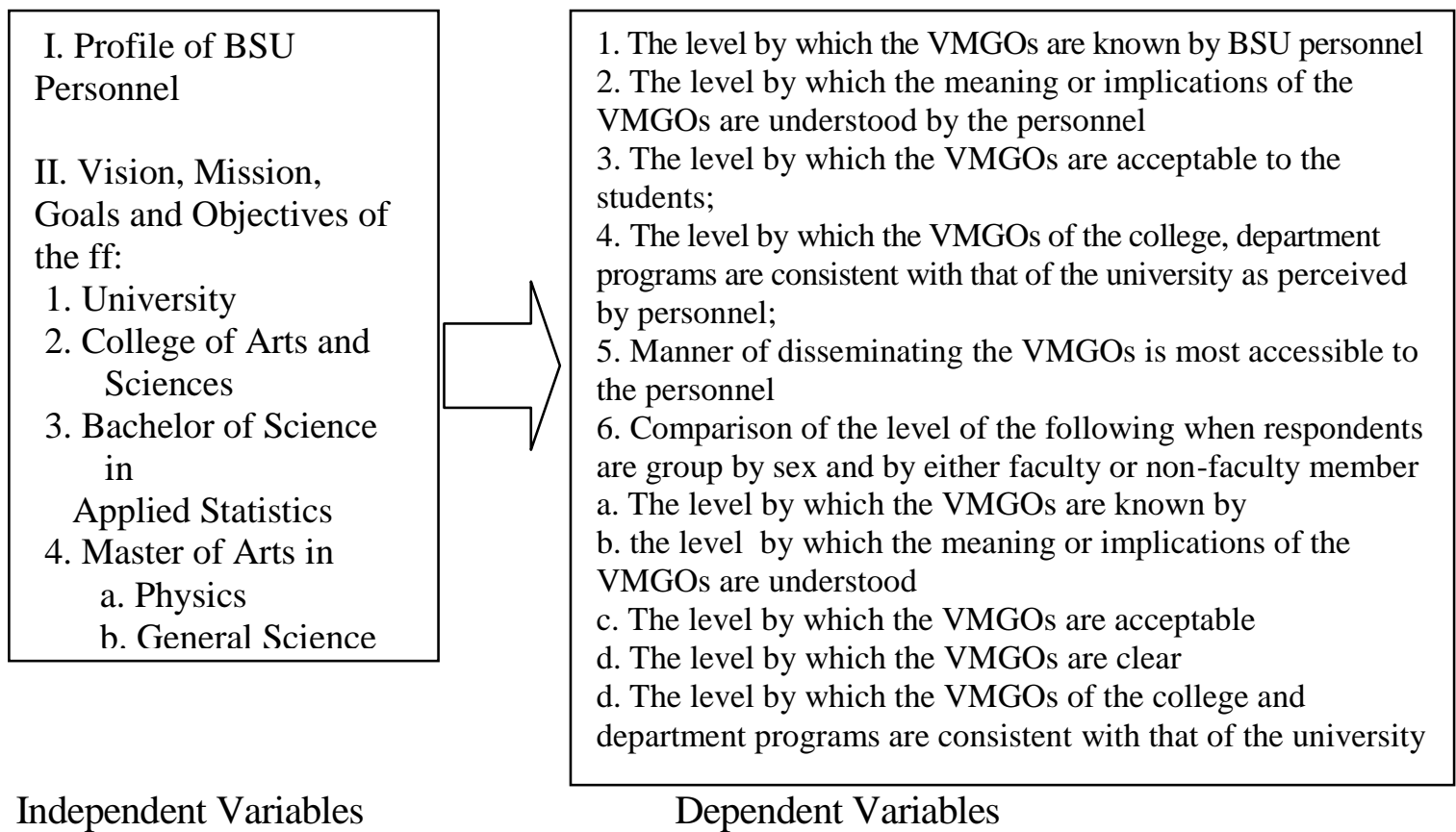

The independent variables in this study are personnel profiles and the vision, mission, goals and objectives of the university; the goals of the College of Arts and Sciences (CAS); and the objectives of Mathematics-Physics-Statistics Department (MPS) programs. The dependent variables are the level of (a) knowledge of personnel of the University's VGMOs (b) understanding of the meaning or implication of the VGMOs (c) consistency of VGMOs; manner of dissemination (d) acceptability of VGMOs; and comparison of the level of awareness, understanding, clarity, acceptability and consistency when respondents were grouped according to sex and according to either faculty or non- faculty member.

\section{Objectives of the Study}

The main objective of the study was to measure the level of knowledge, understanding, acceptability and consistency of the VMGOs of the University, College of Arts and Sciences (CAS), Mathematics-Physics-Statistics Department (MPS) degree programs as perceived by selected University personnel.

Specifically, the study is to be conducted to assess the following:

1. Manner by which the VMGOs were disseminated to selected BSU personnel.

2. The level by which the VMGOs are known by selected University personnel.

3. The level by which the VMGOs are stated clearly as perceived by selected University personnel.

4. The level by which the meaning or implications of the VMGOs are understood by selected University personnel.

5. The level by which the VMGOs are acceptable to selected University personnel.

6. The level by which The VMGOs of the college and department programs are consistent with that of the University; 


\section{Hypotheses of the Study}

The following are the hypotheses of the study:

1. There is no significant difference in the manner by which the VMGOs were disseminated to selected University personnel.

2. There is an average manner by which the VMGOs were disseminated to selected University personnel

3. There is no significant difference in the level of awareness of VMGOs when personnel were grouped according to

a. Sex

b. Faculty or non-faculty

4. There is no significant difference in the level of understanding of VMGOs when personnel were grouped according to

a. Sex

b. Faculty or non-faculty

5. There is no significant difference in the level of acceptability of VMGOs when personnel were grouped according to

a. Sex

b. Faculty or non-faculty

6. There is no significant difference in the level of clarity of VMGOs perceived by University personnel were grouped according to

a. Sex

b. Faculty or non-faculty

7. There is no significant difference in the level consistency of VMGOs when University personnel were grouped according to
a. Sex
b. Faculty or non-faculty

\section{Scope and Delimitation}

The respondents of the study were selected University personnel. A questionnaire checklist was used to gather relevant data on the vision, mission, goals and objectives of BSU, the CAS, and the MPS Department programs respectively. The items in the questionnaire would be arranged according to the objectives of the study. The study was conducted during the second semester of the school year 2015-2016.

\section{Methodology}

\section{Research Design}

This study uses descriptive research with a survey questionnaire to gather the data needed. Questionnaires were distributed to different offices in the University including the administration offices and deans' and departments' offices of the University. 


\section{Respondents}

The subjects of the study were the selected faculty and non-faculty personnel of the University. There were two hundred sixty-seven (267) respondents of the study. One hundred twenty (120) of the respondents are faculty while one hundred forty seven are non-faculty members. One hundred ninety one of the respondents are female while seventy six of them were male.

\section{Instrumentation}

The instrument used in the study was patterned from the study of Cawaon and Aquitania which was drawn from the instrument constructed by Gines (1995) Chair of the Psychology Department of the Philippine Normal University. Most of the contents, however, were taken from the BSU mission and vision, the CAS goals, and the MPS Department programs' objectives.

\section{Treatment of Data}

The data gathered were analyzed using descriptive statistics, specifically frequency counts, percentages, weighted mean and rankings. The following Likert scales were used to measure the level of awareness, acceptability, understanding, clarity, and consistency:

$\begin{array}{lccc}\text { Rate } & \text { Range } & \text { Descriptive Equivalence } & \text { Symbol Used } \\ 1 & 1.00-1.80 & \text { Very Slightly Aware/Acceptable } & \text { VSA } \\ 2 & 1.81-2.60 & \text { Slightly Aware/Acceptable } & \text { SA } \\ 3 & 2.61-3.40 & \text { Moderately Aware/Acceptable } & \text { MoA } \\ 4 & 3.41-4.20 & \text { Very Aware/Acceptable } & \text { VA } \\ 5 & 4.21-5.00 & \text { Very Much Aware/Acceptable } & \text { VMA } \\ & & & \\ 1 & 1.00-1.80 & \text { Very Slightly Understood } & \text { VSU } \\ 2 & 1.81-2.60 & \text { Slightly Understood } & \text { SU } \\ 3 & 2.61-3.40 & \text { Moderately Understood } & \text { MoU } \\ 4 & 3.41-4.20 & \text { Much Understood } & \text { MU } \\ 5 & 4.21-5.00 & \text { Very Much Understood } & \text { VMU } \\ & & & \\ 1 & 1.00-1.80 & \text { Very Slight Clearly Stated/Consistent } & \text { VSC } \\ 2 & 1.81-2.60 & \text { Slight Clearly Stated /Consistent } & \text { SC } \\ 3 & 2.61-3.40 & \text { Moderate Clearly Stated/Consistent } & \text { MoC } \\ 4 & 3.41-4.20 & \text { Much Clearly Stated /Consistent } & \text { VC } \\ 5 & 4.21-5.00 & \text { Very Much Clearly Stated /Consistent } & \text { VMC }\end{array}$

The t-test was used to compare the level of awareness, acceptability, understanding, clarity, and consistency when personnel were grouped according to sex, and when respondents were grouped as to faculty or non-faculty member. The one sample t test was used to compare manner of dissemination with the average. All were tested using a 0.05 level of significance. 


\section{Results and Discussion}

Table 1 presents the manner by which the vision, mission, goals and objectives are accessed by BSU personnel. The University vision, mission, goals and objectives, as well as that of the College of Arts and Sciences goals and objectives and the Mathematics-Physics-Statistics department programs' objectives, were accessed by University personnel mostly through displays followed by brochures. This is apparent since more than half of the BSU personnel within the $55-60 \%$ surveyed ranked display as the primary manner in accessing the above information. Following the display means of accessing is through brochures; the survey revealed that brochures ranked second. On the other hand, pamphlets ranked third in accessing the CAS' objectives and the department's program goals and objectives, while the BSU vision and mission and University goals and objectives were accessed through the Internet. Fourth in rank differs for each strand, for the BSU VM and BSU GO, it is accessed through pamphlets, MPS Department program goals is accessed through publications and for the CAS objectives, it is via classrooms. Fifth in rank is by way of publications that the BSU VM, BSU GO, and CAS O is accessed and it is through classroom display that the MPS department program goals were accessed. Within the 10-15\% of the respondents surveyed, they considered Internet as the sixth in rank, while 5.99\% considered the radio. On the other hand, radio and Internet placed seventh with 4$5 \%$ of the respondent surveyed. Accessing through the Internet is the last in rank with a notable $0-3 \%$ distribution of the surveyed respondent.

Table 1. Manner by Which the Vision, Mission Goals and Objectives are accessed by Personnel

\begin{tabular}{|c|c|c|c|c|c|c|c|c|c|}
\hline \multirow{3}{*}{$\begin{array}{l}\text { Manner of } \\
\text { Access }\end{array}$} & \multicolumn{8}{|c|}{ Level of Access } & \\
\hline & \multicolumn{2}{|c|}{$\begin{array}{l}\text { Vision and } \\
\text { Mission }\end{array}$} & \multicolumn{2}{|c|}{$\begin{array}{l}\text { University } \\
\text { Goals \& } \\
\text { Objectives }\end{array}$} & \multicolumn{2}{|c|}{$\begin{array}{c}\text { CAS Goals \& } \\
\text { Objectives }\end{array}$} & \multicolumn{2}{|c|}{$\begin{array}{c}\text { MPS } \\
\text { Department } \\
\text { Program } \\
\text { Objectives }\end{array}$} & \\
\hline & Percent & Rank & Percent & Rank & Percent & Rank & Percent & Rank & $\mathrm{F}$ \\
\hline Brochures & 56.93 & 7 & 53.93 & 0 & 29.96 & 2 & 38.95 & 2 & $18.27 * *$ \\
\hline $\begin{array}{l}\text { Class } \\
\text { Orientation }\end{array}$ & 34.46 & 3 & 35.96 & 3 & 16.85 & 4 & 5.99 & 5 & $32.161 * *$ \\
\hline Internet & 13.48 & 6 & 11.99 & 6 & 8.99 & 6 & 4.49 & 7 & $4.819 * *$ \\
\hline TV & 3.00 & 8 & 3.00 & 8 & 1.50 & 8 & 0.00 & 8 & $3.003^{*}$ \\
\hline Radio & 5.99 & 7 & 5.99 & 7 & 4.49 & 7 & 5.99 & 6 & 0.282 \\
\hline Pamphlets & 19.48 & 4 & 19.48 & 4 & 17.98 & 3 & 11.99 & 3 & 2.388 \\
\hline Publicatic & 14.98 & 5 & 16.48 & 5 & 11.99 & 5 & 7.49 & 4 & $3.801 *$ \\
\hline Display & 59.55 & 1 & 59.55 & 1 & 60.67 & 1 & 55.06 & 1 & 0.561 \\
\hline
\end{tabular}

The result implies that despite the advent of the Internet, considered to be the quickest way of accessing information, respondents revealed that printed materials are still considered the common and frequent manner of accessing advertisements. This result is accounted for by the fact that all buildings have displays bearing the 
University's VMGOs, College objectives and the Department's program goals. In addition, both the College and Department distribute brochures and program prospectus of which bears the above mentioned information; and more often than not. The College and the Department do not have unified Internet portals of which this information is accessible.

The computed F-values for brochure, class orientation, internet and publication were significant at 0.05 level of significance; this implies that the manner by which the VGMOs were accessed by the personnel differ significantly. For the brochure, it ranks second as the manner by which the VGMOs were accessed by personnel, but differ in terms of number of personnel who do so. The vision and mission as a whole were accessed the most through brochures, Internet and TV. The CAS' goals and objectives as a whole were least accessed through brochures. There were more respondents who had access to the University vision, mission goals and objectives through class orientation, compared with that of the CAS' goals and objectives, and that of MPS Department program objectives. The Internet was ranked sixth by most of the respondents as manner by which the VGMOs were accessed, but there were significant differences in the number of respondents who had access through method. The University vision and mission were accessed most through the Internet, while the MPS department program objectives were least accessed through the Internet compared to the other VGMOs. This is likewise observed with access through TV where the MPS Department program objectives were never accessed through the internet. Access of the GMOs through publication was ranked fifth by the respondents, but again there was a significant difference in the number of respondents who accessed the VGMOs through this manner. The MPS program objectives were least accessed through publication materials.

Table 2 shows the comparison of the level of awareness of personnel when grouped according to sex. The level of awareness on the CAS' objectives, the female group recorded a slight level of awareness with a mean score of 2.60, while a moderate level of awareness for the males with a 2.89 mean.

Table 2. Comparison of the Personnel's Level of Awareness of the Vision, Mission Goals and Objectives when Grouped according to Sex

\begin{tabular}{|c|c|c|c|c|c|}
\hline & \multicolumn{2}{|r|}{ Male } & \multicolumn{2}{|c|}{ Female } & \multirow[b]{2}{*}{ t value } \\
\hline & $\begin{array}{l}\text { Wtd } \\
\text { Mean }\end{array}$ & Description & $\begin{array}{l}\text { Wtd } \\
\text { Mean }\end{array}$ & Description & \\
\hline 1.a. BSU Vision and Mission & 4.21 & VMA & 4.21 & VMA & $0.132 * *$ \\
\hline 1.b. BSU Goals and Objectives & 4.05 & MoA & 3.98 & VA & 0.082 \\
\hline $\begin{array}{l}\text { 1.c. College of Arts and } \\
\text { Sciences Objectives }\end{array}$ & 2.89 & MoA & 2.60 & SA & 0.003 \\
\hline
\end{tabular}

However, despite the differences in the level of awareness, computed t-values of 0.082 and 0.003 indicate that there is no significant difference between the two levels, which indicates that both groups exhibit analogous level of awareness on the BSU goals and College objectives, respectively. The computed t-value of 0.132 resulted in a highly significant difference of awareness level on the University's vision and mission between the males and females which implies that in reality, the female personnel's level of awareness differs from the males. 
Table 3 presents the comparison on the personnel's level of awareness of the VMGOs according whether they were a faculty or non-faculty member. Among the University vision, mission, goals and objectives, the faculty group are very much aware while the non-faculty group are very aware as shown by the computed means of 4.57 and 4.30 for the faculty, and 3.92 and 3.76 for the nonfaculty members respectively. A moderate level of awareness the CAS' goals and objectives is revealed by faculty members while slight awareness level is shown by the non-faculty members.

Table 3. Comparison of the Personnel's Level of Awareness of the Vision, Mission Goals and Objectives when Grouped according to Faculty or Non-Faculty

\begin{tabular}{|l|c|c|c|c|c|}
\hline & \multicolumn{2}{|c|}{ Faculty } & \multicolumn{2}{c|}{ Non-faculty } & \multirow{2}{*}{ t value } \\
\hline & $\begin{array}{c}\text { Wtd } \\
\text { Mean }\end{array}$ & Description & $\begin{array}{c}\text { Wtd } \\
\text { Mean }\end{array}$ & Description & Den \\
\cline { 1 - 5 } $\begin{array}{l}\text { 1.a. University Vision and } \\
\text { Mission }\end{array}$ & 4.57 & VMA & 3.92 & VA & $6.183^{* *}$ \\
\hline $\begin{array}{l}\text { 1.b. University Goals and } \\
\text { Objectives }\end{array}$ & 4.30 & VMA & 3.76 & VA & $5.043^{* *}$ \\
\hline $\begin{array}{l}\text { 1.c. College of Arts and Sciences } \\
\text { Objectives }\end{array}$ & 2.87 & MoA & 2.54 & SA & $1.971^{*}$ \\
\hline
\end{tabular}

Each group disclosed different levels of awareness and computed t-values of $6.183,5.043$ and 1.971 which further affirms that there are significant differences in the level of awareness between groups indeed. This shows therefore, that both groups share varying levels of awareness.

Table 4 shows the level of understanding by personnel of the University's vision and mission; and the University and the CAS' goals and objectives when grouped according to sex. For the vision and mission, the mean score is 3.94 for the male group, while the female groups mean score is 4.10. Both scores indicated a much higher level of understanding. This much higher level of understanding is likewise accorded to both groups on their understanding of the goals and objectives, with respective mean scores of 4.00 and 4.015. However, computed tvalues of 1.343 and .349 further affirm that both groups' level of understanding does not vary, and that they actually exhibit similar understandings of the vision, mission, goals and objectives.

Table 4. Comparison of the Personnel's Level of Understanding of the Vision, Mission Goals when Grouped according to Sex

\begin{tabular}{|l|c|c|c|c|c|}
\hline & \multicolumn{2}{|c|}{ Male } & \multicolumn{2}{c|}{ Female } & \multirow{2}{*}{ t value } \\
\hline & $\begin{array}{c}\text { Wtd } \\
\text { Mean }\end{array}$ & Description & $\begin{array}{c}\text { Wtd } \\
\text { Mean }\end{array}$ & Description & MU \\
\hline 1.a. University Vision and Mission & 3.95 & MU & 4.10 & MU & 1.343 \\
\hline 1.b. University Goals and Objectives & 4.00 & MU & 4.04 & MU & 0.349 \\
\hline $\begin{array}{l}\text { 1.c. College of Arts and Sciences } \\
\text { Objectives }\end{array}$ & 3.00 & MoU & 2.44 & SU & - \\
\hline
\end{tabular}

On the other hand, the computed t-value of -3.049 bared a highly significant difference in the level of understanding between that of the male and female group under the CAS' objectives. The male group's moderate level of understanding varies significantly with the females slightly understood. This indicates that the 
male group has a higher level of understanding of the implication and meaning of the CAS' objectives than that of the female group.

Table 5 presents the comparison on the personnel's level of understanding of the VMGOs when personnel were grouped as either faculty or non-faculty members. Both groups have much understanding of the BSU's goals and objectives as reflected by the computed means of 4.20 and 3.89 respectively for the faculty and non-faculty members. The BSU's vision and mission are very much understood by the faculty group, but only moderately understood by the nonfaculty group. For the CAS' objectives, the faculty members slightly understood while the non-faculty group moderately understood as shown by the computed means of 2.43 and 2.74 for the two groups.

Table 5. Comparison of the Personnel's Level of Understanding of the Vision, Mission Goals and Objectives when Grouped according to Faculty or Non-Faculty

\begin{tabular}{|c|c|c|c|c|c|}
\hline & \multicolumn{2}{|c|}{ Faculty } & \multicolumn{2}{|c|}{ Non-faculty } & \multirow[b]{2}{*}{ t value } \\
\hline & $\begin{array}{l}\text { Wtd } \\
\text { Mean }\end{array}$ & Description & $\begin{array}{l}\text { Wtd } \\
\text { Mean }\end{array}$ & Description & \\
\hline 1.a. University Vision and Mission & 4.23 & VMU & 3.92 & MU & $3.004 * *$ \\
\hline $\begin{array}{l}\text { 1.b. University Goals and } \\
\text { Objectives }\end{array}$ & 4.20 & MU & 3.89 & MU & $2.879 * *$ \\
\hline $\begin{array}{l}\text { 1.c. College of Arts and Sciences } \\
\text { Objectives }\end{array}$ & 2.43 & SU & 2.74 & $\mathrm{MoU}$ & -1.846 \\
\hline
\end{tabular}

The differences in the level of understanding between the two groups were further affirmed by the computed t-values of 3.004 and 2.879 which were highly significant at a 0.05 level of significance. The difference in the levels of understanding of the CAS' objectives, though, was not significant as proven by the computed t-value of 1.846 which is not significant at a 0.05 level of significance. Hypotheses on the difference of understanding level of the BSU's vision, mission, goals and objective are therefore rejected while the hypothesis on the understanding level of the CAS' objectives is accepted.

Table 6 presents the comparison on the personnel's level of acceptability of the VMGOs according to sex. Along the vision, mission, goals and objectives the male group's respective mean scores are 3.89 and 4.13, while the female group's mean score is 3.95 and 4.13. Each mean score indicates a high level of acceptability. A moderate level of acceptability of the CAS' goals and objectives was revealed by both the male and the female groups with mean scores of 3.16 and 3.05. 
Table 6. Comparison of the Personnel's Level of Acceptability of the Vision, Mission Goals and Objectives when Grouped according to Sex

\begin{tabular}{|c|c|c|c|c|c|}
\hline & \multicolumn{2}{|c|}{ Male } & \multicolumn{2}{|c|}{ Female } & \multirow[b]{2}{*}{$\begin{array}{c}\mathbf{t} \\
\text { value }\end{array}$} \\
\hline & $\begin{array}{l}\text { Wtd } \\
\text { Mean }\end{array}$ & Description & $\begin{array}{c}\text { Wtd } \\
\text { Mean }\end{array}$ & Description & \\
\hline 1.a. University Vision and Mission & 3.89 & VA & 4.13 & VA & 1.804 \\
\hline $\begin{array}{l}\text { 1.b. University Goals and } \\
\text { Objectives }\end{array}$ & 3.95 & VA & 4.13 & VA & 1.427 \\
\hline $\begin{array}{l}\text { 1.c. College of Arts and Sciences } \\
\text { Objectives }\end{array}$ & 3.16 & MoA & 3.05 & MoA & -0.617 \\
\hline
\end{tabular}

Despite differences in the mean score, each group disclosed a similar level of acceptability and computed t-values of $1.804,1.427$ and 0.617 , which further affirms that indeed there are no significant differences in the level of acceptability between groups. This entails therefore, that both groups share an unvarying level of acceptability.

Table 7 presents the comparison on the personnel's level of acceptability of the VMGOs according to faculty or non-faculty group. Both groups have moderate acceptance of the CAS' objectives as presented by the computed means of 3.20 and 2.99 for the two groups. For the University vision, mission, goals and objectives faculty members have a very high acceptance while the non-faculty group has a moderate acceptance as reflected by the means of 4.33 and 4.40 for the faculty group, and 3.84 and 3.81 for the non-faculty group.

Table 7. Comparison of the Personnel's Level of Acceptability of the Vision, Mission Goals and Objectives when grouped according to Faculty or Non-Faculty

\begin{tabular}{|c|c|c|c|c|c|}
\hline & \multicolumn{2}{|c|}{ Faculty } & \multicolumn{2}{|c|}{ Non-faculty } & \multirow[b]{2}{*}{$t$ value } \\
\hline & $\begin{array}{c}\text { Wtd } \\
\text { Mean }\end{array}$ & Description & $\begin{array}{c}\text { Wtd } \\
\text { Mean }\end{array}$ & Description & \\
\hline 1.a. University Vision and Mission & 4.33 & VMA & 3.84 & MA & $4.403 * *$ \\
\hline 1.b. University Goals and Objectives & 4.40 & VMA & 3.81 & MA & $5.477 * *$ \\
\hline $\begin{array}{l}\text { 1.c. College of Arts and Sciences } \\
\text { Objectives }\end{array}$ & 3.20 & MoA & 2.99 & MoA & 1.380 \\
\hline
\end{tabular}

The computed t-values of 4.403 and 5.477 were significant at 0.05 level of significance which implies that the acceptability level of the BSU's vision, mission, goals and objectives for both groups differ significantly. The hypothesis that the acceptability level on the University's vision, mission, goals and objectives is therefore rejected. For the CAS' objectives, the computed t-value of 1.38 was not significant at 0.05 level of significance which implies that both groups have same moderate acceptability level.

The comparison on the personnel's perception on the level of clarity of the VMGOs according to sex is shown in Table 8. Among the female group, they perceived a very much clear statement of the vision, mission, goals and objectives. Whereas, the CAS's objectives perceived clarity is on the moderate level. A very clear university vision, mission, goals and objective as well as CAS' goals and objectives were observed for the male group. 
Table 8. Comparison of the Personnel's Level of Clarity of the Vision, Mission Goals and Objectives when Grouped according to Sex

\begin{tabular}{|c|c|c|c|c|c|}
\hline & \multicolumn{2}{|c|}{ Male } & \multicolumn{2}{|c|}{ Female } & \multirow[b]{2}{*}{ t value } \\
\hline & $\begin{array}{c}\text { Wtd } \\
\text { Mean }\end{array}$ & Description & $\begin{array}{l}\text { Wtd } \\
\text { Mean }\end{array}$ & Description & \\
\hline 1.a. University Vision and Mission & 3.84 & $\mathrm{VC}$ & 4.27 & VMC & $3.513 * *$ \\
\hline $\begin{array}{l}\text { 1.b.University Goals and } \\
\text { Objectives }\end{array}$ & 4.00 & $\mathrm{VC}$ & 4.25 & VMC & $2.249^{*}$ \\
\hline $\begin{array}{l}\text { 1.c. College of Arts and Sciences } \\
\text { Objectives }\end{array}$ & 3.63 & $\mathrm{VC}$ & 3.26 & $\mathrm{MoC}$ & $-2.042 *$ \\
\hline
\end{tabular}

The differences in the mean scores of both groups under each statement did signify significant variations in the perceived level of clarity as validated by the computed t-values of 3.513, 2.249 and -2.042 . The result then indicated a varied perception of clarity between the males and females. The hypothesis that there are no significant differences in the level of clarity of the VMGOs is therefore rejected. This means that female considered the VMGOs to have been stated very clearly, but the males do not fully perceive that way as the females do.

Table 9 presents the comparison on the personnel's level of acceptability of the VMGOs when respondents were grouped as either faculty of non-faculty members. As implied by the computed means of $4.30,4.40$ and 3.77 , faculty members find the University vision, mission, goals and objectives very much clearly stated and the CAS' objectives as very clearly stated. The non-faculty members have a different level of clarity as reflected by the computed means of $4.03,4.00$ and 3.04. The non-faculty perceived the University VMGOs stated very clearly, while the CAS' objectives were stated moderately clearly.

Table 9. Comparison of the Personnel's Perception on the Level of Clarity of the Vision, Mission Goals and Objectives Grouped according to Faculty or NonFaculty

\begin{tabular}{|c|c|c|c|c|c|}
\hline & \multicolumn{2}{|c|}{ Faculty } & \multicolumn{2}{|c|}{$\begin{array}{l}\text { Non-faculty } \\
\end{array}$} & \multirow[b]{2}{*}{ t value } \\
\hline & $\begin{array}{l}\text { Wtd } \\
\text { Mean }\end{array}$ & Description & $\begin{array}{l}\text { Wtd } \\
\text { Mean }\end{array}$ & Description & \\
\hline $\begin{array}{l}\text { 1.a. University Vision and } \\
\text { Mission }\end{array}$ & 4.30 & VMC & 4.03 & VC & $2.427 *$ \\
\hline $\begin{array}{l}\text { 1.b. University Goals and } \\
\text { Objectives }\end{array}$ & 4.40 & VMC & 4.00 & VC & $4.026^{* *}$ \\
\hline $\begin{array}{l}\text { 1.c. College of Arts and } \\
\text { Sciences Objectives }\end{array}$ & 3.77 & VC & 3.04 & $\mathrm{MoC}$ & $4.552^{* *}$ \\
\hline
\end{tabular}

The computed t-values of $2.427,4.026$ and 4.552 which were all significant at 0.05 level of significance which implies that the difference in the perceived level of clarity differs significantly between the two groups; this hypothesis is therefore rejected. The clarity level of the VMGOs differs significantly as perceived by the faculty and non-faculty group.

Displayed in Table 10 is the comparison on the personnel's perception on the level of consistency of the VMGOs according to sex. With the mean scores of 3.68 and 3.75, the perceived level of consistency of the College's objectives with that of the University's VMGOs is very consistent. Similarly, with the mean scores of 
3.63 and 3.75, both sexes reflected a very consistent perceived consistency of the MPS program objectives with that of the CAS' goals and the University's VMGOs.

Table 10. Comparison of the Personnel's Level of Consistency of the Vision, Mission Goals and Objectives when Grouped according to Sex

\begin{tabular}{|c|c|c|c|c|c|}
\hline & \multicolumn{2}{|c|}{ Male } & \multicolumn{2}{|c|}{ Female } & \multirow[b]{2}{*}{$\begin{array}{c}\mathbf{t} \\
\text { value }\end{array}$} \\
\hline & $\begin{array}{l}\text { Wtd } \\
\text { Mean }\end{array}$ & Description & $\begin{array}{c}\text { Wtd } \\
\text { Mean }\end{array}$ & Description & \\
\hline $\begin{array}{l}\text { The College of Arts and Sciences } \\
\text { Objectives }\end{array}$ & 3.68 & VC & 3.75 & VC & 0.480 \\
\hline $\begin{array}{l}\text { The department of Math-Statistics } \\
\text { and Physics Degree Program } \\
\text { Objectives }\end{array}$ & 3.63 & VC & 3.75 & VC & 0.869 \\
\hline
\end{tabular}

Despite differences in the mean scores, each group disclosed alike level of perceived consistency of the CAS' goals and MPS' program objectives. The resulting t-values of 0.480 and 0.869 further affirm that indeed there are no significant differences in the perceived level of consistency between the males and the females. This entails therefore, that both groups' shares conforming perceived level of consistency. Moreover, result points out that the respondents considered and agreed to the idea that stated CAS' goals and MPS' program objectives followed a cascading protocol.

Table 11 presents the comparison on the personnel's perception on the level of consistency of the VMGOs according to faculty and non-faculty. Both groups showed same level of consistency as shown by the computed means all showing a very consistent CAS' objectives with the MPS' program objectives.

Table 11. Comparison of the Personnel's Perception on the Level of Consistency of the Vision, Mission Goals and Objectives when Grouped according to Faculty or Non-Faculty

\begin{tabular}{|c|c|c|c|c|c|}
\hline & \multicolumn{2}{|c|}{ Faculty } & \multicolumn{2}{|c|}{ Non-faculty } & \multirow[b]{2}{*}{ t value } \\
\hline & $\begin{array}{l}\text { Wtd } \\
\text { Mean }\end{array}$ & Description & $\begin{array}{l}\text { Wtd } \\
\text { Mean }\end{array}$ & Description & \\
\hline $\begin{array}{l}\text { The College of Arts and Sciences } \\
\text { Objectives }\end{array}$ & 3.93 & $\mathrm{VC}$ & 3.56 & $\mathrm{VC}$ & $3.076 * *$ \\
\hline $\begin{array}{l}\text { The department of Math-Statistics } \\
\text { and Physics Degree Program } \\
\text { Objectives }\end{array}$ & 3.93 & $\mathrm{VC}$ & 3.54 & $\mathrm{VC}$ & $3.300^{* *}$ \\
\hline
\end{tabular}

Though the descriptive equivalence of the computed means all showed to be very consistent, the differences in the mean score of each group disclosed significant difference in the level of consistency based on the computed t-values of 3.076 and 3.300 which were significant at 0.05 level of significance. This indicates therefore, that both groups shared varying levels of perceived consistency. 


\section{Conclusion}

Based on the results of the study, the following findings are therefore concluded:

1. The widespread manner of accessing the VMGOs is through the printed media such as displays, brochures, pamphlets and publications. Accessing the BSU's VMGOs through oral dissemination, such as ads on TV, radio and the Internet, were not frequently considered in accessing the University's VMGOs. There is a significant difference in the number of respondents accessing the VGMOs through brochure, class orientation, Internet, TV and publications.

2. Male and female groups exhibited significant differences in the level of awareness on the University's vision and mission, but analogous in level of awareness on the College goals and objectives; and on the program objectives. Faculty and non-faculty members also showed significant differences in the awareness level of the University VGMOs, College goals and objectives; and the Department program objectives.

3. Both female and male respondents showed no significant difference in the understanding level of the College goals and objectives, while females showed higher levels of understanding of the University's VMGOs as well as the Department's program objectives. Faculty members also showed higher understanding levels of the University's VGMOs and College's goals and objectives.

4. Both male and female respondents have the same acceptability level of the University's VGMOs as well as that of the College's and Department's program objectives. Again, faculty members showed higher acceptability level of the University's VMGOs and College goals and objectives, but analogous level with the Department program objectives.

5. Female respondents gave a significantly higher clarity level of the University's VMGOs, College goals and objectives, as well as Department program objectives; this is likewise observed with the faculty and nonfaculty members. Faculty members find the University's VGMOs, College goals and objectives, as well as the Department degree program very much clearly stated.

6. The consistency level of the University's VGMOs, College goals and objectives, and the Department program objectives were very consistent as perceived by both female and male respondents. Faculty members on the other hand gave higher consistency levels compared to the non-faculty members. 


\section{Recommendations}

Based on the conclusions, the following are recommended:

1. The University and the College should continuously work to improve the accessibility of the awareness, understanding and acceptance of its vision, mission, goals and objectives.

2. Assessment on the awareness, understanding and acceptance of the VMGOs by the personnel should be done periodically.

3. Increase awareness, understanding and acceptance of the VMGOs thru orientation and other means should be conducted among newly-hired personnel.

4. Future research undertakings should be conducted similar to this study involving other personnel and other institutions.

\section{References}

Calder WB (2014) Achieving an institution's values, vision, and mission. College Quarterly $17(2)$.

Cawaon FC, Aquitania CD (1996) Awareness and acceptability of BSU-CN mission, goal and objectives. La Trinidad, Benguet: College of Nursing, Benguet State University.

Dolipas BB, Lubrica JV, Bawang EG, Lubrica MAB, Oryan SL, Ramoss JLS et al. (2006) An assessment of the vision, mission, goals and objectives of Benguet State University; College of Arts and Sciences; Mathematics-Physics-Statistics Department; Bachelor of Science in Information Technology. La Trinidad, Benguet: Benguet State University.

Galangco NRS (1997) OAR seminary education in the Philippines: status and implication to the order of Agustinian recollects. Unpublished Dissertation. Baguio City, Philippines: Saint Louis University.

Gines AC (1995) The PNU mission, philosophy and CAS goal as perceived by PNU faculty, staff, students and alumni. Manila, Philippines: College of Arts and Sciences, PNU.

Palma JC (1992) Curriculum development system. Manila National Book Store, Inc 



\title{
Empirical Assessment on the Impact of Leverage and Capital Adequacy on Performance of Non-Bank Financial Institutions in Bangladesh
}

\author{
By Liton Chandro Sarkar*
}

\begin{abstract}
Non-Bank Financial Institutions (NBFIs) epitomize the most significant source of financing in our economy. NBFI is highly levered in nature. This study tries to empirically identify how capital adequacy and leverage impact NBFIs' performance in Bangladesh. A number of econometric models using panel data from 2009 to 2019 of 23 NBFIs of Bangladesh have been estimated to achieve the objective of this study. In this research, Return on Assets, Return on Equity and Tobin's $Q$ are used as a measure of NBFIs performance of Bangladesh. According to estimated result it has been found that capital adequacy has a positive effect on profitability of NBFI's in Bangladesh. However, the research has found conflicting results when impact of leverage on NBFI performance is measured. Taking the empirical findings into consideration, the management of the NBFIs should embrace policies that are likely to help the NBFIs to maintain enough capital.
\end{abstract}

Keywords: leverage, capital adequacy, NBFI performance, profitability, NBFI equity

\section{Introduction}

Most of the NBFIs in Bangladesh is a profit oriented monetary and financial transitional organization which usually accepts term deposits, offers loan and finance funds among businesses, NBFIs and individuals. A sound and healthy financial system is very crucial for any economy. If an NBFI fails, it would affect its retail and institutional clients which could trigger a negative multiplier effect on the economy. To maintain customers' trust, a proper regulatory framework is required in this industry. NBFI capital which functions as buffer against losses is one of the most important parts of the regulatory framework. According to Sharp (1964), the amount that a NBFI holds apart from assets and deposits is called the NBFI capital. It is evident from the definition that higher level of capital makes a NBFI safer for its depositors. Adequate capital is the level of capital that a NBFI should keep ensuring the prudent business operations (Nwankwo 1991).

High leverage (higher level of debt) is one of the major characteristics of NBFI as the NBFI is a loan and deposit driven organization. Improper blend of debt and equity in a firm may lead to financially painful situation like shrinking profit. Finding the perfect combination of debt and equity is a challenging task for managers as the optimum use of leverage differs from industry to industry. Miller and Modigliani (1958), in one of the earlier studies presented "The Irrelevance

\footnotetext{
*Deputy Director, Bangladesh University of Professionals (BUP), Bangladesh.
} 
Theory of Capital Structure" argued that a business's basic earning power entirely determines its value and decision regarding capital structure does not influence a business enterprise's worth in an effortlessly competitive market condition.

There were numerous studies and researches conducted in the banking industry to explore the association and relationship among leverage, capital adequacy and a firms' performance. However, those researches have showed a mixed result. Gilbert and Wheelock (2007) argue that capital adequacy requirement improves the safety and quality of the banks and has positive impact on profitability. However, alternative school of thought is also present in the literature. Cavallo and Majnoni (2001) showed that the high capital requirements lead to contraction of NBFI credit which eventually lowers the profit. In a study conducted in the context of European countries, Gleason et al. (2000) revealed that a firms' leverage has a considerable negative impact on financial firms' performance. On the other hand, James and Hadlock (2002) found that companies' performance and leverage are positively related. James and Hadlock (2002) also stated that use of higher level of debts leads to higher profitability. Likewise, Holz (2002) also suggest similar relationship. According to Smith and Watts (1992), growth potential of a business and corporate leverage has a negative relationship. In a study on bank, Schepens (2016) emphasizing on the uneven tax treatment on debt and equity of banks. He claimed that a more alike treatment of banks debt and equity leads to upsurge in the level of common equity which eventually increases bank capital ratios.

In Bangladesh, NBFS have been regulated and given license under the Financial Act-1993 and controlled by Bangladesh Bank. Under this act there also a regulation which name is the "Financial Institution Regulation-1994". According to the Financial Institution Regulation-1994, the minimum paid-up capital for NBFIs in Bangladesh is BDT. 1.0 (one) billion. Compare with banks in Bangladesh, NBFIs commercial operating line is narrow. NBFIs in Bangladesh are permitted to take periodical deposit from 2013. The first NBFI was established in 1981. According to Bangladesh Bank data, at present 34 NBFIs are operated in Bangladesh. Among them 19 NBFIs are private owned, 12 NBFIs are joint venture and rest of 3 are government-owned. Total branches of NBFI are 276. While out of 34 NBFIs only 23 NBFIs are listed Bangladesh Stock market. The structure and branches of NBFIs in Bangladesh are shown in Table 1.

Table 1. Structure and Branches of NBFIs, Bangladesh (As on 30 June, 2020)

\begin{tabular}{|l|c|c|c|c|c|c|c|c|}
\hline \multirow{2}{*}{ Structure of NBFIs } & \multicolumn{10}{|c|}{ Year } \\
\cline { 2 - 11 } & 2013 & 2014 & 2015 & 2016 & 2017 & 2018 & 2019 & 2020 \\
\hline Government-owned & 3 & 3 & 3 & 3 & 3 & 3 & 3 & 3 \\
\hline Joint Venture & 10 & 10 & 10 & 11 & 12 & 12 & 12 & 12 \\
\hline Private & 18 & 18 & 18 & 19 & 19 & 19 & 19 & 19 \\
\hline $\begin{array}{l}\text { Total NBFIs in } \\
\text { Bangladesh }\end{array}$ & 31 & 31 & 31 & 33 & 34 & 34 & 34 & 34 \\
\hline \multicolumn{9}{|l|}{} \\
\hline No of Branches of NBFIs & 2013 & 2014 & 2015 & 2016 & 2017 & 2018 & 2019 & 2020 \\
\hline Total Branches & 175 & 195 & 210 & 224 & 254 & 262 & 273 & 276 \\
\hline
\end{tabular}

Source: Department of Financial Institutions and Markets, Bangladesh Bank. 
The trends in assets, liabilities and deposits of NBFIs are shown in Table 2.

Table 2. Trends in Assets, Liabilities and Deposits of NBFIs, Bangladesh (in billion BDT) (As on 30 June, 2020)

\begin{tabular}{|l|c|c|c|c|c|c|c|c|}
\hline Particulars & 2013 & 2014 & 2015 & 2016 & 2017 & 2018 & 2019 & 2020 \\
\hline Total Assets & 436.3 & 520.1 & 611.0 & 713.9 & 841.1 & 870.3 & 870.3 & 874.3 \\
\hline Total Liabilities & 350.4 & 424.2 & 509.0 & 606.4 & 726.0 & 762.1 & 751.8 & 762.2 \\
\hline $\begin{array}{l}\text { Liabilities- Assets } \\
\text { Ratio }\end{array}$ & 80.3 & 81.6 & 83.3 & 84.9 & 86.3 & 87.6 & 82.2 & 87.1 \\
\hline Total Deposit & 198.3 & 238.5 & 318.1 & 382.4 & 468.0 & 480.1 & 458.1 & 459.4 \\
\hline $\begin{array}{l}\text { Deposit as \% of } \\
\text { Total Liabilities }\end{array}$ & 56.6 & 56.2 & 62.5 & 63.1 & 64.5 & 66.1 & 60.9 & 60.3 \\
\hline
\end{tabular}

Source: Department of Financial Institutions and Markets, Bangladesh Bank.

To the researchers' best knowledge there is a lack of academic researches related to determination of the influence of leverage and capital adequacy on NBFIs' performance in Bangladesh. Safiuddin et al. (2015) attempted to find capital structure's impact on the Bangladeshi firms using descriptive statistics. Safiuddin et al. (2015) examined the data of 10 firms for a five-year period (20082012) and found that leverage has negative effect on the organization's performance. Though, they did not use any econometric model to explain this relationship. The present study tries to fill this gap through econometric analysis involving variables linked to the NBFIs' financial performance, leverage and capital adequacy.

\section{Literature Review}

Numerous research and studies have been conducted on the profitability of the financial institutions. Most of most these researches had been conducted on bank. As decision regarding capital and debt is one of the major financial decisions for any firm, it has a strong presence in the financial academic literature. Miller and Modigliani (1958) suggest that optimal capital structure is nonexistent. In a fully effective capital market situation, there is no connection between companies' values and its capital structure. From then on, besides emphasizing on capital structure solely, some economists also paid attention to explore the way firm's capital structure influences performance.

This research tries to examine the impact of leverage and capital adequacy on the NBFIs' performance or profitability. In line with the objective of the study most relevant literatures on this issue will be discussed from now on.

As an extension to MM theory Myers (1984) came up with static trade-off theory which accounts for the cost of bankruptcy and agency costs of leverage into attention. It suggested that tax could be avoided through debt financing but at the expense of risk increment. If the benefit from tax avoidance surpasses the cost 
associated with increased risk, a firm should consider adding leverage to its capital structure. Agency theory explains the relationship between firm's shareholders (principal) and firm's executives (agent). Agent is hired by the principal to run business. The concerns for this theory are the goal conflict between the principal and agent, and different risk tolerance level for the principal and agent. Signaling theory takes internal factors into account and suggests that asymmetry of information exists among investors and internal managers. Investors can judge value of this firm from the signal received from managers' decision on capital structure.

Examining the asset- liability ratio Ross (1977) suggested positive correlation between asset-liability ratio and company's value. Afterwards, Myers (1984) anticipated financial pecking order for an organization which start with firm's retained earnings, followed by loan financing, then issuance of equity and lastly comes to play in order to lessen the problem of uneven data and information between firms' investors and authorities.

The impact of capital on NBFI profitability is quite uncertain. In general, interest payments are reduced due to higher level of capital and that lowers the profitability by decreasing the tax shield coming from interest deductibility. But Berger (1995) argues that higher capital lowers the expected bankruptcy cost which positively impacts the profitability. On a study on U.S. commercial banks over the period from 1983-1989, he showed capital positively granger-causes the profitability. Correspondingly, from a study on a sample of NBFIs from Asian countries, Chien-Chiang and Hsieh (2013) found that capital ratios and NBFI profitability are positively correlated. There are also some other studies which found conflicting results. For instance, investigating a taster of banks from eight European countries, Goddard et al. (2013) stated a negative connection between capital and profitability ratios. Similarly, Altunbas et al. (2007) found that wellcapitalized NBFIs and banks in Europe are inefficient which causes lower profitability.

Unlike capital adequacy, Leverage showed positive impact on financial firms' profitability in the previous studies. Lawal (2014) argued that leverage plays major role in amplifying the value of Nigerian NBFIs and suggested that leverage usage would be promoted to upsurge the firm's value by managers, stockholders and regulators. Abubakar (2015) examined the relation between leverage and success of the NBFIs using a selective sample of 11 out of the 23 commercial NBFIs operating in Nigeria and found a positive correlation among debt to return on equity and equity ratio. Exploring an unbalanced panel data over the period 20052011, Beltratti and Paladino (2015) tried to find how leverage is related to income for international banks. They have established an econometric model considering both country specific variables and bank specific. They concluded and showed a positive correlation between the capital ratio and residual income for the global banking sector.

In the context of Iran, Ebrat et al. (2013) found the evidence of both positive and negative co-relationship between performance off firm and capital. They examined evidence from 85 Iranian companies from Tehran Stock Exchange. Yadav and Salim (2012) studied the performance of 237 Malaysian businesses 
organization and found a varied co-relationship between firm performance and capital structure. Leverage negatively affects the performance of firms where performance is measured through earning per share (EPS), ROE and ROA. But when growth is taken into consideration leverage seemingly has a positive effect on it. Zeitun and Tian (2007) showed a significant impact of a capital structure choice on the firms' performance. According to Manawaduge et al. (2011), use of more short-term in comparison to long-term debt to finance the operations is common for majority of the Sri Lankan companies.

Majority of the literature shows that capital adequacy and leverage have noteworthy and significant influence on the firms' performance. The scenario of Bangladeshi NBFIs is yet to be revealed.

\section{Objectives of the Research}

The board objective of this research is to evaluate and analyze the relationship among leverage, capital adequacy and firms' performance in the context of Bangladeshi NBFIs. To accomplish this principal objective, following specific objectives have been covered:

I. To quantify and identify the influence of leverage and capital adequacy on the NBFIs' performance in Bangladesh.

II. To provide some recommendations and policy guidelines based on the empirical results.

\section{Variables Construction}

Following variables identified for this research:

\section{NBFIs' Performance (Dependent Variable)}

According to Chakravarthy (1986), firms' financial performance is related to its purpose and persistence of maximizing profit for investors and shareholders while the firm's operational performance relates to expansions and growth resulting from sales and market value (Sandberg and Hofer 1987). Tobin's Q, ROA and ROE are used as proxy of financial performance in this research. The dependent variables of this study are distinct as follows:

$$
\begin{aligned}
& \text { Tobin's } Q=\frac{(\text { Market value of equity }+ \text { Book value of debt })}{\text { Book value of assets }} \\
& R O A=\frac{\text { Profit after tax }}{\text { Total assets }} \\
& R O E=\frac{\text { Profit after tax }}{\text { Total equity }}
\end{aligned}
$$




\section{Leverage and Capital Adequacy (Independent Variable)}

The most used indicator of NBFIs' capital adequacy is CAR (Capital Adequacy Ratio). But due to unavailability of the related data, total equity to total asset (CAP) ratio is used as substitution for capital adequacy in this study (Zheng et al. 2017). To get insight into the market perception, MBVR or the ratio of market value of the equity of the NBFI to book value of the same is also incorporated in the model. Total debt to total equity (TDTE) ratio has been used for leverage estimation. NBFI size calculated as logarithm of total asset (LogTA) is another independent variable in this model. As size is amalgamation of debt and equity, it is considered as a component of both capital adequacy and leverage.

In line with the previous researches mentioned above the researchers form expectations on the behaviour of independent variables on firm performance. Measures with expected impact of all the variables (dependent and independent) used here in this study are shown in the Table 3.

Table 3. Variables, Notations, Measures, Expected Impacts on the Performance of NBFIs and Sources of Data

Dependent Variables

\begin{tabular}{|c|c|c|c|c|}
\hline Variables & Notations & Measures & $\begin{array}{l}\text { Expected } \\
\text { Impact }\end{array}$ & $\begin{array}{l}\text { Sources } \\
\text { of Data }\end{array}$ \\
\hline Tobin's $Q$ & TQ & $\frac{(\text { Market value of equity }+ \text { Book value of debt) }}{\text { Book value of assets }}$ & & $\begin{array}{c}\text { Annual } \\
\text { reports } \\
\text { and } \\
\text { DSE } \\
\text { website }\end{array}$ \\
\hline $\begin{array}{l}\text { Return on } \\
\text { Assets }\end{array}$ & ROA & $\frac{\text { Profit after tax }}{\text { Total assets }}$ & & $\begin{array}{l}\text { Annual } \\
\text { reports }\end{array}$ \\
\hline $\begin{array}{l}\text { Return on } \\
\text { Equity }\end{array}$ & ROE & $\frac{\text { Profit after tax }}{\text { Total equity }}$ & & $\begin{array}{l}\text { Annual } \\
\text { reports }\end{array}$ \\
\hline
\end{tabular}

\section{Independent Variables}

\begin{tabular}{|l|c|c|c|c|}
\hline Variables & Notations & Measures & $\begin{array}{c}\text { Expected } \\
\text { Impact }\end{array}$ & Sources of Data \\
\hline $\begin{array}{l}\text { Total Debt to Total } \\
\text { Equity }\end{array}$ & TDTE & $\frac{\text { Total debt }}{\text { Total equity }}$ & + & Annual Reports \\
\hline $\begin{array}{l}\text { Total Equity to } \\
\text { Total Assets }\end{array}$ & CAP & $\begin{array}{c}\text { Total } \text { equity } \\
\text { Total assets }\end{array}$ & $+/-$ & Annual Reports \\
\hline Size & LogTA & Log (Total assets) & $+/-$ & Annual reports \\
\hline $\begin{array}{l}\text { Market Value of } \\
\text { Equity to Book } \\
\begin{array}{l}\text { Value of Equity } \\
\text { Ratio }\end{array}\end{array}$ & MBVR & $\frac{\text { Market Value of Equity }}{$\cline { 3 - 5 }} & $+/-$ & $\begin{array}{c}\text { Annual Reports } \\
\text { and DSE website }\end{array}$ \\
\hline
\end{tabular}

\section{Research Methodology}

With regard to research methodology, this research has been examined and analyzed on pragmatic outcomes from literature and applied those models on 
NBFIs in Bangladesh. The research tailed a quantitative approach. In this research, generally used secondary data collected from selected NBFIs' annual report for the development of initial model to analyze and scrutinize the impact of leverage and capital adequacy on the NBFIs' performance of Bangladesh. However, researchers have consulted with academics and NBFI professionals to derive recommendations. The researchers have selected the data of all 23 NBFIs enlisted in Dhaka Stock Exchange (DSE). Due to the unavailability of the data, the NBFIs which are not listed in the stock market are not included in the study. These NBFIs are observed over the years 2009-2019 (10 years), allowing the researchers to form a panel data set. Descriptive statistics analysis, diagnosis statistics analysis and correlation matrix analysis were used to understand the panel data.

\section{Empirical Model}

The empirical diagnostic model of the research assumes that profit or firms performance of NBFIs " $i$ " in the period " $t$ " depends on the leverage level and level of capital adequacy of NBFIs " $i$ " in the period " $t$ " with others independent variables which are expected to influence the NBFIs performance.

This study initially uses a pooled ordinary regression model as Park (2011) suggests OLS (Ordinary Least Squares) generate most consistent and efficient parameter estimates where individual effect $\mu_{i}$ (cross-sectional or time specific effect) does not exist $\left(\mu_{\mathrm{i}}=0\right)$.

Rendering to this assumption this research will analyze and examine the impact of leverage and capital adequacy on NBFIs' performance using the following regression models:

$$
\begin{aligned}
& T Q_{i t}=\beta_{0}+\beta_{1} C A P_{i t}+\beta_{2} T D T E_{i t}+\beta_{3} \log T A_{i t}+\beta_{4} M B V R_{i t}+\varepsilon_{i t} \\
& R O E_{i t}=\beta_{0}+\beta_{1} C A P_{i t}+\beta_{2} T D T E_{i t}+\beta_{3} \operatorname{LogTA} A_{i t}+\beta_{4} M B V R_{i t}+\varepsilon_{i t} \\
& R O A_{i t}=\beta_{0}+\beta_{1} C A P_{i t}+\beta_{2} T D T E_{i t}+\beta_{3} \log T A_{i t}+\beta_{4} M B V R_{i t}+\varepsilon_{i t}
\end{aligned}
$$

where, Tobin's Q or $T Q_{i t}$, Return on equity or $R O E_{i t}$ and Return on asset or $R O A_{i t}$ are financial performance indicators for NBFI $i$ in year $t . \mathrm{CAP}_{\mathrm{it}}$ (Total equity to Total assets ratio), TDTE $_{\text {it }}$ (Total debt to Total equity ratio), LogTA $A_{i t}$ (size of the NBFIs) and $\mathrm{MBVR}_{\mathrm{it}}$ (market value of equity to book value of equity ratio) are explanatory variables for the NBFI $i$ in year $t \mathrm{i}$. And $\beta_{0}-\beta_{4}$ are regression coefficients and $\varepsilon_{i t}$ is the error term.

STATA statistical software has been used to conduct necessary statistical analysis starting from descriptive statistics to the development of the final model after cleaning the data for errors.

Pooled OLS does not provide the best result in the presence of heteroscedasticity and autocorrelation. Homoscedasticity, i.e., no heteroscedasticity suggests that each disturbance terms in model have the same variance and no autocorrelation means that disturbance terms are not correlated with each other (Greene 2012). If the individual effect $\mu_{\mathrm{i}}$ exists $\left(\mu_{i} \neq o \mu_{i} \neq o\right.$ ) in the longitudinal 
data assumptions of having homoscedasticity and no auto correlation may be violated due to the heterogeneity (individual specific characteristics). This problem can be dealt in panel data model. This panel regression enables to control for the unobservable effects subject to entity. Fixed effect model assumes constant individual-specific error over time whereas random effect model assumes it random. Based on the nature of those issues either random effect or fixed effect model may be used.

\section{Fixed Effect and Random Effect Model}

The equation of "Fixed Effect Model" considering all the dependent variables of this study as PROFIT is:

$$
\text { PROFIT }_{i t}=\left(\beta_{0}+\mu_{i}\right)+\beta_{1} C A P_{i t}+\beta_{2} T_{D T E}+\beta_{3} \log T A_{i t}+\beta_{4} M B V R_{i t}+v_{i t}
$$

where, $\mu_{i}$ indicates random or fixed effect to NBFI or period of time that is excluded from the regression. It can be associated with other regressors as an individual effect is time invariant and treated as a part of the intercept. $v_{i t}$ represents independent and identically distributed error. Although, "Random Effect Model" is used to analyze the differences in error variance components across period of time or individual. Here, disparity across individuals (NBFIs) is supposed to be random and not correlated with the independent variables. The equation of random effect model is:

$$
\text { PROFIT }_{i t}=\beta_{0}+\beta_{1} \text { CAP }_{i t}+\beta_{2} \text { TDTE }_{i t}+\beta_{3} \operatorname{LogTA}_{i t}+\beta_{4} \text { MBVR }_{i t}+\left(\mu_{i}+v_{i t}\right) \ldots
$$

It has been presumed that, in a random effect model, individual effect (heterogeneity) and any predictor variables are not correlated. Based on this supposition, the model estimates error variance subject to times or groups (Park 2011).

Diagnostic Tests for Model Selection

Several diagnostic tests have been used to validate the estimated regression model in this research. Those are:

\section{Test for Serial Autocorrelation}

Drukker (2003) recommends that Wooldridge test can have better estimate in a practically sized sample. Wooldridge (2002) emanates with a modest test that is known as "Wooldridge test" to perceive serial correlation in the individual error term in a panel data framework. 
Test for Heteroscedasticity

Heteroscedasticity means a condition where the variance of the regress and differs across the dataset. Heteroscedasticity creates problems in analysis as most approaches in regression analysis assume equal variance. Modified Wald test is used to identify groupwise heteroscedasticity in fixed effect model. Greene (2012, p. 324) shows the estimate for the Modified Wald test Statistic as follows:

$w^{n}=\sum_{i=1}^{n} \frac{\left(\hat{\sigma}_{i}^{2}-\hat{\sigma}^{2}\right)}{f_{i i}}$

Here, $\hat{\sigma}^{2} \hat{\sigma}^{2}$ is the disturbance variance estimator of the regression and $f_{i i} f_{i i}$ is estimate of $\operatorname{Var}\left[\hat{\sigma}_{i}^{2} \hat{\partial}_{i}^{2}\right]$. The resulting test statistic is Chi-squared.

Test for Cross-Sectional Dependence

Cross-sectional dependence across errors may arise if there is existence of mutual shocks and overlooked components which eventually become chunk of the error term and error terms becomes correlated across cross- sections. This results in contemporaneous correlation which can be identified using Pesaran CD test suggested by Pesaran (2004).

\section{Hausman Specification Test}

Hausman (1978) proposes a specification test in econometrics that can be applied to hypothesis testing problems with two different estimators. To select between "Fixed Effect Model" and "Random Effect Model" Human Specification test has been applied in this research.

\section{Results and Discussion}

Same cross-sectional component has been observed over period of time in panel-data that ensures both time and space dimensions in dataset (Greene 2012). Due to this unique feature panel data can estimate better than only time series or cross-section data. With the support of STATA statistical software, regression analysis has been done to go in depth of the influence of capital structure on the selected Bangladeshi NBFIs performance.

\section{Descriptive Analysis}

The output of the descriptive statistics analysis of all the variables of the research is: 
Table 4. Summary of Descriptive Statistics

\begin{tabular}{|l|c|c|c|c|c|c|c|}
\hline Variable & ROE & ROA & TQ & CAP & TDTE & LogTA & MBVR \\
\hline Obs. & 291 & 291 & 283 & 291 & 291 & 291 & 282 \\
\hline Mean & 16.32 & 1.13 & 1.17 & 0.05 & 10.78 & 10.88 & 2.86 \\
\hline Std. Dev. & 19.25 & 2.25 & 0.46 & 0.08 & 28.58 & 0.32 & 6.56 \\
\hline Min & $(193.16)$ & $(22.93)$ & 0.46 & $(0.67)$ & $(414.66)$ & 10.14 & $(37.64)$ \\
\hline Max & 184.35 & 13.51 & 5.77 & 0.14 & 230.97 & 11.80 & 63.36 \\
\hline Variance & 370.82 & 5.08 & 0.21 & 0.001 & 817.44 & 0.10 & 43.10 \\
\hline Skewness & $(2.89)$ & $(4.56)$ & 5.31 & $(5.36)$ & $(9.77)$ & $(0.14)$ & 4.14 \\
\hline Kurtosis & 73.30 & 56.10 & 41.92 & 34.36 & 181.22 & 2.53 & 42.23 \\
\hline
\end{tabular}

Table 4 estimates the "Standard deviation", "Mean", "Minimum and Maximum" values of the variables, "Variance", "Skewness" and "Kurtosis" values. Thus, here the researcher provides a broad-spectrum summary of the features of the data. It can be noted that mean of all the variables (dependent and independent) is positive. However, the mean of ROA and ROE are 1.13 and 16.32 correspondingly which indicates moderate performance of the NBFIs during 2009-2019. The Tobin's Q mean value is 1.17. As Tobin's Q mean value is greater than one, it can be deduced that the market value of the NBFIs is more than their book values. This indicates that the profits made are greater than the expense of using assets of the selected NBFIs of interest and also suggests that additional investment is needed to be made by the selected NBFIs. In contrast, the mean of the CAP and TDTE are 0.05 and 10.78 respectively indicating a trifling amount of equity compared to debt of the NBFIs. MBVR is 2.86 , market value of equity being almost triple of book value of equity of the DSE enlisted NBFIs. The skewness shows that majority of the data are not symmetrical. Only LogTA is quite symmetrical. All the Kurtosis values are positive, and most of the values are much higher than zero meaning that the data do not follow normal distribution.

\section{Correlation Matrix Analysis}

Table 5. Summary of Combined Pair-Wise Correlation Matrix

\begin{tabular}{|l|c|c|c|c|c|c|c|}
\hline & TQ & ROE & ROA & CAP & TDTE & LogTA & MBVR \\
\hline TQ & 1 & & & & & & \\
\hline ROE & - & 1 & & & & & \\
\hline ROA & - & - & 1 & & & & \\
\hline CAP & 0.3143 & -0.0481 & -0.3727 & 1 & & & \\
\hline TDTE & -0.016 & 0.6246 & 0.0444 & 0.0988 & 1 & & \\
\hline LogTA & -0.1810 & -0.1633 & 0.1845 & 0.3921 & -0.0028 & 1 & \\
\hline MBVR & 0.6676 & 0.3666 & 0.0898 & 0.1003 & 0.5821 & -0.052 & 1 \\
\hline
\end{tabular}

The matrix in Table 5 shows the combined pair-wise correlation calculations. Tobin's Q is positively correlated to CAP and MBVR while it is negatively 
correlated to TDTE and LogTA of the NBFIs. ROE is positively correlated TDTE and MBVR, whereas it is negatively correlated to CAP and LogTA. ROA is positively correlated to all the independent variables except CAP. Most of the relationships are quite weak except for the correlation between ROE and TDTE, and Tobin's Q and MBVR.

\section{Diagnostic Analysis}

In Table 4, the outcomes of the "Modified Wald" test for groupwise heteroscedasticity in "Fixed Effect Regression Model" tests for three models are mentioned. The researcher has gone for the test of heteroscedasticity and the result is the presence of heteroskedasticity. Table 6 shows that heteroskedasticity is present in all the three models, meaning that the variances of the error terms vary from observation to observation.

Wooldridge test for auto-correlation in panel data for the three models was done in STATA statistics software and the results are shown in Table 6 representing that all the models contain autocorrelation. Therefore, there is correlation between the members of the series of observations ordered in time.

Table 6. Heteroskedasticity, Autocorrelation and Cross-Sectional Dependence Test Results

\begin{tabular}{|c|c|c|c|}
\hline \multicolumn{4}{|c|}{ Tests } \\
\hline & Tobin's Q & ROE & ROA \\
\hline \multicolumn{4}{|c|}{ "Modified Wala" Test (For Groupwise Heteroskedasticity) } \\
\hline \multicolumn{4}{|c|}{$\mathrm{H}_{0}$ : sigma $(\mathrm{i})^{2}=$ sigma $^{2}$ for all $\mathrm{i}$} \\
\hline$\chi^{2}(30)$ & $1.5 \mathrm{e}+08$ & 11640.25 & 21723.69 \\
\hline Prob. $>\chi^{2}$ & 0.0000 & 0.0000 & 0.0000 \\
\hline \multicolumn{4}{|c|}{ "Wooldridge" Test (For Autocorrelation) } \\
\hline \multicolumn{4}{|c|}{$\mathrm{H}_{0}$ : No autocorrelation } \\
\hline $\mathrm{F}(1,29)$ & 9.063 & 28.727 & 21.291 \\
\hline Prob. > F & 0.0054 & 0.0000 & 0.0001 \\
\hline \multicolumn{4}{|c|}{ "Pesaran" Test (For Cross-sectional dependence) } \\
\hline \multicolumn{4}{|c|}{$\mathrm{H}_{0}$ : No Cross-Sectional dependence } \\
\hline $\begin{array}{l}\text { "Pesaran" Test } \\
\text { results }\end{array}$ & 6.642 & 31.286 & 20.837 \\
\hline Prob. & 0.00 & 0.00 & 0.00 \\
\hline
\end{tabular}

Table 6 also shows the outcomes of "Pesaran's" cross-sectional dependence test. The outcomes of the "Pesaran" test demonstration that there is cross-sectional dependence among the data of all the three models.

Here in Table 7, for all the three models, $\mathrm{H}_{0}$ : Difference in coefficients is not systematic (Random Effect) 
Table 7. Hausman Test for Tobin's Q, ROA and ROE Model

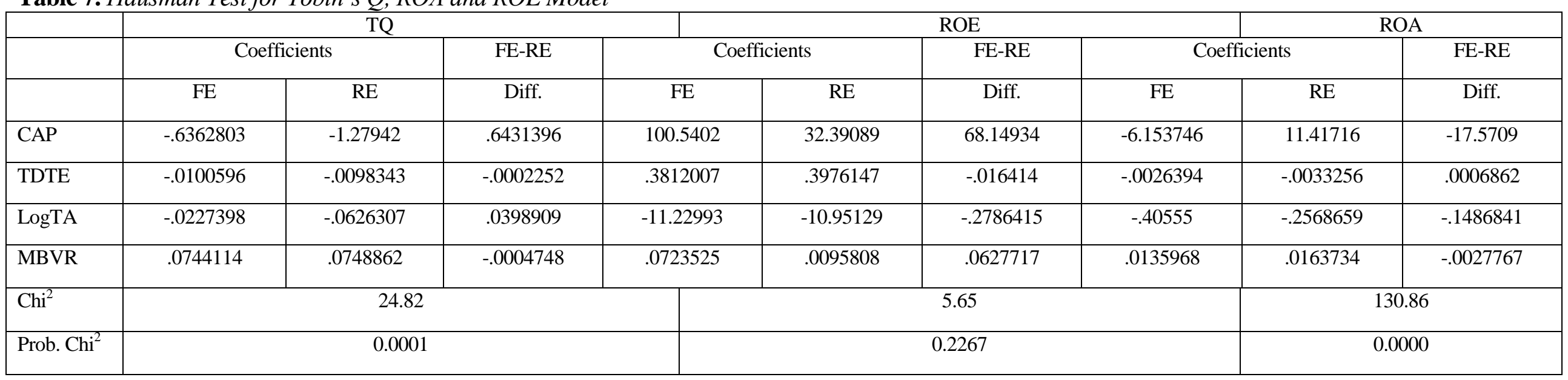


The null hypothesis has been rejected for Tobins'Q model and ROA model. This suggests presence of fixed effect. On the other hand, presence of random effect has been suggested for ROE model as we fail to reject the null hypothesis.

\section{Selection of Final Model}

Selection of model that provides best estimate is the major concern of panel data analysis. As there is indication of first order auto-correlation and heteroscedasticity in the dataset of this study, general pooled ordinary least square model may lead to biased estimate. To handle this issue random effect and fixed effect models are assessed. According to Hausman specification test, fixed effect has been found when Tobin's Q and ROA have been used as dependent variable. In the presence of cross-sectional dependence, Driscoll and Kraay (1998) standard errors for coefficient assessed by fixed effects (within) regression will provide the best estimate. On the other hand, due to presence of the random effect and crosssectional dependence, PCSE or Panel Corrected Standard Error method has been applied in the model where ROE is the dependent variable. Using STATA statistics software, the researchers found the result of this regression model which is presented in the Table 8 .

The final model for Tobin's $\mathrm{Q}$ in Table 6 displays that the independent variables TDTE and MBVR are significant at $1 \%$ significance level. Among them TDTE has negative relationship with Tobin's Q whereas the relationship between Tobin's Q and MBVR is positive. It indicates that the less the debt compared to equity, the more the profit. And when NBFIs have the equities' market value more compared to the book value of the same, the performance becomes better.

Table 8. Final Models for the Three Estimated Equations

\begin{tabular}{|l|c|c|c|}
\hline \multirow{2}{*}{ Variables } & \multicolumn{3}{|c|}{ Coefficient of Variables } \\
\cline { 2 - 4 } & Tobin's Q & ROE & ROA \\
\hline \multirow{2}{*}{ CAP } & -0.636 & $34.3019^{* * *}$ & -6.153 \\
& $(-1.45)$ & $(3.00)$ & $(-1.65)$ \\
\hline \multirow{2}{*}{ TDTE } & $-0.01006^{* * *}$ & $0.4001^{* * *}$ & -0.0026 \\
& $(-4.45)$ & $(14.44)$ & $-0.72)$ \\
\hline \multirow{2}{*}{ LogTA } & -0.0227 & $-14.6211^{* * *}$ & -0.4055 \\
& $(-0.75)$ & $(-2.34)$ & $(-1.02)$ \\
\hline \multirow{2}{*}{ MBVR } & $0.0744^{* * *}$ & 0.0584 & $(0.78)$ \\
& $(5.04)$ & $(0.54)$ & 6.030 \\
Cons. & $1.36037^{* * *}$ & 168.463 & $(1.37)$ \\
\hline Diagnostic statistic of the estimated models & $(4.06)$ & 0.0543 \\
\hline $\mathrm{R}^{2}$ & 0.7535 & 0.5241 & 0.3901 \\
\hline F/chi^2 & 21.55 & 384.97 & . \\
\hline
\end{tabular}

The final model for ROE shows that the independent variables CAP, TDTE and LogTA (NBFI size) are significant at $1 \%$ level. Among them, TDTE and CAP 
have a positive relationship with ROE whereas LogTA has negative relationship with ROE. This indicates that the effect of capital adequacy on the performance of NBFIs is positive. In this research, a negative relationship also found between TDTE with NBFIs performance in the model for Tobin's Q. But in this model for ROE found a positive relationship between them. The outcome of ROE model also suggests the smaller the NBFI's size, the better the NBFI's performance.

The final model for ROA shows that no variable is truly significant. Diagnostic statistic also indicates a poor explanatory power of this model whereas models for Tobins' Q and ROE show quite satisfactory explanatory power.

\section{Recommendations}

The regulatory authority and NBFI management may take the following issues into their consideration according to the findings of this study.

1. As capital adequacy positively impacts the financial performance of NBFI, NBFI management should think of strengthening capital base through maintaining sufficient capital to monitor the use of leverage in NBFI's asset.

2. As we cannot be sure about the effect of leverage NBFI profitability, the regulatory institutions of NBFIs along with the management of NBFIs, should adopt policies that are likely to monitor the use of debt instruments with more caution.

3. Empirical result displays that MBVR has significant positive relationship with NBFIs performance. Most of the Bangladeshi NBFIs in the study are vastly levered. Equity's market value is almost triple of its book value of the NBFIs of interest. It suggests that investors' trust reflects in the NBFI performance. Further studies can be done in this regard.

4. As size of the NBFI negatively affects the NBFI performance, the NBFIs which are big in terms of total asset should try to focus on profitability rather than on expanding the size.

5. According to the Business Standard Report (2020), because of the liquidity crisis, 06 (Six) NBFIs are now in a defenseless and vulnerable state after PLFS (Peoples Leasing and Finance Services) and BIFC (Bangladesh Industrial Finance, which are stimulating and bracing for liquidation. Therefore, related authority and stake holder should concentrate on increasing and updating the credit evaluation policy and procedure, loans, advances, leases, interest income and diversification of products for improving their profitability.

6. Government and stakeholder should attempt to uphold and maintain stable development and growth to increase public sureness and confidence in NBFIs of Bangladesh. 


\section{Conclusion}

The basis of this research is to empirically examine the effect of leverage and capital adequacy on NBFIs performance of Bangladesh. Taking into account that information and data were gathered from the yearly reports of 23 (Twenty-three) enrolled enlisted NBFIs of DSE for the period of last ten years from 2009 to 2019. It was found TDTE and MBVR significantly affect NBFI performance. The researchers have found CAP, TDTE and LogTA (NBFI size) as significant independent variable using ROE as dependent variable. However, there is no significant correlation among leverage, capital adequacy and performance of Bangladeshi NBFIs' when performance is measured by ROA. Evidence from empirical result suggests that capital adequacy has positive influence on the profitability of Bangladeshi NBFIs whereas size negatively affects the performance of NBFIs. Leverage has significant impact on NBFI profitability but the study is inconclusive to make comment on the direction of the significance as leverage shows both positive and negative relationship with NBFI performance. Thus, there is a mixed result regarding the influence of capital adequacy and leverage on NBFIs' performance which is reliable with the findings of existing literature.

There is scope for further study regarding the impact of leverage and capital adequacy on NBFIs' performance by considering some other ratios as proxy of capital adequacy and leverage. There has been a limitation in this study of not having access to data of capital adequacy ratio (CAR). Some of the commercial NBFIs have also been excluded from the study due to data unavailability. In spite of the limitation, the researchers have given their full effort to make the study a valuable one which might help the policy makers to bring effective decisions for the profitability and growth of the NBFIs of Bangladesh.

\section{References}

Abubakar A (2015) Relationship between financial leverage and financial performance of deposit money banks in Nigeria. International Journal of Economics, Commerce and Management 3(10): 759-778.

Altunbas Y, Santiago C, Edward PG, Philip M (2007) Examining the relationships between capital, risk and efficiency in European banking. European Financial Management 13(1): 49-70.

Bangladesh Bank Annual Report (2018-2019) Performance, regulations and supervision of NBFIs. Chapter 7. Bangladesh Bank.

Beltratti A, Paladino G (2015) Bank leverage and profitability: evidence from a sample of international banks. Review of Financial Economics 27(Nov): 46-57.

Berger AN (1995) The relationship between capital and earnings in banking. Journal of Money, Credit and Banking 27(2): 432-456.

Cavallo M, Majnoni G (2001) Do Banks provision for bad loans in good time? Empirical evidence and policy implications. Policy Research Working Paper, 2619. Washington, DC: World Bank.

Chakravarthy BS (1986) Measuring strategic performance. Strategic Management Journal 7(5): 437-458. 
Chien-Chiang L, Hsieh MF (2013) The impact of bank capital on profitability and risk in Asian banking. Journal of International Money and Finance 32(1): 51-81.

Driscoll JC, Kraay AC (1998) Consistent covariance matrix estimation with spatially dependent panel data. Review of Economics and Statistics 80(4): 549-560.

Drukker DM (2003) Testing for serial correlation in liner panel-data models. The Stata Journal 3(2): 168-177.

Ebrat R, Emadi F, Saadati R, Safari G (2013) The impact of capital structure on firm performance: evidence from Tehran stock exchange. Australian Journal of Basic and Applied Science 7(4): 1-8.

Gilbert RA, Wheelock DC (2007) Measuring commercial bank profitability: proceed with caution. Federal Reserve Bank St Louis Review 89(Nov): 515-532.

Gleason KC, Lynette KM, Ike M (2000) The interrelationship between culture, capital structure and performance: evidence from European retailers. Journal of Business Research 50(2): 185-191.

Goddard J, Hong L, Phil M, John OSW (2013) Do bank profits converge? European Financial Management 19(2): 345-365.

Greene WH (2012) Econometric analysis. $7^{\text {th }}$ Edition. Upper Saddle River, NJ: Prentice Hal.

Hausman JA (1978) Specification test in econometrics. Econometrica 46(6): 1251-1271.

Holz CA (2002) The impact of the liability-asset ratio on profitability in china's industrial state-owned enterprises. China Economic Review 13(1): 1-26.

James C, Hadlock C (2002) Do banks provide financial slack? Journal of Finance 57(3): 54-67.

Lawal AI (2014) Capital structure and the value of the firm: evidence from the Nigeria banking industry. Journal of Accounting and Management 4(1): 31-41.

Manawaduge A, Zoysa A, Chowdhury K, Chandarakumara A (2011) Capital structure and firm performance in emerging economics: an empirical analysis of Sri Lankan firms. Corporate Ownership and Control 8(4): 253-263.

Miller MH, Modigliani F (1958) The cost of capital, corporate finance and the theory of investment. American Economic Review 48(3): 261-297.

Myers SC (1984) Capital structure puzzle. NBER Working Paper No W1393. National Bureau of Economic Research (NBER).

Nwankwo GO (1991) Bank management: principles and practice. Lagos: Maithouse Press Limited.

Park HM (2011) Practical guides to panel data modeling: a step-by-step analysis using stata. Tutorial Working Paper. Japan: Graduate School of International Relations, International University of Japan.

Pesaran MH (2004) General diagnostic tests for cross section dependence in panels. Cambridge Working Paper in Economics, No 0435. Cambridge: Faculty of Economics, University of Cambridge.

Ross SA (1977) The determination of financial structure: the incentive-signaling approach. The Bell Journal of Economics 8(1): 23-40.

Safiuddin M, Islam MM, Anisuzzaman M (2015) Impact of financial structure on firm's performance: a study on financial and non-financial sector in Bangladesh. European Journal of Business and Management 7(3): 30-38.

Sandberg WR, Hofer CW (1987) Improving new venture performance: the role of strategy, industry structure and the entrepreneur. Journal of Business Venturing 2(1): 5-28.

Schepens G (2016) Taxes and bank capital structure. Journal of Finance and Economics 120(3): 585-600.

Sharp WF (1964) Capital asset prices: a theory of market equilibrium under conditions of risk. The Journal of Finance 19(3): 425-442. 
Smith Jr. CW, Watts RL (1992) The investment opportunity set and corporate financing, dividend and compensation policies. Journal of Financial Economics 32(3): 263292.

The Business Standard Report (2020) Six more nonbank financial institutions in trouble. The Business Standard. Retrieved from: https://tbsnews.net/economy/banking/sixmore-non-bank-financial-institutions-trou ble. [Accessed 12 December 2020]

Wooldridge JM (2002) Econometric analysis of cross section and panel data. Retrieved from: http://public.econ.duke.edu/ vjh3/e262p_07S/reading s/Wooldridge_Panel_ Data_Chapters.pdf. [Accessed 15 June 2015]

Yadav R, Salim M (2012) Capital structure and firm performance: evidence from malaysian listed companies. Procedia-Social and Behavioral Sciences 65(Dec): 156166.

Zeitun R, Tian G (2007) Capital structure and corporate performance: evidence from Jordan. Australasian Accounting Business and Finance Journal 1(4): 40-61.

Zheng C, Rahman MM, Begum M, Ashraf BN (2017) Capital regulation, the cost of financial intermediation and bank profitability: evidence from Bangladesh. Journal of Risk and Financial Management 10(2): 9. 

Athens Journal of Business \& Economics -

Volume 8, Issue 2, April 2022 -Pages 177-192

\title{
Greece in the Eurozone: An Evaluation of the First Two Decades
}

\author{
By Gregory T. Papanikos*
}

\begin{abstract}
On the $31^{\text {st }}$ of December 2021, the euro celebrated its two decades in circulation. Initially, twelve countries adopted the euro as their new national currency, Greece being one of them. Starting in 2020, euro is the official currency of nineteen European Union countries. This paper aims to examine three issues. Firstly, the paper investigates Greek people's perception about the euro, using data from the recent issue of the Eurobarometer (December 2021). Secondly, the economic performance of Greece is briefly examined by comparing the Greek Gross Domestic Product (GDP) two decades before and two decades after the introduction of euro. Finally, the Greek participation to the eurozone has been a controversial, political issue. The political developments in Greece during the first two decades of the euro are also studied, emphasizing the dramatic political events after the double elections of 2012. The period of the two decades ends with the detrimental impact of COVID-19. This issue is also mentioned by reviewing some recent publications.
\end{abstract}

Keywords: Eurozone, Greece, GDP, per capita GDP, Eurobarometer, euro, elections, politics

\section{Introduction}

This paper evaluates the first two decades of Greece's membership to the eurozone. The euro circulated with coins and banknotes on 1 January 2002. Many hoped for the best and few feared for the worst. Based on my published work on this issue, ${ }^{5}$ which was the result of being both an academic economist and an active policymaker, an effort is made here to gauge whether the Greek economy is worse off, relative to what would have been the case if Greece had stayed outside the euro, and instead keeping its national currency of drachmae. Of course, it is impossible to simulate 20 years of economic performance with the drachmae and compare it with the actual economic performance within the eurozone. Thus, the analysis is rather speculative.

The costs and benefits of the Greek decision to be a member of the eurozone was investigated by Papadopoulos and Papanikos (1997) after a request by the Greek Government. The part of this report which dealt with the costs of Greece's euro expected at the time are included in an appendix in Papanikos (2014a). That was an ex-ante evaluation of the euro effect on the Greek economy. This study attempts an ex-post evaluation, but it is not an easy task because during this period

\footnotetext{
*President, Athens Institute for Education and Research, Greece; Honorary Professor of Economics, University of Stirling, UK; and Professor, MLC Ljubljana, Slovenia.

${ }^{5}$ The cited publications include the relevant references, which readers can access them if they are interested.
} 
of twenty years, the Greek economy was influenced by three events, two of which were noneconomic.

The first noneconomic event was the Olympic Games of 2004, preparations for which started in 1997, the year the International Olympic Committee (IOC) awarded the organization of the 2004 Olympic Games to Athens. The preparations for the games--mainly building up the required infrastructure-have had a longlasting economic effect. Their duration coincided with the preparation of the Greek economy to introduce the euro and the first years of its circulation. The Olympic Games were awarded when the Greek national currency was the drachmae, but when the Games actually took place, the euro was the official Greek national currency. Thus, when in macro-econometric analyses, a dummy variable is used to account for the structural change of euro; this variable simultaneously catches up to the economic effects of Olympic Games. As a coincidence, I was asked to do an economic analysis of the Olympic Games' impact simultaneously with my assignment of economic analysis of the introduction of the euro. ${ }^{6}$

The second noneconomic event was the impact of COVID-19 which led to an economic lockdown with serious economic, social and primarily health effectsnot only in Greece, but throughout the entire world. In a series of studies, I have investigated various aspects of the current pandemic by looking at what Thucydides had to say of the pandemic effect which hit Athens in $430 \mathrm{BCE}$ and lasted for about 5-6 years (Papanikos 2021b). I also examined the tourism impact of COVID-19 (Papanikos 2020a).

The third event was economic. The Great Recession started in the USA in 2008 but hit Greece very hard in 2010. This has had serious economic and political repercussions which are further examined in the following sections.

There are two issues with the introduction of euro. Firstly, it is the institutional change from a national currency to a common currency. This by itself has mainly positive effects by reducing the transaction costs of doing business in the common currency of an area. As we shall see, these positive effects have been fully recognized and appreciated by the majority of people in the eurozone. Secondly, it is the actual exchange value of the common currency itself. All countries use the same nominal euro, but the real effective exchange rate for each country differs. In Papanikos (2015a), I estimated that the Greek effective exchange rate was overvalued, and a devaluation of the euro would have benefited Greece to cope with the Great Recession. Since then, the nominal value of the euro has been devaluated relative to US dollars which is usually taken as representing the foreign currency. This study does not repeat the 2015 study, but it should be clear that eurozone member-countries do not have the same real effective exchange rate which has significant effects on their international trade, and therefore GDP.

This paper is descriptive and provides an overview of how the euro affected the Greek public opinion, economy, and politics. The paper is organized into six

\footnotetext{
${ }^{6}$ The first was assigned by the Research Institute of Tourism and the second by the Government of Greece. The first produced a book publication (Papanikos 1999) and the second a report which was presented to the Ministry of Development. I have also examined the Olympic Effect in a series of articles; see Kartakoullis et al. (2003), and Papanikos (2022a, 2020e, 2004a, 2004b, 2003).
} 
sections, including this introduction. The next section discusses what Greeks think about the euro after 20 years of experience. I use the latest Eurobarometer findings. I compare the Greek feelings about the euro relative to the eurozone average. Economics is only one dimension of the euro effect. People may derive pride from using a common currency and belonging to a group of European countries. Especially for Greeks, this is felt even more sensitively because it is one of their many myths which gave the name to this continent, and now to its common currency. Thus, having the euro means more than money; it may transcend an ideal that Europeans are willing to pay the economic cost of having it.

In section three, I compare the GDP and GDP per capita performance of the Greek economy in the two decades prior, and after, the introduction of the euro. The key question in this section is whether the Greek economy did better or worse in the euro years. This is not the most appropriate comparison, but it is very difficult to simulate what would have been the economic performance of Greece without the euro and then compare it with the actual performance inside the eurozone. However, given the political animosity at the time in Greece when extremists were campaigning on the worst scenario, echoing people's many concerns because of the uncertainties of the new currency, the question of whether the Greek economy is better or worse has its own merit.

In section four, the political hostilities are examined which were instigated by the Great Recession of 2008. The section discusses the Greek politics of the euro years. The political cycle had two phases. The first lasted up to 2012 where Greek politics followed the trends of being ruled by one-party governments. The Great Recession and the fact that Greece was a member of the eurozone was a crash-test for the Greek political system. New parties emerged, and for the first time in the postwar Greek political history a coalition government was formed in 2012 which governed up to 2015, and then another coalition government ruled Greece from 2015 and 2019. On this, see Papanikos (2022b). In the last two years of the two decades of the euro, the Greek political system returned to the one-party government. This political cycle was the result of Greece being a member of the eurozone as explained in this section.

In section five the impact of COVID-19 is examined through the prism of the many papers published in ATINER's various journals. Still, the impact of COVID-19 is still in effect and no conclusion can be reached. This section emphasizes the multiple effects this pandemic has had on the economy and the society at large. In the last two years (2020-2021) more than 30 papers have been published in the various journals of ATINER; an edited book of these studies has been prepared by Boutsioli et al. (2022).

Conclusions are given in the last section and relate to the three-and-a-half issues discussed in this paper: people's opinions about the euro; the euro effect on total and per capita Greek GDP; the developments of Greek politics during the euro years; and the impact of COVID-19. 


\section{What Do the Euro Countries and Greeks Think About the Euro?}

This section looks at what Europeans have to say about the euro. The data are retrieved from the most recent Eurobarometer available (December 2021). Since the focus is on Greece, I compare the European average with the opinions of Greeks. I have selected just a few questions, but I think they are characteristic of how the euro is perceived today by Greeks, relative to the average of the 19 countries in the eurozone.

Figure 1 shows the average European's opinion about the euro. Over the last 15 years the opinion remained stable. By the end of the two decades of euro's circulation, $78 \%$ of Europeans have a positive view, while $14 \%$ think that it was a bad idea.

A common European identity can be expressed by many things, and the idea of having a common something, like a currency, is considered as an indicator of a European cohesion. The exact question asked was, "Does the euro make you personally feel more European than before or would you say that your feeling of being European has not changed?"

Figure 2 gives the percentage of all Europeans who share the common currency. It seems that over the years the idea of the common currency makes more and more people feel an affinity to Europe. In 2007, $22 \%$ of the people in the eurozone countries stated that the euro made them feel more European. In 2021, this figure was $32 \%$. Those who answered that nothing has changed decreased in number, but still dominate with $66 \%$. However, this might have an ambiguous reasoning. Those who felt as Europeans before, the euro would not have changed their attitudes towards Europe.

Figure 1. Europeans Opinion About the Euro, 2007-2021

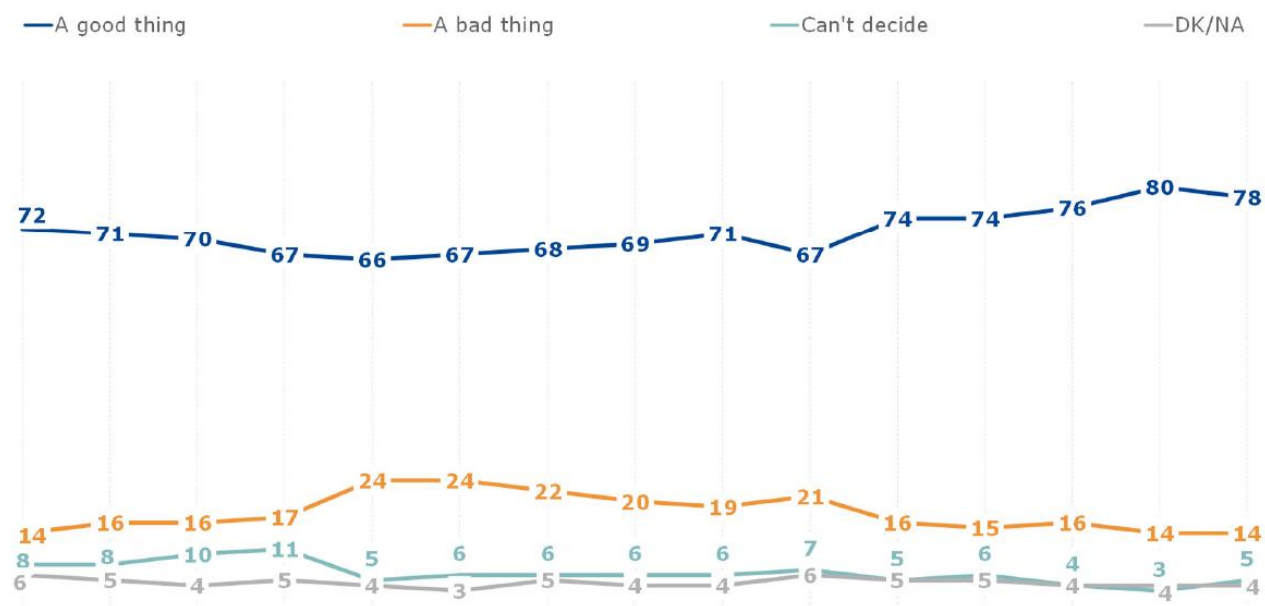


Figure 2. The European Affinity Because of the Euro, 2007-2021

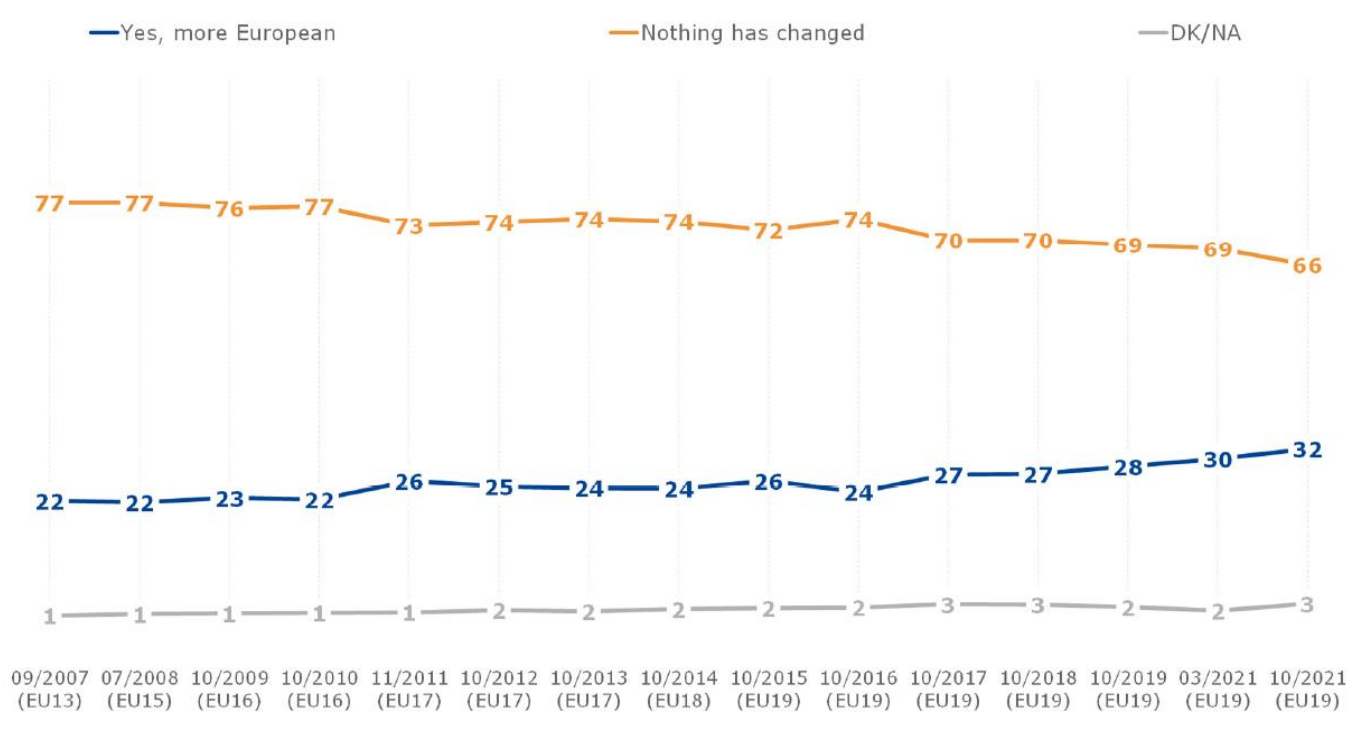

I turn now to what Greeks think about the euro and compare it with the average opinion of others in the eurozone. Table 1 compares some key questions with the Greek opinions on the euro with the average of the eurozone.

Table 1. Greece vs EU Average Opinions on the Euro, 2021

\begin{tabular}{|l|l|c|c|}
\hline No. & Question & $\begin{array}{c}\text { Eurozone } \\
\text { Average }\end{array}$ & Greece \\
\hline Q1.1 & $\begin{array}{l}\text { Generally speaking, do you think that having the Euro is a good for your } \\
\text { country? }\end{array}$ & 69 & 73 \\
\hline Q1.2 & Generally speaking, do you think that having the Euro is a good for EU? & 78 & 79 \\
\hline Q2 & $\begin{array}{l}\text { Does the Euro make you personally feel more European than before or } \\
\text { would you say that your feeling of being European has not changed? }\end{array}$ & 32 & 28 \\
\hline Q7.1 & More & 66 & 72 \\
\hline Q7.3 & $\begin{array}{l}\text { Do you think that the Euro has made easier to do business in different EU } \\
\text { countries? }\end{array}$ & 53 & 58 \\
\hline Q7.4 & $\begin{array}{l}\text { Do you think that the Euro has made it easier to compare prices and shop } \\
\text { in different EU countries, including online? }\end{array}$ & 82 & 85 \\
\hline Q8 & $\begin{array}{l}\text { Do you think that the degree to which economic policy, including } \\
\text { budgetary policies, is coordinated in the Euro area is appropriate? Should } \\
\text { there be more or less coordination among Euro-area governments? }\end{array}$ & 15 & 5 \\
\hline & $\begin{array}{l}\text { Appropriate } \\
\text { More Coordination }\end{array}$ & 64 & 85 \\
\hline
\end{tabular}

Source: Eurobarometer, December (2021).

Greeks, on average, think that the euro is good for Greece and the eurozone relative to the eurozone's average, but there are no huge differences. On the issue of affinity, the European idea, 28\% of Greeks stated that the euro made them feel more European, relative to a $32 \%$ of the eurozone average. "Nothing changed," 
said $72 \%$ of Greeks and $66 \%$ of Europeans. However, this may be interpreted that Greeks felt more like Europeans than the rest of Europe even before the introduction of Euro.

The next three questions are economic in nature. One of the advantages of a common currency is that it reduces the transaction costs of doing business in the area. Traveling became easier, said 53\% of the Europeans, while $58 \%$ of Greeks thought so as well. Doing business became easier, said $82 \%$ of Greeks relative to an average of $79 \%$ of all Europeans. Comparing prices became easier, stated $85 \%$ of Greeks and $82 \%$ of all Europeans.

The last question, I think, is the most important for the future of the eurozone. Most Europeans (64\%), and even many more Greeks (85\%), thought that a fiscal coordination would have been better for the eurozone. This compares with the monetary policy which is now regulated centrally by the European Central Bank. ${ }^{7}$

In general, it appears that Greeks feel, on average, that the euro was not a bad idea after all. This is very important because Greece suffered economically the most of all eurozone countries because, as I argued (Papanikos, 2015), the exchange value of the euro was detrimental for the Greek exports which included tourism revenues. However, the economic performance of the euro years did not deteriorate the economic welfare of the Greek people, as this is demonstrated by comparing the GDP and the GDP per capita in the next section.

\section{Total and Per Capita GDP}

For economists, people's opinions are considered with great skepticism. What is important is not what people say, but what they do. In economics "doing" is "producing" and "consuming". At the macroeconomic level, the GDP captures the essence of total final production generated in a given year; then divided by population is an indication of wellness of a country's economy.

Thus, did the euro produce more or less total and per capita Greek GDP? There are two ways to answer this question already mentioned in the introduction of the paper. Firstly, a more accurate measure would have been if data could be constructed of what the Greek GDP would have been without the euro. Then, these data would have been compared with the actual GDP produced in Greece as a member of the eurozone. This is not possible. Secondly, one may compare whether total and per capita GDP was higher or lower in the pre-euro period, relative to the euro period. This is shown in Figures 3 and 4.

\footnotetext{
${ }^{7}$ Of course, monetary policy relates to the value of the euro vis-à-vis other currencies (the exchange rate), the interest rate and the rate of inflation. On these issues many papers have been published in this and other journals of ATINER; see Binatli and Sohrabji (2019), Colonescu (2017, 2018), Correia (2016), Correia and Carvalho (2016), Gambarotto et al. (2019), Gentilucci (2020), Kallianiotis (2018), Klein (2021), Korus (2019), Leen (2016), Luchena Mozo (2017), Reid (2018), Siddiqui (2020), Sommeiller (2020), and Turnbull (2016).
} 
Figure 3. GDP in Billions of 2015 Euro

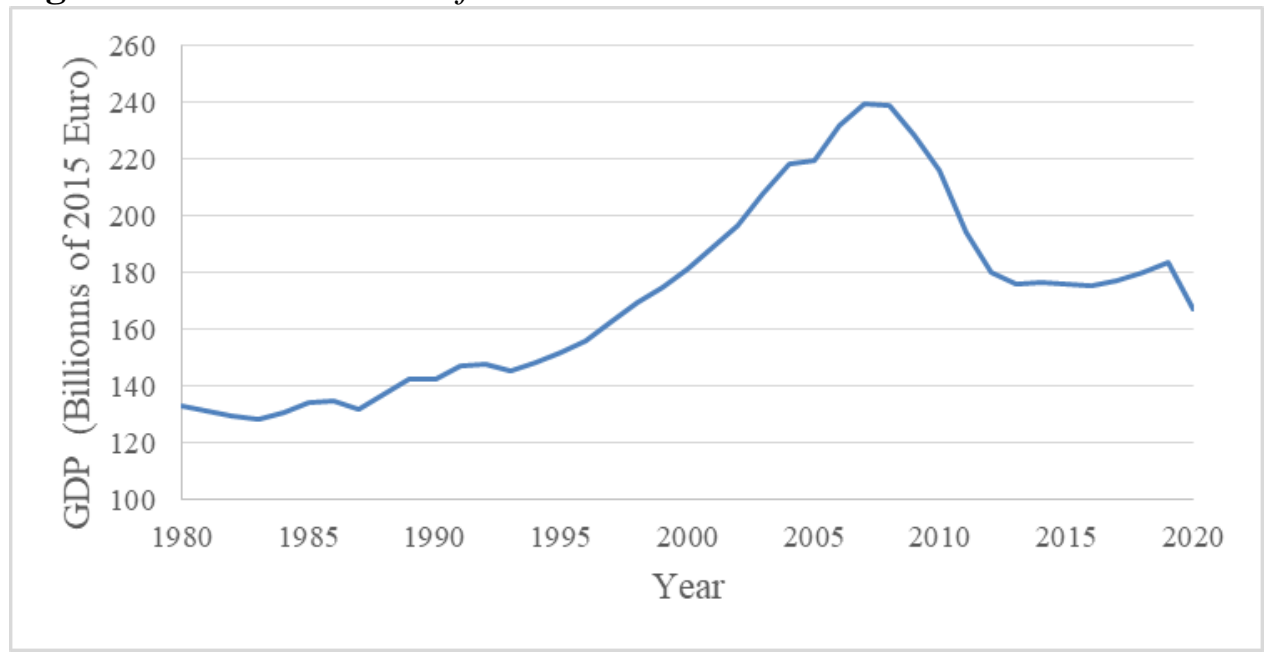

Figure 4. Per Capita GDP in Thousands of 2015 Euro

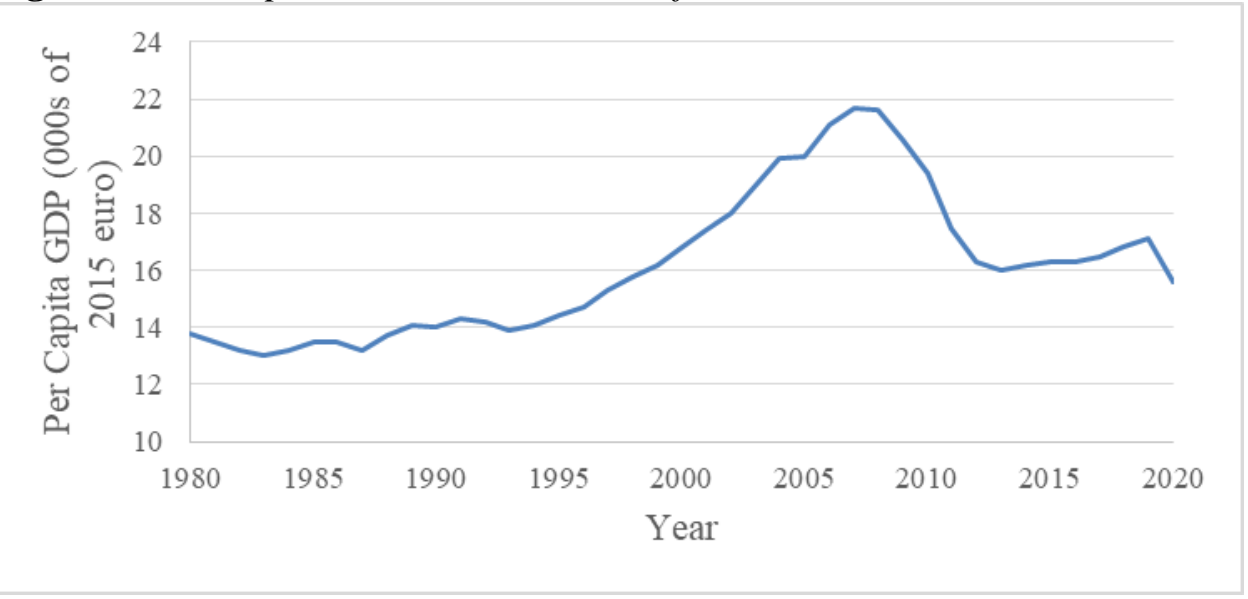

I have explained the Greek economy elsewhere in many publications, both the macroeconomic and microeconomic aspects, and I do not repeat them here. ${ }^{8}$ Instead, I make a number of points based on the two figures (Figures 3 and 4).

Firstly, the introduction of the euro was accompanied by an unprecedented increase in total and per capita GDP. Never before have the two variables reached such high levels. Even though this cannot be directly attributed to the euro itself, it does relate to the general positive international economic environment which gave rise to lower interest rates. It was this possibility of borrowing money at low rates which led the Greek Government to borrow money at unprecedented high levels

\footnotetext{
${ }^{8}$ The most important is my book (Papanikos 2014a) where I present a detailed economic analysis with an emphasis on the debt crisis of 2010. Other studies include Michelis et al. (2004), Papadopoulos and Papanikos (1997, 2002, 2005), Papanikos (2014a-c, 2015a-j). In addition, the Greek economy, and especially its tourist sector, is affected by the political and military developments in the Eastern Mediterranean. On the issue of military and its effect on international trade and economic growth see Papanikos (2015k), and on the issue of energy see Papanikos (2017). The thorny issue of Greek-Turkish relations is examined in Papanikos (2020c, 2020d, and 2021e).
} 
which led to the Greek debt crisis of 2010 as I demonstrated with all the details and data in Papanikos (2014a).

Secondly, after 2008 the total and per capita GDP dramatically decreased at unprecedented rates for peace years. Never before had the rates of growth of the two variables reached so low. This was the effect of the Great Recession and the debt crisis previously mentioned.

Thirdly, despite these huge variations in total and per capita GDP, these two variables remained higher than any value of the pre-euro period with the exception of the two years of 2020 and 2021 when the lockdown due to COVID-19 hit all the eurozone economies harshly.

\section{The Greek Political Debate in the Euro Years}

This section builds on my previous writings and my personal experience as a policymaker. ${ }^{9}$ From 1997 until 2011, I served as a General Secretary of the Greek Economic and Social Council, which provided me with firsthand experience with the politics of the debate. For many people, the euro meant an increase in their economic welfare. They thought that the euro would bring higher wages, lower unemployment rates, inflation rates and borrowing rates.

Starting in 2002, the political debate of whether Greece was ready to switch between currencies was over. Issues such as the change of menu prices and cashiers disappeared from the mass media in the first month of 2002. There were not the huge transaction costs many were expecting. Nobody even noticed that real wages were increasing at a higher rate than productivity. The gap was filled with foreign borrowing which no political party condemned, with the exception of a handful of politicians. In elections after elections, from the 1980s onwards (Table 2), the issue of Europe was at the top of the political agenda.

Table 2. Elections Years, 1983-2021

\begin{tabular}{|c|c|c|}
\hline Year & Party Coming First Relative to Previous Elections & Type of Government \\
\hline 1985 & Same & One party \\
\hline 1989 & Change & Interim \\
\hline 1990 & Same & Interim \\
\hline 1990 & Same & One party \\
\hline 1993 & Change & One party \\
\hline 1996 & Same & One party \\
\hline 2000 & Same & One party \\
\hline 2004 & Change & One party \\
\hline 2007 & Same & One party \\
\hline 2009 & Change & One party \\
\hline 2012 & Change & Interim \\
\hline 2012 & Same & Coalition \\
\hline 2015 & Same & Coalition \\
\hline 2015 & Same & Coalition \\
\hline 2019 & Change & One party \\
\hline
\end{tabular}

\footnotetext{
${ }^{9}$ See among many others Papanikos (2014a, 2019, 2021d, 2022b).
} 
The most important elections which took place in the euro years was in 2012 for two reasons. Firstly, for the first time since 1974 the two opposition parties formed a coalition government to deal with the real threat of Greece being pushed out of the eurozone. Never before was Greece at the brink of getting out of the eurozone and maybe even from the European Union. This collaboration gave rise to the growth of many small parties, which in the general elections of 2015 , led to another party which was far away from what many voters would have thought a few years back. A left party collaborated with an extreme right party, even though there was the alternative option for the left to collaborate with a center or centerleft party to form a government. The rest of this section is devoted to the two political events.

\section{The 2012 Double Elections}

The Greek general elections of the $6^{\text {th }}$ of May 2012 did not result in the formation of a coalition government. According to the Greek Constitution, new elections were called for on the $17^{\text {th }}$ of June 2012.

The five-and-a-half weeks between the two elections gave the opportunity to all Greek parties to reconsider their positions and form pre-election coalitions which are based on the three main issues of the May and the June elections. These issues are (Table 3):

1. The classical ideological division between right and left, or center-right and center-left.

2. The split between those who want the euro and those who prefer a return to a national currency.

3. The position between the necessity of the austerity measures imposed by the troika and those who wanted a unilateral abolishment of them.

Table 3. Typology of Issues

\begin{tabular}{|l|c|c|}
\hline Issue & \multicolumn{2}{|c|}{ Options } \\
\hline Ideology & Center-Right & Center-Left \\
\hline Eurozone-European Union & Pull out & Stay in \\
\hline Austerity Measures & Necessary & Not Necessary \\
\hline
\end{tabular}

The new elections made it even clearer the political parties' positions on the last two issues of the euro and the austerity measures. It should be mentioned that those political parties which considered the austerity measures necessary also agreed that the austerity program needed to be reconsidered towards (a) extending the implementation period and (b) supplementing the austerity program with measures to promote output growth and employment. They considered the new political developments in Europe, primarily the election of Francois Holland in France, as more favorable towards a renegotiation of the austerity measures with the troika.

The results of the election of the 17 of June 2012 and of 6 of May 2012 were analyzed along three lines: ideology, political parties' stance on the eurozone, and 
their attitude towards the austerity program. In sum, the main points are the following:

1. Although June 2012 elections were considered very important, $37.53 \%$ of the eligible Greek voters decided not to vote (Table 4). This was higher than the May 2012 percentage of $34.9 \%$, and even higher than the $29.05 \%$ of the 2009 elections. This is not interpreted as political apathy, but as a deliberate protest against the political system. Some voters might have abstained because they did not want to vote against their traditionally preferred political party.

2. Contrary to the May 2012 election results, in the June 2012 elections only $5.98 \%$ of the electorate was not represented in the parliament because they did not meet the required statutory minimum rate of $3 \%$ of the votes. In May $2012,19 \%$ of the Greek voters chose a party that is not represented in the Parliament. The 2009 rate was only 5\%.

3. On the ideology issue, the percentages remained the same with a very small increase to the left of $0.54 \%$ (Table 5).

4. On the eurozone membership issue (Table 6), in 2012 the Greek electorate had the option for the first time to vote for parties which openly declared their devotion or hostility to the euro experiment. In May 2012, 81.92\% of Greeks voted for parties which see Greece's future inside the eurozone. In June 2012 this percentage increased to $88.04 \%$. This is very high and similar to the Eurobarometer's measure in the end of 2021.

5. On the austerity issue (Table 7), in June 2012, 52.96\% of Greeks voted for parties which claim that austerity measures are painful but necessary. In May 2012 the rate was $51.65 \%$.

Table 4. Greek Elections of June 2012 and May 2012

\begin{tabular}{|l|c|c|c|c|}
\hline & $\begin{array}{c}\text { People entitled to } \\
\text { vote } \\
(1)\end{array}$ & $\begin{array}{c}\text { Number of People } \\
\text { Voted } \\
(2)\end{array}$ & $\begin{array}{c}\text { Percent of } \\
\text { People Voted } \\
(3)\end{array}$ & $\begin{array}{c}\text { Percent of Voters } \\
\text { Abstained } \\
(4)\end{array}$ \\
\hline June 2012 & $9,949,300$ & $6,215,029$ & $62.47 \%$ & $37.53 \%$ \\
\hline May 2012 & $9,949,401$ & $6,477,060$ & $65.10 \%$ & $34.9 \%$ \\
\hline
\end{tabular}

Table 5. Right and Left

\begin{tabular}{|l|c|c|c|}
\hline Election Year & $\begin{array}{c}\text { June 2012 } \\
\text { Ideology }\end{array}$ & $\begin{array}{c}\text { May 2012 } \\
\%\end{array}$ & $\begin{array}{c}\text { June 2012/May } \\
2012 \\
\% \text { Difference }\end{array}$ \\
\hline Right to Center & $48.26 \%$ & $49.00 \%$ & $-0.74 \%$ \\
\hline Left to Center & $51.47 \%$ & $50.93 \%$ & $+0.54 \%$ \\
\hline
\end{tabular}

Table 6. In and Out of the Eurozone

\begin{tabular}{|l|c|c|c|}
\hline Election Year & $\begin{array}{c}\text { June 2012 } \\
\text { Eurozone }\end{array}$ & $\begin{array}{c}\text { May 2012 } \\
\%\end{array}$ & $\begin{array}{c}\text { June 2012/May } \\
2012 \\
\% \text { Difference }\end{array}$ \\
\hline In & $88.04 \%$ & $81.92 \%$ & $+6.12 \%$ \\
\hline Out & $11.96 \%$ & $18.08 \%$ & $-6.12 \%$ \\
\hline
\end{tabular}


Table 7. Austerity Measures

\begin{tabular}{|l|c|c|c|}
\hline \multicolumn{1}{|c|}{ Election Year } & $\begin{array}{c}\text { June 2012 } \\
\%\end{array}$ & $\begin{array}{c}\text { May 2012 } \\
\%\end{array}$ & $\begin{array}{c}\text { June 2012/May } \\
2012 \\
\% \text { Difference }\end{array}$ \\
\hline $\begin{array}{l}\text { Austerity Measures } \\
\text { Eurozone }\end{array}$ & $52.96 \%$ & $51.65 \%$ & $1.31 \%$ \\
\hline Not necessary & $47.04 \%$ & $48.35 \%$ & $-1.31 \%$ \\
\hline Difference & $5.92 \%$ & $3.30 \%$ & $2.62 \%$ \\
\hline
\end{tabular}

The Double Elections of 2015 and the Referendum in Between

The coalition government ruled until early 2015, when, on the issue of choosing the next President of the Hellenic Republic, the parliament was unable to elect a president. According to the constitution, a new election was called. As all had expected, a left party won the elections on the $25^{\text {th }}$ January 2015.

Analyzing the election results (Papanikos 2015h), I had predicted that new general elections were coming. These new elections were called early in the fall of the same year. In between, there was a referendum. On this, in my book (Papanikos 2014a, p. 147) I had predicted that the left power, when it would come to power, would (a) call for a referendum, (b) the question would be vague so it can be interpreted as either a no to euro or a no to the memorandums in general, or a no to a specific memorandum which allegedly was on the table, but the eurozone countries took it off once the referendum was called, and (c) Greeks would vote no because when people are directly or indirectly asked if they want to pay taxes they will say no. This is the reason tax and budget issues cannot be determined in a referendum as is clearly stated in the Greek Constitution.

\section{The COVID-19 Impact}

In 2019 new elections were held and a new one-party government of the traditional Greek right was formed. However, the new government was faced with the challenge of COVID-19, of which the effects are still on and nobody can predict how long it will last. On this issue, I have written extensively. In Papanikos (2021b), I looked at how a pandemic influenced the economic and social life in ancient Athens as described by Thucydides. The effect of the pandemic at the European Union level was examined in Papanikos (2020b). I also examined the devastating effect on Greek tourism in Papanikos (2020a). Finally, the EU's recovery plan was analyzed in Papanikos (2021c).

COVID-19 has many impacts. In a series of papers published in the various journals of ATINER, the themes included: Health Issues (Menekli et al. 2021, Papanikos 2021a, Parodi et al. 2021, Shah et al. forthcoming), Mass Media and Communication Issues (Crescentini and Padricelli forthcoming, De Falco et al. 2021, Fitzpatrick forthcoming, Mengu et al. 2021, Osisanwo 2022); Social Aspects (Bäckman 2021, Jurić 2022, Lust forthcoming, Okaka and Omondi forthcoming, Papanikos 2020b, Polo Martín 2022); Business and Economics Issues (Adejare et al. forthcoming, Papanikos 2021c, Reid forthcoming, Struwig and Watson 
forthcoming, Uwah et al. forthcoming); Tourism Issues (Gukiina and Lamunu 2021, Jones forthcoming, Jones and Comfort 2020, Papanikos 2020a); Education Issues (Güvercin et al. forthcoming, Ismaili and Ibrahimi 2021, Papanikos 2021b); Law Issues (Iancu 2021, Patraus and Ofrim 2021).

The above literature shows that the impact of COVID-19 is a very serious one and no one can predict when it will end.

\section{Conclusions}

This paper investigated the opinions of Europeans and Greeks about the euro twenty years after its circulation. About four-fifths of people in the eurozone think that the euro is good for their country and Europe at large.

Despite the dismal picture painted and the uncertainty surrounding the introduction of the euro, the Greek economy did better in the two decades of the euro, relative to the two decades preceding the introduction of the euro.

The politics during the same period were stable up to the Great Recession of 2008. The Greek economy was hit hard; the hardest in Europe. The need to implement harsh austerity measures undermined the trust in Europe and in the euro. This shattered the political developments in Greece, leading to double elections within one year (in both 2012 and 2015). At the end of this period (20192021), these political episodes have subsided and again Greece is governed by a strong one-party government. However, COVID-19 has hit the whole world but it seems that the European Union has decided to cope with this new challenge following a different approach. Since the impact is still active, only the future will show whether these measures were effective. Future studies will definitely examine this issue.

\section{References}

Adejare BO, Olaore GO, Udofia EE, Adenigba OA (forthcoming) COVID-19 pandemic and business survival as mediation on the performance of firms in the FMCG-sector. Athens Journal of Business \& Economics. Available at: https://www.athensjournals. gr/business/2021-4138-AJBE-Adejare-07.pdf.

Bäckman G (2021) The outbreak of coronavirus (COVID-19) plagues the world. Athens Journal of Social Sciences 8(3): 181-190.

Binatli AO, Sohrabji N (2019) Monetary policy transmission in the Eurozone. Athens Journal of Business \& Economics 5(1): 79-92.

Boutsioli Z, Bigelow V, Gkounta O (2022) Essays on COVID-19. Athens: Athens Institute for Education and Research (ATINER).

Colonescu C (2017) Macroeconomic effects of the European Monetary Union: a counterfactual analysis. Athens Journal of Business \& Economics 3(2): 171-186.

Colonescu C (2018) The effects of Donald Trump's tweets on US financial and foreign exchange markets. Athens Journal of Business \& Economics 4(4): 375-388.

Correia L (2016) The European crisis: repercussions on the Portuguese economy. Athens Journal of Mediterranean Studies 2(2): 129-144. 
Correia L, Carvalho D (2016) Cyclical dynamics of unemployment: Portugal versus the euro area. Athens Journal of Business \& Economics 2(2): 149-166.

Crescentini N, Padricelli GM (forthcoming) The relevance of scientific dissemination during the vaccine campaign: the Italian virologist communication on social media. Athens Journal of Mass Media and Communications. Available at: https://www. athensjournals.gr/media/2021-4354-AJMMC-SOC-Crescentini-07.pdf.

De Falco CC, Punziano G, Trezza D (2021) A mixed content analysis design in the study of the Italian perception of COVID-19 on Twitter. Athens Journal of Social Sciences 8(3): 191-210.

Fitzpatrick N (forthcoming) No news is not good news: the implications of news fatigue and news avoidance in a pandemic world. Athens Journal of Mass Media and Communications. Available at: https://www.athensjournals.gr/media/2021-4336AJMMC-SOS-Fitzpatrick-05.pdf.

Gambarotto F, Rangone M, Solari S (2019) Financialization and deindustrialization in the Southern European periphery. Athens Journal of Mediterranean Studies 5(3): 151172.

Gentilucci CE (2020) The Mediterranean model in European economic thought. Athens Journal of Mediterranean Studies 6(3): 179-198.

Gukiina J, Lamunu E (2021) The near abasement of Uganda hotels' staff altruistic behaviour by COVID-19 pandemic: a relief model. Athens Journal of Tourism 8(4): 269-290.

Güvercin D, Kesici AE, Akbaşlı S (forthcoming) Distance education experiences of teacher-parents during the COVID-19. Athens Journal of Education. Available at: https://www.athensjournals.gr/education/2021-4145-AJE-Kesici-05.pdf.

Iancu L-O (2021) Insolvency of the natural person and COVID-19 in Romania. Athens Journal of Law 7(4): 563-574.

Ismaili J, Ibrahimi EHO (2021) The D-learning alternative during COVID-19 crisis: a preliminary evaluation based on Kirkpatrick's model. Athens Journal of Technology and Engineering 8(2): 181-198.

Jones P (forthcoming) A review of the UK's tourism recovery plans post COVID-19. Athens Journal of Tourism. Available at: https://www.athensjournals.gr/tourism/20 21-4470-AJT-Jones-03.pdf.

Jones P, Comfort D (2020) The COVID-19 crisis, tourism and sustainable development. Athens Journal of Tourism 7(2): 75-86.

Jurić T (2022) Google trends as a method to predict new COVID-19 cases and sociopsychological consequences of the pandemic. Athens Journal of Mediterranean Studies 8(1): 67-92.

Kallianiotis IN (2018) How efficient is the foreign exchange market? Athens Journal of Business \& Economics 4(3): 293-326.

Kartakoullis N, Papanikos G, Karlis G (2003) City and sport marketing strategy: the case of Athens 2004. The Sport Journal 6(2): 1-6.

Klein C (2021) The never-ending quest for the European fiscal policy's objectives: stability vs. convergence or stability and convergence? Athens Journal of Business \& Economics 7(1): 41-66.

Korus A (2019) Spillover effects from the ECB's unconventional monetary policies: the case of Denmark, Norway and Sweden. Athens Journal of Business \& Economics 5(1): 53-78.

Leen AR (2016) The multiannual financial framework of the European Union: a political power game. Athens Journal of Social Sciences 3(1): 7-18.

Luchena Mozo GM (2017) Progress in the revision of inheritance and gift tax under the European Union law: judgement of the EU court of justice (seventh chamber), 26 
May 2016, commission v Greece (C-244/15, CLI:EU:C:2016:359). Athens Journal of Law 3(2): 121-140.

Lust J (forthcoming) The structural conditions for the expansion of COVID-19 in Peru. Athens Journal of Social Sciences. Available at: https://www.athensjournals.gr/social/ 2021-4173-AJSS-SOC-Lust-05.pdf.

Menekli T, Doğan R, Yıldız E (2021) Relationship between stress perceived and gastrointestinal symptoms in intensive care nurses during COVID-19 pandemic: a cross-sectional study. Athens Journal of Health and Medical Sciences 8(4): 217-230.

Mengu S, Mengu M, Gunay K (2021) Value-based communication during COVID-19 pandemic: a study on the twitter messages of Turkish Ministry of Health. Athens Journal of Mass Media and Communications 7(1): 23-44.

Michelis L, Papadopoulos AP, Papanikos GT (2004) Regional convergence in Greece in the 1980s: an econometric investigation. Applied Economics 36(8): 881-888.

Okaka FO, Omondi P (forthcoming) Knowledge, attitude, and practices (KAP) towards COVID-19 among older people living in informal settlements in Nairobi City, Kenya. Athens Journal of Social Sciences. Available at: https://www.athensjournals. $\mathrm{gr} / \mathrm{social} / 2021-4430-A J S S-S O S-O k a k a-05 . p d f$.

Osisanwo A (2022) "This virus is a common threat to all humans": discourse representation of COVID-19 in selected newspaper editorials. Athens Journal of Mass Media and Communications 8(1): 59-78.

Papadopoulos AP, Papanikos GT (1997) Single European currency: implications for Greek Industry. Part of the Project The Future of Greek Industry. Ref. No.: A/EПВ12054/403/Ф.6.1.3. Athens: Greek Government (Ministry of Development).

Papadopoulos AP, Papanikos GT (2002) Exchange rate regimes and the linkage between money and output in Greece. Journal of Policy Modelling 24(2): 103-117.

Papadopoulos AP, Papanikos GT (2005) The determinants of vinegrowers employment and policy implications: the case of a Greek island. Agricultural Economics 32(1): $61-72$.

Papanikos GT (1999) Tourism impact of the 2004 Olympic Games (in Greek). Athens: Tourism Research Institute, https://bit.ly/3qtun4b.

Papanikos GT (2003) The economics of professional sports and Olympic Games. Athens: Athens Institute for Education and Research (ATINER), https://bit.ly/3qFUgxC.

Papanikos GT (2004a) The economics and management of mega athletic events: Olympic Games, professional sports, and other essays. Athens: Athens Institute for Education and Research (ATINER), https://bit.ly/3sWOQBm.

Papanikos GT (2004b) The determinants of employment creation in small regional firms. International Regional Science Review 27(2): 187-204, https://bit.ly/3erEL6P.

Papanikos GT (2014a) The economic crisis of Greece: a class analysis in support of memorandums (in Greek). Athens: Athens Institute for Education and Research (ATINER), https://bit.ly/3zau3LK.

Papanikos GT (2014b) Greek trade unions, the euro and the current crisis. The Singapore Economic Review 59(4): S1-S2, https://bit.ly/3zqiBLO.

Papanikos GT (2014c) The Greek sovereign debt: are there really any options? Romanian Journal of Fiscal Policy 5(2): 1-25, https://bit.ly/3HeEL6z.

Papanikos GT (2015a) The real exchange rate of euro and Greek economic growth. Journal of Economic Asymmetries 12(Nov): 100-109, https://bit.ly/3qq4m5H.

Papanikos GT (2015b) Taxing wealth and only wealth in an advanced economy with an oversized informal economy and vast tax evasion: the case of Greece. Vierteljahrshefte zur Wirtschaftsforschung, DIW Berlin 84(3): 85-106, https://bit.ly/3Hc8BbS. 
Papanikos GT (2015c, May 27) A Grexit would not be a catastrophe for all. LSE European Politics and Policy (EUROPP) Blog.

Papanikos GT (2015d, April 13) The Greek economic crisis: facts and myths. Available at: http://www.atiner.gr/gtp/The Nature of Greek Economic Crisis.pdf, https://bit.ly/3JkfFVQ.

Papanikos GT (2015e, March 4) The long and winding road to reform Greece's economy. The Conversation.

Papanikos GT (2015f, February 4) Greece's new debt deal may appease creditors but it won't help the economy. The Conversation.

Papanikos GT (2015g, January 26) The "Works and Days" of Syriza's first week in power. Available at: http://www.atiner.gr/gtp/The Works and Days of Syriza's first week in power.pdf, https://bit.ly/3qMNxSH.

Papanikos GT (2015h, January 26) With Greece backing euro but Syriza in government, another election may beckon. The Conversation and New Statesman.

Papanikos GT (2015i, January 22) ECB decision should be good news for Greece, but Syriza will get in the way. The Conversation.

Papanikos GT (2015j, January 6) Hard evidence: can Germany throw Greece a lifeline and save the euro? The Conversation.

Papanikos GT (2015k) Spending, international trade and economic growth in the Mediterranean basin. Athens Journal of Mediterranean Studies 1(2): 187-194, https://bit.ly/3z2lUc6.

Papanikos GT (2017) Energy security, the European Energy Union and the Mediterranean countries. Athens Journal of Mediterranean Studies 3(4): 341-354, https://bit.ly/3H6pgO6.

Papanikos GT (2019) Andreas G. Papandreou: economist and prime minister (in Greek). Athens, Greece: Athens Institute for Education and Research (ATINER), https://bit.ly/3FMYryl.

Papanikos GT (2020a) The impact of the COVID-19 pandemic on Greek tourism. Athens Journal of Tourism 7(2): 87-100, https://bit.ly/3mDAfqi.

Papanikos GT (2020b) The demographics of COVID-19 in the European Union. Athens Journal of Social Sciences 7(4): 279-290.

Papanikos GT (2020c) Could this have been written by the great president of Turkey? Libya versus Cyprus. Mimeo. Available at: https://bit.ly/3qqirAd.

Papanikos GT (2020d) Turkey is on the right side of history on Hagia Sophia. Mimeo. Available at: https://bit.ly/3qs0BNl.

Papanikos GT (2020e) The participation legacy at Olympic Games. Athens Journal of Sports 7(4): 251-262, https://bit.ly/3mAr8a1.

Papanikos GT (2021a) Deaths due to COVID-19, lockdowns, vaccinations and weather temperatures: the case of Greece. Athens Journal of Health and Medical Sciences 8(3): 201-216, https://bit.ly/3ESOyOd.

Papanikos GT (2021b) Thucydides and the synchronous pandemic. Athens Journal of History 7(1): 71-94, https://bit.ly/3Jpvk6q.

Papanikos GT (2021c) The European Union's recovery plan: a critical evaluation. Athens Journal of Mediterranean Studies 7(2): 85-102, https://bit.ly/32CMVH5.

Papanikos GT (2021d, October 30) Estimates of electing the leader of PASOK in the forthcoming elections of 5 and/or 12 December 2021. Working Paper (in Greek). Available at: https://bit.ly/3GHJ6iv.

Papanikos GT (2021e) Turkey at the dawn of the 2020s: old challenges and new prospects. Athens Journal of Mediterranean Studies 7(4): 253-266, https://bit.ly/315pfL0. 
Papanikos GT (2022a) An ex-post analysis of the 2004 Olympic effect Athens Journal of Sports (forthcoming), https://bit.ly/3JiXHDb.

Papanikos GT (2022b) The use of primaries by political parties: the case of PASOK. Athens Journal of Social Sciences. 9(2): 201-222, https://bit.ly/3sCbfnb.

Parodi P, Maraglino F, Caraglia A (2021) The impact of COVID-19 epidemic on immunization activities in Italy. Athens Journal of Health and Medical Sciences 8(1): 53-66.

Patraus ME, Ofrim IM (2021) Contractual unpredictabiliy in the context of COVID-19 pandemic. Athens Journal of Law 7(4): 485-506.

Polo Martín B (2022) COVID-19: cartography as a witness of change of Spanish urban models along history due to sanitary crisis. Athens Journal of Mediterranean Studies 8(1): $29-48$.

Reid JL (2018) Has the Brexit vote affected the United Kingdom's largest trading partners? Athens Journal of Social Sciences 5(3): 291-312.

Reid JL (forthcoming) The economic effect of the COVID-19 lockdown in the United States: was the cure worse than the disease? Athens Journal of Health and Medical Sciences. Available at: https://www.athensjournals.gr/health/2021-4261-AJHMSPOL-Reid-05.pdf.

Shah FA, Ali MA, Naeemullah, Bilal M (forthcoming) A study of paediatric supracondylar fractures of the humerus presented during the COVID-19 pandemic. Athens Journal of Health and Medical Sciences. Available at: https://www.athensjour nals.gr/health/2020-3855-AJHMS-Shah-09.pdf.

Siddiqui K (2020) The U.S. dollar and the world economy: a critical review. Athens Journal of Business \& Economics 6(1): 21-44.

Sommeiller E (2020) The working poor facing the great recession in Southern Europe. Athens Journal of Business \& Economics 6(4): 303-330.

Struwig M, Watson S (forthcoming) Working capital management and systems disruption during the COVID-19 pandemic: evidence from South Africa. Athens Journal of Business \& Economics. Available at: https://www.athensjournals.gr/business/20214266-AJBE-MGT-Struwig-05.pdf.

Turnbull S (2016) Terminating currency options for distressed economies. Athens Journal of Social Sciences 3(3): 195-214.

Uwah UE, Udoayang JO, Uklala PA (forthcoming) Post COVID-19 and the acceptance of financial inclusion as a new normal in financial transactions: implications for Nigerian accountants and other financial service providers. Athens Journal of Business \& Economics. Available at: https://www.athensjournals.gr/business/20203821-AJBE-ACC-Uwah-05.pdf. 